\title{
Charles VAUDET
}

(1930)

\section{La Vérité}

sur la

\section{Question Romaine}

\author{
Préface de François Albert
}

Député, Ancien Ministre

\begin{abstract}
Un document produit en version numérique par Claude Ovtcharenko, bénévole, Journaliste à la retraite près de Bordeaux, à $40 \mathrm{~km}$ de Périgueux

Courriel: c.ovt@wanadoo.fr
\end{abstract}

Dans le cadre de la collection: "Les classiques des sciences sociales"

Site web: http://classiques.uqac.ca/

Une collection développée en collaboration avec la Bibliothèque

Paul-Émile-Boulet de l'Université du Québec à Chicoutimi

Site web: http://bibliotheque.uqac.ca/ 
Cette édition électronique a été réalisée par Claude Ovtcharenko, bénévole, journaliste à la retraite près de Bordeaux, à 40 km de Périgueux.

Courriel: c.ovt@wanadoo.fr

à partir de :

Charles Vaudet

La Vérité sur la Question Romaine

Préface de François Albert, député, ancien Ministre.

Paris : Les Éditions de Lucèce, 1930.

Polices de caractères utilisée :

Pour le texte: Times New Roman, 14 points.

Pour les citations : Times New Roman, 12 points.

Pour les notes de bas de page : Times New Roman, 12 points.

Édition électronique réalisée avec le traitement de textes Microsoft Word 2004 pour Macintosh.

Mise en page sur papier format : LETTRE (US letter), 8.5'’ x 11'’)

Édition numérique réalisée le 4 août 2007 à Chicoutimi, Ville de Saguenay, province de Québec, Canada. 


\section{CHARLES VAUDET}

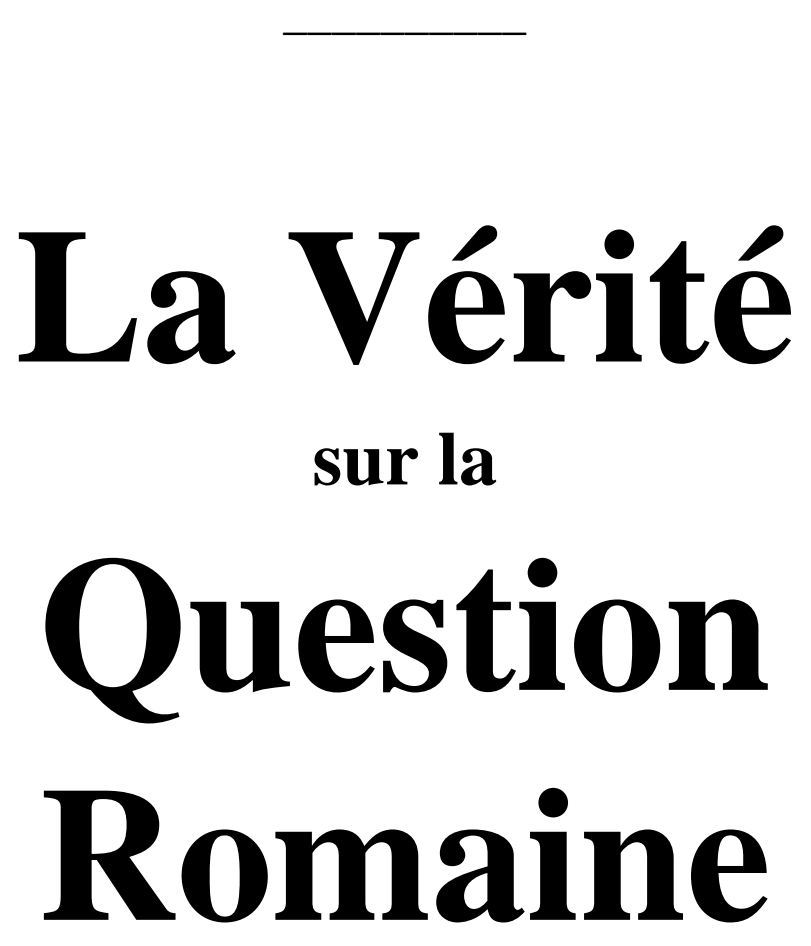

Préface de François Albert

Député, Ancien Ministre

Ce livre est plus qu'actuel, il est urgent.

VICTOR HUGO

(Hist. d'un Crime)

Les Editions de Lutèce

33, Rue Pixérécourt, PARIS 


\section{Table des matières}

Préface, de François Albert, député, ancien Ministre.

1. $\quad$ Ses origines. - Les deux glaives

II. $\quad$ Le rêve de domination universelle

III. $\quad$ Crise de mysticisme. Marie Alacoque. L’intoxication jésuitique

IV. $\quad$ Au seuil de la Révolution. L'agitation à l'intérieur, la menace à l'extérieur

V. $\quad$ L'œuvre de haine et de sang. La prière de Louis XVI. Le crime catholique.

VI. Explosion du fanatisme religieux

VII. $\quad$ Le plan de la Papauté. Châtiment, expiation et pénitence imposés à la France de la Révolution.

VIII. Napoléon et l'Église

IX. $\quad$ La Revanche de Rome. La Terreur Blanche. L'Invasion Noire. La « Congrégation ».

X. $\quad$ Nouvelle incarnation des Jésuites : La Société de St-Vincent-de-Paul

XI. $\quad$ La République de 1848 et les Jésuites

XII. $\quad$ Le Second Empire et les Jésuites

XIII. L’accroissement formidable des Congrégations

XIV. $\quad$ La Double action des Jésuites

XV. $\quad$ L’expédition du Mexique

XVI. L’Amérique contre le papisme

XVII. L’infaillibilité pontificale

XVIII. $\quad$ La guerre de 1870-70. Rome reprise au Pape par les Italiens

$\underline{\mathrm{XIX}}$.

XX. Le mouvement Communaliste et Communiste

XXI. Les véritables auteurs du massacre des otages

XXII. L'intrigue romaine en Europe de 1871 à 1880

XXIII. $\quad$ La fin d'un rêve

XXIV. Le gouvernement des curés

XXV. $\quad$ La République «légalisée ». Le Coup d’État du 16 Mai 1876 
XXVI. $\quad$ La République se défend.

XXVII. Le Pape des " conciliations opportunes »

XXVIII. La Curie Romaine. Les Jésuites préparent « la grande saignée régénératrice $»$.

XXIX. La Séparation. L’action perfide du socialisme chrétien. L’attitude des partis de gauche en face du péril clérical

XXX. Espionnage et diffamation de la France par la milice noire

XXXI. L'intrigue Romaine en Russie : le pope Gapone et le moine Raspoutine agents des Jésuites

XXXII. $\quad$ Au seuil de la grande guerre. Le plan du « Gesu » en 1911

XXXIII. L'Église catholique, apostolique et romaine est seule responsable de la guerre de 1914. Les preuves capitales

XXXIV. Les crimes des Jésuites. Le cardinal Rampolla meurt empoisonné

XXXV. L'attentat de Sarajevo. Les lois laïques et le carnet B.

XXXVI. La propagande royaliste. Pie X et Ferreta meurent empoisonnés.

XXXVII. Benoît XV, le faux neutre

XXXVIII. L’Église seule a tiré profit de la guerre de 1914

XXXIX. Le parti populaire et don Sturzo

XL. $\quad$ L'Italie nouvelle. Les étapes de la trahison. La première victoire du Vatican et des Jésuites

XLI. $\quad$ Sous la matraque

XLII. CONCLUSION. La Question Romaine n’est pas résolue. Le triomphe des Jésuites. Vers une Révolution fédérative et jésuitisée ? 


\section{PRÉFACE}

$\underline{\text { Retour à la table des matières }}$

À la bonne heure! Voici un homme qui n'a pas peur du ridicule. Jadis, cette crânerie était baptisée courage civique. Maintenant, au lendemain de la guerre où semble s'être épuisé le capital de vertu de toute une génération, il faudrait sans doute inventer un vocable nouveau pour caractériser l'audace de ceux qui osent penser et sentir autrement que le Français moyen, lequel s'impose à son tour de penser et sentir uniquement par procuration donnée, sans la moindre restriction ni réserve, à quelques centaines de snobs, de boulevardiers, de gens à la mode, petite troupe d'arbitres "spirituels » qui tient à peu près dans notre monde actuel le rôle des marquis dans le théâtre de Molière : "Tarte à la crème ! »

Charles Vaudet a voulu se payer le luxe de paraître démodé, selon le mot de Renan : Il n'a pas craint d'étudier et d'écrire l'histoire du cléricalisme, de ce parasite poussé sur la fleur suave de la foi, qui peu à peu l'altère, la ronge et se substitue à elle pour exploiter de nobles instincts aux fins de domination politique, sociale, voire économique. Puis, comme le cléricalisme est un mot trop vague, trop général pour faire l'objet d'une science aussi précise que l'histoire, à cette abstraction qui semble appartenir à la polémique plutôt qu'à la réalité objective, il a présenté cette force obscure et impénitente du passé sous l'espèce concrète de la Compagnie de Jésus. Celle-ci du moins n'est pas un être de raison, ni un fantôme créé par l'imagination des laïques exaltés, mais un organisme bien défini dont les faits et gestes, 
pour mystérieux qu'ils puissent être, ont cependant laissé des traces certaines inscrites dans d'irréfutables documents.

Vieilleries que tout cela! dira-t-on. Et pourquoi donc vous plaît-il de reléguer ainsi dans le domaine des choses mortes une institution qui s'atteste aussi vivante, aussi active que jamais? De ce que son œuvre présente échappe aux regards superficiels de celui qu'étourdit le mouvement chaque jour plus trépidant et plus complexe de la vie, de ce qu'elle procède par cheminements de plus en plus souterrains, ne s'ensuit-il pas au contraire qu'il importe de remonter aux sources pour se rendre compte de tout ce qu'elle put accomplir aux époques écoulées, où déjà le plus souvent l'influence de la Congrégation invisible et présente échappait aux contemporains?

Certes, je ne prétends pas que l'histoire soit la seule "Maîtresse de la vie », comme écrivait Cicéron. Ce serait faire la part trop belle à la tradition et fermer la porte au progrès, dont la chimère fut souvent le nom de baptême. Mais comment contester au vieux sénateur républicain, qui pécha volontiers par oubli du passé, qu'elle soit une "lumière de vie ", presque toujours indispensable pour éclairer dans sa course l'humanité incertaine et vacillante. Le culte des précédents n'est pas la condition suffisante d'une marche assurée vers le mieux; de les connaître en paraît toutefois la condition nécessaire.

Aussi bien, ceux qui s'appliquent à la faire piétiner ou même rétrograder ont-ils toujours pour premier soin de jeter un voile opaque sur les expériences antérieures susceptibles de mettre chaque âge en garde contre les erreurs ou les pièges où sont tombées les générations précédentes. D’où vient le mépris affecté de cette moderne histoire sainte que Charles Vaudet s'applique à ressusciter, sinon précisément de ceux qui voudraient en étouffer le souvenir afin de rééditer les entreprises dont le succès fut entravé par la vigilance laïque ? Il est assez suspect d'entendre constamment répéter : "Autres temps, autres mœurs », par les mêmes gens qui par ailleurs se révèlent chevaliers servants de toutes les traditions et s'inspirent d'elles pour recommander avec persévérance un nouvel «esprit nouveau ».

C'est pourquoi l'on ne saurait témoigner trop de reconnaissance aux écrivains qui ont le loisir et les moyens de retracer, à l'usage des 
citoyens de demain, les étapes de cette perpétuelle contre-révolution, dont l'ignorance est la principale garantie de réussite. Charles Vaudet appartient à cette cohorte de chercheurs patients qui n'entendent pas laisser prescrire les leçons de l'histoire. Il possède, sur les événements qu'il a entrepris de faire revivre et d'enchaîner, une documentation exceptionnellement riche. Il n'a pas voulu la conserver pour sa seule édification, à la façon de ces collectionneurs dont l'égoïsme pimente la curiosité. Il a tout au contraire tenu à ouvrir ses archives toutes grandes pour que l'électeur futur y puisse puiser de quoi se mettre en garde contre les surprises toujours menaçantes de ceux qui, eux, n'ont pas oublié leurs privilèges de jadis et se montrent d'autant plus attentifs à les reconquérir que les bouleversements considérables ont distrait l'attention publique de toute une stratégie occulte, mais patiente, que rien ne détourne de son but.

Charles Vaudet n'a pas seulement fait œuvre de chercheur patient et averti, mais aussi d'éducateur. Il a su réaliser, sans souci de la coquetterie, la saine devise de l'écrivain désintéressé: instruire et plaire.

Député

François Albert.

Ancien Ministre 
La Vérité Sur la Question Romaine (1930)

\section{I \\ Ses origines. - Les deux glaives}

$\underline{\text { Retour à la table des matières }}$

L'accord conclu entre l'Église romaine et Mussolini, — car c'est outrager la nation italienne que de l'identifier avec un pareil aventurier, - n’a rien qui doive émouvoir la Libre Pensée. On peut, à la rigueur, le prendre au sérieux, mais sûrement pas au tragique. Nous en donnerons les raisons. Laissons donc les feuilles de sacristie chanter chaque jour l'hosanna de la délivrance et les fascistes, c'est-à-dire les réactionnaires de tous les pays, multiplier les Te Deum et les réceptions pour célébrer le " grand triomphe de l'Eglise » que la Croix appelle dans son délirant enthousiasme « la seconde victoire de Montmartre ", expression plutôt évocatrice des joyeusetés de la Butte que les neuvaines du Sacré-cœur. Et malgré l'impudent défi aux francsmaçons internationaux, aux libres penseurs de l'Ancien et du Nouveau Monde venus il y a vingt-cinq ans tenir leurs assises à Rome même (allusion au magnifique congrès international de 1904 qui réunit les plus glorieux représentants de la science et de la philosophie, en face du Vatican), rappelons sommairement, pour l'instruction de la génération présente qui semble ignorer de plus en plus les forfaits de l'Eglise et de la papauté, les origines de cette question romaine qui n'est en réalité que la longue et sanglante lutte du pouvoir civil contre l'ambition des pontifes de soumettre à leur autorité absolue le temporel et le spirituel et d'établir leur domination universelle. 
Pure démocratie au début, répandue en communautés et gouvernée par une oligarchie d'évêques, l'Eglise ne date guère sa puissance territoriale que du IV ${ }^{\mathrm{e}}$ siècle, c'est-à-dire depuis Constantin. Car il faut reléguer dans le fatras des légendes le soi-disant pontificat de l'apôtre Pierre, né d'un puéril jeu de mots (Tu es Petrus), inventé après coup pour légitimer la filiation de la papauté avec le thaumaturge Ieschou et les Evangiles. Aussi l'expression patrimoine de Saint-Pierre n'a-t-elle aucun sens historique. En réalité, entrant dans Rome (312), précédé du Labarum, Constantin ne fit guère que confirmer, avec l'octroi de certains pouvoirs d'administration, la juridiction spirituelle de l'évêquepape Melchiade sur l'ensemble des chrétiens et des autres évêques. De même, par l'édit de Milan, (313) et le Concile de Nicée (323), il n'avait voulu que consolider la religion naissante en prêtant déjà au droit canonique l'appui du bras séculier. Cependant, en vertu de la maxime qui est encore sienne aujourd'hui : la fin justifie les moyens, l'Eglise n'a pas hésité à fabriquer de toutes pièces une fausse abdication de Constantin en sa faveur, lui attribuant « toute la dignité, toute la gloire et toute la puissance impériale dans l'empire romain », tandis qu'il se retirait à Constantinople, qu'il venait de fonder. C'est ce que Pierre de Marca, archevêque de Paris (1662), qui écrivit précisément un traité sur l'accord du sacerdoce et de l'Etat, appelle la fraude pieuse des papes, " excusable, ajoute-t-il, en raison de la sainteté du but poursuivi ». D’ailleurs, le droit divin, étant lui-même une imposture, ne peut s’appuyer que sur le mensonge.

S'enrichir d'abord, dominer ensuite, tel est le double but de la papauté, et toutes les occasions lui sont bonnes. Des derniers empereurs, elle obtient, en échange de son indulgence pour leurs crimes, de vastes domaines ; des barbares qui envahissent l'empire, elle exploite la crédulité et tol !ère toutes les cruautés contre l'abandon des duchés dont Rome était le centre, et, de ce moment (751), on peut dire que les Etats de l'Eglise existent en fait. Aussi, lorsque le moine Boniface, envoyé au pape Zacharie, consacre à Soissons (752) la royauté de Pépin le Bref, la récompense ne se fait pas attendre : elle consiste dans une «zone d'influence » reconnue au pape dans l'ancien exarchat de Rome, et, peu après le renouvellement du sacre par le pape Etienne II en personne (754), elle vaut à celui-ci, pour son dérangement, donation de vingt-deux cités de l'exarchat de Ravenne et de Pentapole, offerts à la « République de Saint-Pierre », selon les termes mêmes de la 
donation. Ce noyau territorial devait s'augmenter par la suite des Marches, de la Romagne, d'une partie de la Toscane léguée par la grande comtesse Mathilde à son saint et désintéressé amant, le pape Grégoire VII, et en outre du comtat Venaissin, soit 180000 hectares enclavés dans notre Provence, et qui resta terre papale jusqu'en 1791.

À partir de ce moment, l'Eglise marche à la conquête du monde occidental. Elle fonde une multitude d'ordres religieux, mendiants, prédicateurs ou guerriers. Ses légions de moines pénètrent partout. Ses papes proclament ouvertement que leur Dieu les a placés au-dessus des princes, non seulement en matière de foi, mais aussi en matière de politique. Avec un constant esprit de suite, même au onzième siècle, alors que le crime sous toutes ses formes est, à cette époque, le fond de l'histoire pontificale, qu'en cent sept ans, trente-deux papes se succèdent à Rome, donnant l'horrifiant spectacle d'une luxure effrénée alliée à la plus féroce cruauté, c'est toujours à la réalisation de son rêve de DOMINATION UNIVERSELLE que l'Eglise catholique, apostolique et romaine, emploie toutes ses forces matérielles et morales.

Et, de fait, sans la turbulence des factions qui divisent l'Italie et l'indépendance des riches républiques (Venise, Gênes, etc.) du nord de la péninsule, ce rêve apparaîtrait vraiment comme réalisé au douzième siècle. Grégoire VII, dans ses Dictatus papæe, a condensé tous les éléments du pire gouvernement de la théocratie qui amena l'empereur d'Allemagne, Henri IV, humilié et repentant, dans les neiges de Canossa. Ce pape, qui avait formé le projet d'une Europe catholique fédérée sous la croix, établit les principes fondamentaux de la doctrine immuable que l'Eglise n'a jamais désavouée, à savoir : la souveraineté absolue d'un seul homme sur l'humanité entière, sur les esprits comme sur les corps, sur les pensées comme sur les actions, par la soumission sans réserves, justifiant ainsi tous les crimes du christianisme, l'Inquisition, les guerres de religion et le rôle néfaste de la papauté dans les luttes sanglantes des Etats. "L’Église romaine, dit-il, n’a jamais erré et ne peut errer. Au pontife suprême seul appartiennent les insignes de la dignité impériale. Tous les princes doivent le saluer en lui baisant les pieds... »

En vertu de cette puissance absolue, Grégoire VII excommunie en France Philippe $\mathrm{I}^{\mathrm{er}}$ et humilie en Allemagne Henri IV. Le pape 
Alexandre III force le roi d'Angleterre à s'agenouiller devant le tombeau de Thomas Becket ; Innocent III, qui, selon sa propre expression, "méprise le monde pour mieux dominer », excommunie PhilippeAuguste, prononce la déchéance de Jean-sans-Terre, enlève à l'empereur les Deux-Siciles et dépouille le comte de Toulouse au profit de Simon de Montfort. En somme, dès le treizième siècle, la papauté prend en main les affaires de l'Europe. L'an 1294, Boniface VIII affirme cette toute-puissance de la papauté. Le jour même de son sacre, ce sont les rois de Hongrie et de Sicile tenant les brides de son cheval, qui le conduisent à Saint-Jean de Latran ; ce sont également eux seuls qui, couronne en tête, le servent au festin qui termina la fête. C'est à ce même Boniface qu'est due la théorie des DEUX GLAIVES au service de l'Eglise : « le premier, le spirituel, elle s'en sert elle-même, le second, le temporel, elle le remet aux princes pour s'en servir aussi longtemps qu'elle le commande ou le tolère... La puissance séculière n'est qu'une émanation de la puissance ecclésiastique... » Et au grand jubilé de l'an 1300, devant plus de cent mille pèlerins accourus de toutes parts, Boniface VIII parut en habits impériaux, faisant porter devant lui le sceptre et l'épée.

Ses successeurs, amplifiant sa doctrine, s'efforcèrent de ressusciter l'empire romain au profit de la papauté. Mais, par un juste retour des choses, les papes : Alexandre VI, — qui eut cinq enfants, dont Lucrèce Borgia, - Jules II, Léon X et Paul II, - qui se maria ouvertement et eut deux enfants, - en évoquant les souvenirs et les mœurs de l'antiquité païenne pour affiner leurs vices et pimenter leurs orgies, précipitent, à leur insu, l'explosion de tendances et d'aspirations nouvelles. Car, à la liberté de plus en plus grande des mœurs, correspond une indépendance de plus en plus large de l'esprit, et, par la renaissance, l'humanité, selon la forte expression de Michelet, " commence à s'asseoir dans la justice et dans la raison ». Sous le grand souffle de la Réforme, qui enlève à l'Eglise la plus grande partie des pays septentrionaux, c'en est fait de l'unité catholique. La papauté tend à devenir une puissance italienne. Ses débauches et ses crimes lui ont fait perdre toute autorité morale, même dans ses propres Etats, et c'est avec raison que Machiavel constate que « les peuples voisins de Rome sont d'autant moins religieux qu'ils en sont plus près ». Dès lors, il semble bien que l'Eglise romaine doive renoncer pour toujours à la 
constitution d'une grande république chrétienne sous la double autorité de ces « deux moitiés de Dieu » : le pape et l'empereur. 
La Vérité Sur la Question Romaine (1930)

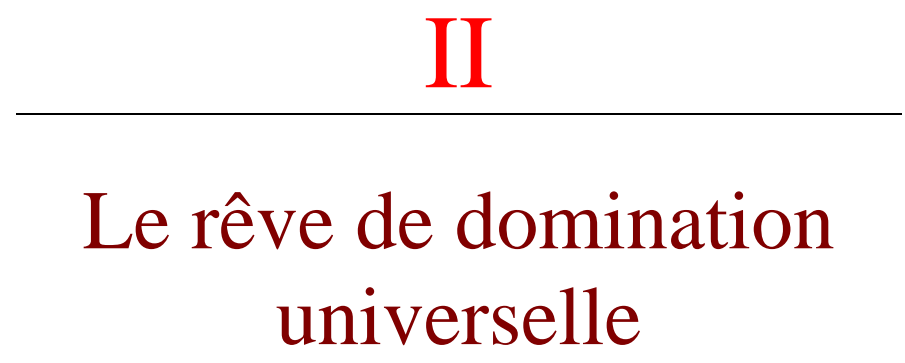

$\underline{\text { Retour à la table des matières }}$

«Mais l'histoire de la civilisation romaine nous démontre, écrit Spuller, qu'à la suite de chaque tentative faite par la raison humaine pour reconquérir ses droits, il s’est formé, soit une société religieuse, soit une congrégation pour arrêter le progrès dans sa marche. » Le jésuitisme naissant après le mouvement de libre examen de la réforme en est une preuve éclatante. L'histoire de la COMPAGNIE DE JÉSUS, qu'on n'épuiserait pas en plusieurs volumes, ne saurait être considérée ici que par rapport à l'immense force qu'elle mit dès sa naissance au service de la papauté, en vertu du quatrième vœu de ses membres : soumission absolue au pape. Une hiérarchie parfaitement établie de la base au faîte, une rigoureuse discipline, une obéissance passive au point de faire de chaque affilié « un cadavre dans la main de son chef (périnde ac cadaver) ", selon la dernière recommandation de son fondateur, Ignace de Loyola, tel est le secret de la puissance acquise en quatre cents ans par cette organisation, « vaste ministère de la police universelle qui surpasse celle du fameux gouvernement de Venise ", de l'avis de Richelieu. Ses constitutions, qu'on peut comparer au Prince de Machiavel, ses Instructions secrètes, vainement reniées par ses dirigeants, ont révélé au monde l'effroyable morale à double sens 
de cette société excusant ou légitimant tous les vices et tous les meurtres, enseignant les moyens de pratiquer les premiers et de commettre les seconds, et souvent même les commettant cyniquement au grand jour, comme l'affaire Paredes, en narguant tous les pouvoirs et toutes les lois, ad majorem Dei gloriam - avec cette addition récente sacratissimi cordis Jesus. Véritables janissaires de la papauté dont ils se proclament "l'oracle, le bras droit, le bouclier ", ils déclarent d'abord la servir pour la défendre, mais en réalité, pour la dominer, et, avec elle, se rendre, selon l'expression d'un de leurs généraux, " maîtres de l'univers ». Cette conspiration permanente à travers les âges du mensonge et de la fourberie contre la vérité — ainsi l'a jugée Joseph de Maistre, qui fut pourtant l'élève des jésuites - a son plan bien arrêté, modifiable selon le temps et les circonstances, et dont le facteur principal est l'espionnage universel. Aussi le «pape noir» actuel peut-il répéter ce que disait un de ses prédécesseurs - sous la Restauration - au duc de Pressac: " De cette chambre, monsieur, je gouverne non seulement la Chine, mais le monde entier, sans que personne sache comment cela se fait. »C'est l'exécution de ce plan qui nous suivrons dans toutes ses manifestations, que nous résumerons aussi brièvement que possible, jusqu'à l'heure présente du « Triomphe » (momentané, espérons-le, pour le salut de l’humanité) des jésuites, dont la comédie de Latran a été la consécration tapageuse.

Humbles et modestes à leurs débuts, les jésuites ont parcouru le monde au sortir de la crypte de Saint-Pierre-de-Montmartre, où s'est formé leur société, reconnue bien après par le pape Paul III (1340), et ce n'est que sous Henri II et sur l'invitation de celui-ci qu'ils revinrent se fixer en France, ou mieux y créer une sorte de sodalité (1551). Mais, déjà chasés d'Allemagne (1547) pour leurs doctrines jugées séditieuses, ils étaient accueillis plus que fraîchement par le Parlement et l'Université de Paris, dont le courageux chancelier Pasquier s'opposa à leur enseignement. C'est que, en effet, avec une profonde habileté, les jésuites, s'inspirant de l'esprit de la Réforme, mais pour des vues contraires, s'offraient à faire gratuitement l'instruction des masses, sachant bien que "celui qui possède les générations naissantes possède la société ». C'était livrer la jeunesse à la direction d'un ordre ennemi de la société elle-même, avec laquelle ses membres ont complètement rompu, au point de se considérer, d'après leurs Constitutions, comme sans famille et sans patrie. Cette méthode, ils 
l'employèrent partout, et partout ils furent combattus par tous ceux qui avaient le pressentiment de leur néfaste influence sur l'esprit des générations futures. Fidèles à leurs habitudes de dissimulation, ils se courbèrent sous l'orage, mais n'en continuèrent pas moins à fonder clandestinement des écoles pour les pauvres et des collèges pour les riches. En même temps, faisant appel au mysticisme du Moyen Age, ils créaient dans les centres les plus importants comme population des congrégations ou soladités, sortes de clubs dont les réunions, interdites au profane, se tenaient dans les cryptes souterraines des églises et au cours desquelles, recherchant, comme leur fondateur, ce qui émeut les sens, ils feignaient de suprêmes extases dans les contemplations d'un Christ agonisant, d'une Vierge pâmée de douleur, et, par contraste, dans l'adoration de l'Enfant Jésus, d’une Vierge couronnée, ou encore de l'agneau de la crèche. Bref, exploitant la croyance aux faits miraculeux, aux légendes moyenâgeuses, sous la blanche bannière de Marie, dont le nom devint leur mot d'ordre, " par cet appel à l'énervation des cœurs, à la servitude des âmes ", ils se créèrent en très peu de temps une influence extraordinaire.

Dès lors, il n'est pas d'attentats, de troubles politiques où ils n'aient eu leur part d'action tantôt secrète, tantôt publique. Les complices de Charles IX et de Catherine de Médicis prennent les jésuites pour conseillers et se réunissent dans leur repaire pendant l'horrible nuit de la Saint-Barthélemy. La Sainte-Ligue est sous leur direction occulte ; à leur instigation, Jacques Clément, dominicain il est vrai, mais dont ils glorifièrent le crime, assassine Henri III, trop peu catholique à leur gré. Puis c'est au tour de Henri IV de mourir sous le poignard de Ravaillac, après dix-sept précédents attentats ourdis par les jésuites. Dans le même temps, chassés d'Angleterre, du Portugal et d'Anvers, ils font assassiner Maurice de Nassau, en Hollande, et sont expulsés de Venise, de Bohême, de Moravie, de la Pologne, etc., etc... Le monde entier les repousse et les maudit. On les croit morts à jamais. Ce sont leurs ennemis qui meurent. Eux, soutenus par une fortune quasi incalculable et qu'ils n'ont cessé d'accroître depuis le jour où le pape Grégoire XIII (1572) leur a conféré « le droit de se livrer partout au commerce et aux affaires de banque ", trouvent toujours des auxiliaires disposés à les servir par intérêt ou par l'appât des honneurs que leur influence, nullement affaiblie, malgré d'innombrables ennemis, peut procurer à qui les sert fidèlement. Et c'est ainsi qu'à défaut de la 
tiare qu'ils ambitionnent secrètement pour la gloire de leur ordre, ils se haussent jusqu'au trône avec Jean Casimir, novice jésuite, cardinal et roi de Pologne en 1648, où les jésuites, chassés en 1621, sont rentrés à la suite du jésuite-roi et tiennent en leurs mains tout le haut enseignement du royaume.De même avec Louis XIV, le fameux RoiSoleil, qu'ils ont mis sous leur éteignoir en l'affiliant à leur sodalité ou confrérie des Messieurs, ainsi appelée parce que, pour faire partie de cette grande congrégation, il fallait être gentilhomme ou d'opulente bourgeoisie. Le roi et les principaux personnages de la Cour y étaient affiliés. Il existe, à la Bibliothèque Nationale et à celle de l'Arsernal, un gros recueil intitulé Histoire des Congrégations et Sodalités jésuitiques, depuis 1563 jusqu'en 1709, où l'on trouvera confirmation du fait. Le P. Graffet, qui dirigea cette congrégation de 1668 à 1692, a publié en 1678 un tout petit livre : Manuel à l'usage des Congréganistes, devenu très rare parce qu'on était tenu de le restituer à la congrégation à la mort de l'affilié. Quelques exemplaires portent le titre suivant : Règles de la Maison professe de Notre-Dame de Saint-Louis, à Paris ; ce petit livre comprend 143 pages et les 26 articles des statuts de la congrégation, dont le quartier général était à l'église des révérends pères de la rue Saint-Antoine, où habitaient les plus riches comme les plus commerçantes familles de France.

On voit que les références ne nous manquent pas pour confirmer l'affiliation royale. Et l'on s'explique alors, sans plus, la révocation de l'Edit de Nantes, les dragonnades, la persécution des Jansénistes, etc., etc..., tous ces crimes perpétrés sans aucun doute à l'inspiration des jésuites, dont le père Lachaise et le père Letellier étaient les délégués ou mieux les admoniteurs de la Société de Jésus auprès de leur éminent et majestueux confrère. On ne s'étonne plus de ces accès de sanglante piété par lesquelles le " grand roi » était persuadé qu’il rachetait l'ignominie de sa vie privée. Son absolutisme n'était-il pas on ne peut mieux apparenté à cette obéissance passive prêchée par les jésuites. Eux, comme lui, n'avaient-ils pas le même but: faire que la France, que le monde entier ne formât qu'un seul troupeau conduit par un seul berger?

La Congrégation des Messieurs avait pour mission apparente et avouée les pratiques religieuses et les œuvres de charité. 
Par les congrégations qu'ils fondaient un peu partout, ce qui leur permettait de rester ou de revenir, comme en France, dans les pays d'où ils avaient été chassés, les jésuites dominaient toute l'Europe. Par leurs missionnaires, ils régnèrent en Amérique et jusqu'aux extrémités de l'Asie ; ils inaugurèrent au Paraguay le communisme le plus tyrannique que l'on puisse rêver, amassèrent des trésors chez les princes indiens, devinrent mandarins à la cour de Pékin. Le but d'Ignace de Loyola était atteint : le jésuitisme étendait sa puissance sur toutes les parties de l'univers connu. 
La Vérité Sur la Question Romaine (1930)

III

\title{
Crise de mysticisme.
}

\author{
Marie Alacoque \\ L'intoxication jésuitique
}

$\underline{\text { Retour à la table des matières }}$

Pour achever d'établir en France son influence d'une façon durable, le jésuitisme, spéculant sur l'ignorance des masses, avait cru bon de renforcer par la superstition et le miracle son action délétère, en reprenant la propagande mystique du XVIe siècle qui avait livré la France aux horreurs de la Ligue et, peu après, aux guerres de religion. Les jésuites fondèrent, coup sur coup, les Associations laïques du SacréCour de Marie, de la Croix, du Saint-Sacrement, du Saint-Esclavage de Marie. De cette époque date le culte dit du Sacré-Cœur. D’une malheureuse visitandine de Paray-le-Monial, aux trois quarts folle au point de graver à la pointe d'un canif sur sa poitrine le nom de Jésus, ils firent leur prophétesse et après sa mort l'objet d'un pèlerinage auquel, depuis, Lourdes et la Salette ont fait une sérieuse concurrence. La fureur des affiliations mystiques et mystérieuses devint si intense que les "révérends pères » eurent l'audace de prêcher leurs doctrines dans les casernes, pour s'emparer de l'armée. Celle-ci, en 1716, au lendemain de la mort de Louis XIV, se trouva subitement infestée de confréries et d'archiconfréries dont les affiliés, choisis de préférence parmi les illettrés, s’engageaient par serment à défendre le pape et à 
combattre les jansénistes. Quarante soldats du régiment de Bretagne osèrent présenter leurs statuts à leur colonel, en refusant de lui obéir désormais, "s’il refusait de s’affilier au Sacré-Cœur de Marie ». L’armée fut protégée par des mesures énergiques que prit la Régence libertine et brillante qui succédait aux vingt dernières années de bigotisme de Louis XIV et de la Maintenon, "cette maîtresse coquine, froide, impassible, implacable, ayant un balancier à la place du cœur... et qui, lors de la révocation de l'Edit de Nantes, spéculait sur les propriétés que les hérétiques étaient forcés de vendre au plus tôt... » (Alexandre Dumas fils). Mais la noblesse, la bourgeoisie et surtout les classes populaires furent à ce point perverties par le jésuitisme - à peu près comme aujourd'hui, du reste - que les intendants et gouverneurs de province constataient en 1762 que plus de deux mille bourgs et villes étaient affiliés à la néfaste confrérie et qu'il existait plus de sept cents associations. Des mémoires du temps rapportent qu'un ministre de Louis XV fut trouvé mort revêtu des insignes d'affiliation du Saint-Esclavage de Marie.

Ebranlés quelque peu par la mort de Louis XIV et l'éloignement de la cour du père Letellier, confesseur du défunt roi, tenus à l'écart par Philippe d'Orléans très indifférent aux choses religieuses, ils revinrent triomphants à la cour avec Louis XV, en s'employant par leurs agents au traité secret de 1719, qui projetait la réunion de la France avec l'Espagne. Ce triomphe les grisa au point de vouloir intriguer en toutes choses et contre tout le monde et de finir par liguer contre eux tous les partis, même le clergé séculier et d'autres ordres, comme les Sulpiciens. Mais ils commirent la lourde faute de s'attaquer aux encyclopédistes et de se heurter à leur ancien élève Voltaire, qui, reprenant l'œuvre de Pascal et Arnaud, livra l'Eglise et ses fanatiques défenseurs à toutes les humiliations de l'ironie et du sarcasme philosophique. L'attentat de Damiens, dans lequel les jésuites trempèrent par haine d'une cour qui les détestait et de la favorite, la marquise de Pompadour, qui les méprisait, suivi de près par la faillite d'un de leurs révérends, le père Lavalette, leur porta évidemment un coup terrible et qui eût été mortel pour toute autre société que la leur. Spéculateurs, agioteurs, surtout aux colonies françaises, dans toutes sortes d'entreprises, ils pouvaient très facilement solder un passif de 3 millions. Mais ils voulurent crâner, se croyant sûrs de l'impunité, au point d'offrir ironiquement à leurs créanciers de les payer par une messe à 
leur intention. Ils exigèrent même d'être jugés par le Parlement, qui répondit à tant d'audace par l'examen de leurs fameuses Constitutions.

Au bout d'une année, au cours de laquelle ils assassinèrent le roi du Portugal, le Parlement rendit son arrêt le 6 avril 1762. Les jésuites, convaincus de désobéissance aux lois et au souverain, de nuire à la tranquillité de l'Etat, de vol et de tromperie en matière commerciale, avaient huit jours pour se dissoudre ou quitter la France, et leur collège principal, Louis-le-Grand, était fermé. Leurs vœux étaient déclarés abusifs et leurs biens immenses devaient être vendus et aliénés au profit de l'Etat. Ils préférèrent quitter la France. Certes, ils étaient bien malades, peut-être mourants, mais, comme disait un janséniste, «le pouls battait encore. »

Il battait même si bien qu'après la sentence de condamnation du pape Clement XIV qu'ils empoisonnèrent, ils eurent l'audace, eux dont le fondateur Loyola avait proclamé si hautement l'infaillibilité pontificale, de protester contre la décision du pontife, qui devait payer de sa vie cet acte énergique devant lequel avait reculé précisément, par la crainte du poison, son prédécesseur Benoît XIV. A noter que Clément XIV rappelait, dans son bref, l'attitude parfois arrogante des jésuites avec la Cour romaine et leur obstination orgueilleuse à garder leurs statuts : Sint ut sunt aut non sint, avaient-ils répondu à toutes les suggestions de réforme.

Les disciples de Loyola trouvèrent le moyen d'avoir toujours un pied en France - comme le feront plus tard, en 1880, leurs successeurs animés des mêmes intentions hostiles à tout ce qui n'est pas l'Eglise. Mais, pour donner le change, quelques-uns reçurent l'hospitalité du grand Frédéric de Prusse, d'autres furent accueillis par Catherine de Russie. Ils se répandirent en flagorneries et en actions de grâce envers ces deux souverains. L'un d'eux, prêchant le Carême, prétendit même que le cheval du roi Frédéric était tombé à genoux devant le saint Viatique! Les hommes d'Eglise avaient déjà bien épousé des nationalités pour les besoins de leur cause. En Russie, ils se firent cosaques, pour sauver leur Institut. Cependant, cédant aux objurgations de la France et de l'Espagne, le pape voulut contraindre 
la Prusse et la Russie à les chasser. Et ils durent vivre dans les deux empires sous un nom d'emprunt et en modifiant leur costume.

Mais le moment approchait où, pour réaliser leur rêve commun de domination universelle, la papauté et les jésuites devaient avoir besoin de se réconcilier, si toutefois ils avaient jamais été désunis. Car de tout temps les gens d'Eglise ont excellé dans ces sortes de comédies qui font illusion aux diplomates de carrière, témoin la dernière en date, celle de Mussolini et de Ratti, tous deux jésuites, et qui jouèrent leur rôle avec une égale habileté dans la comédie de Latran. 
La Vérité Sur la Question Romaine (1930)

IV

\section{Au seuil de la Révolution}

\section{L'agitation à l'intérieur, la menace à l'extérieur}

\section{$\underline{\text { Retour à la table des matières }}$}

L'estime et l'affection de celle que le peuple ne cessa d'appeler l'Autrichienne, Marie-Antoinette, étaient tout acquises aux hommes noirs. Ceux-ci, fins renards, ne se hâtèrent pas trop de reparaître. Ils préférèrent agir par les congrégations et affiliations religieuses. Vers 1782, le lieutenant général de police fut avisé que les anciens pères jésuites faisaient une propagande dangereuse pour la sécurité de l'Etat. Avis en fut donné au roi. On prit quelques précautions et les « renards de Loyola » rentrèrent dans leurs tanières.

Mais, bientôt, ils sortirent de leurs retraites. Le cabinet de SaintPétersbourg revint à la charge pour imposer au pape Pie VI leur rétablissement. Celui-ci céda, à la condition expresse que la Compagnie ne pourrait exister qu'en Russie. A la même époque, un Tyrolien nommé Paccanari, tour à tour tailleur de pierres, soldat et bandit, se mit à la tête d'un certain nombre d'ecclésiastiques pour faire revivre le jésuitisme, principalement en ce qui concernait l'enseignement et les missions, sous le nom de Pères de la Foi (1785) ; mais, cinq ans plus tard, la nouvelle société, qui avait une maison à Rome, se fondait 
dans une autre compagnie: les Pères du Sacré-cœur de Jésus, qu’avaient créée le père de Broglie et l'abbé Tournely.

Ainsi reconstituée, la société fit appel aux jésuites réfugiés en Russie, et, pendant la période de la Terreur, plusieurs d'entre eux vinrent à Paris, avec des passeports russes et des attributions de qualités qui déjouaient la sagacité des plus habiles agents du Comité de Salut public. Ils entretinrent le fanatisme religieux dans le peuple, de concert avec les anciens moines et les prêtres "réfractaires ", c'est-à-dire non assermentés, et leur action se manifesta surtout par la fondation d'une multitude de sectes, chargées de l'exécution du plan unique concerté avec la papauté, et dont le but était de conspirer contre la Révolution et de rétablir en l'aggravant l'ancien ordre de choses... Telle fut l'origine des diverses sociétés connues sous le nom de Cœur de Jésus, des Victimes de l'Amour de Dieu, des Pères de la Foi. Dans son rapport du 3 messidor an XII, le Conseil d'Etat signale le caractère particulier à chaque société. La première fondée en 1791 par un ancien prêtre de Saint-Malo, nommé Corivière, lui paraît très dangereuse par le rigoureux secret dont elle s'entoure. Les Victimes de l'Amour de Dieu et le Cour de Jésus ne sont pas plus rassurantes. Composés principalement de femmes et d'anciens domestiques de grande maison, ces sortes de clubs religieux tenaient leurs assises dans les caves et les oratoires particuliers. Quant aux Pères de la Foi, « ce ne sont, disait Portalis, que des jésuites déguisés ; leur existence est donc incompatible avec le bien public de la nation. »

La Révolution, passant comme un torrent sur l'organisation religieuse de la France, emporta dans un premier afflux toutes les institutions monastiques. Mais elle eut le tort, par la Constitution de 1791, de vouloir - qu'on me permette cette expression - laïciser le culte, en créant un clergé constitutionnel et en s'efforçant d'opposer à la religion catholique une religion nouvelle. Les déistes s'arrêtaient à la substitution légale du protestantisme à la foi romaine, les athées voulaient remplacer celle-ci par le culte de la Nature et de la Raison. Cette dernière manière de voir prévalut, et on ne peut que s'en féliciter, car elle représentait un progrès logique et conforme au mouvement du siècle, en l'absence de la séparation de l'Eglise et de l'Etat. La substitution du protestantisme au catholicisme, surtout en présence de l'incendie qui allumait tout l'Ouest catholique et royaliste de la 
France, aurait accru encore les forces de l'insurrection. Néanmoins, au lieu d'instaurer d'abord le régime des prêtres assermentés, dont la plupart ne tinrent guère leur serment, d'organiser ensuite avec Hébert le culte de la Raison, et avec Robespierre celui de l'Etre suprême dont les autels de gazons furent dressés dans toutes les communes, il eût été préférable de laisser le culte et les prêtres en dehors de la Constitution, et de comprendre qu'un gouvernement ne doit s'occuper des problèmes de conscience qu'une heure dans sa carrière : à l'heure où il déclare qu'il n'a pas à en connaître. On imagine dans ces conditions ce que dut être la vie du pays de 1791 à 1792 ; d'abord, période pendant laquelle les prêtres étaient encore considérés comme fonctionnaires publics et devaient être ou assermentés ou "réfractaires ", et ensuite de 1792 à 1802, alors que, devant les intrigues et les soulèvements provoqués par les jésuites, la Convention considéra comme nécessaire d'opposer à l'ancienne une nouvelle religion.

Peut-être la paix religieuse ne fut-elle pas plus précaire en ces temps troublés que ne le furent les autres institutions, et, ainsi que l'a écrit le regretté maître Aulard, «l'habitude aidant, il est certain que l'effet du temps, l'esprit de tolérance et la protection des lois nous eussent bientôt délivrés de la sacerdocratie romaine. »

Mais c'était compter sans l'Eglise et les jésuites, et les plans combinés d'agitation à l'intérieur, et d'appui matériel et moral à l'extérieur aux coalisés et aux émigrés, qui devaient aboutir, dans l'esprit de leurs criminels auteurs, à faire dépecer notre pays et en livrer les lambeaux palpitants aux conjurés de la première Sainte Alliance : "Ainsi en avait décidé l’Eglise pour se sauver et assurer sa prépotence. » 


\title{
V \\ L’œuvre de haine et de sang.
}

\author{
La prière de Louis XVI \\ Le crime catholique.
}

Sur tous les points de France, des confréries comme celle de SaintLaurent-sur-Sèvres provoquaient des révoltes sanglantes. Dans une paroisse de Caen, deux ou trois cents femmes surexcitées par les missionnaires du Saint-Esprit lapidaient le "curé assermenté », le chassaient jusque dans son église, où elles descendaient le réverbère du chœur pour le pendre devant son autel. Dans les campagnes, les prêtres « réfractaires » prêchaient contre la suppression de la dîme, qu'ils représentaient aux paysans comme un attentat aux intérêts du ciel. Des bulles pleines de menaces arrivaient du Vatican, qui terrorisaient les esprits simplistes et les portaient aux pires excès. On répandait les prières insurrectionnelles au Cour de Jésus, et surtout la Prière de Louis $X V I$, qui surexcitaient l'exaltation religieuse et la révolte des Vendéens. Dans cette prière supposée, le roi promettait, sitôt délivré : $1^{\circ}$ de rétablir sans délai l'Eglise en France dans toutes ses prérogatives ; $2^{\circ}$ de révoquer toutes les lois qu'il plairait au pape de lui indiquer ; $3^{\circ}$ d'établir dans l'année de sa délivrance une fête solennelle en l'honneur du Sacré-Cœur de Jésus, laquelle serait célébrée à perpétuité tous les ans, avec procession réparatrice des profanations de la Révolution ; $4^{\circ}$ de se rendre, sous trois mois, après sa délivrance, à No- 
tre-Dame de Paris, pour y consacrer sa personne, sa famille et son royaume au Sacré-Cœur de Jésus ; $5^{\circ}$ d'ériger dans ladite église une chapelle ou un autel audit Sacré-Cœur ; $6^{\circ}$ de renouveler tous les ans l'acte de consécration de l'article 4.

(Nous reviendrons sur cette répugnante dévotion au Sacré-Cœur, que l'Assemblée de 1871 a osé instaurer officiellement à Montmartre et qui est l'œuvre des jésuites.)

Nous pourrions multiplier ces exemples de l'activité criminelle des disciples de Loyola. Pendant ce temps-là, Rome et le Vatican ne restaient pas inactifs. Le pape Pie VI accueillait à bras ouverts les prêtres réfractaires, appelait à Rome les Frères de la Doctrine chrétienne, tout en gardant le contact avec le représentant de la France. Mais il concluait une série d'accords avec les coalisés et, dès que la fortune des armes lui apparaissait comme contraire à la France, faisait assassiner ses ambassadeurs, comme Hugo de Basseville et le général Duphot. Le premier fut massacré parce que la flotte française, à Civita Vecchia, avait été très éprouvée par la tempête, et que la Curie romaine, la croyant en pleine déroute, avait excité le peuple contre l'infortuné Basseville ; le second fut tué par les gardes pontificaux, qu'il voulait empêcher de tirer sur le peuple.

C'est ce qu'on appela à cette époque « le crime catholique ", dont toute l'horreur mérite d'être racontée : Hugo de Basseville, blessé à mort, fut laissé trente-six heures sans soins ; au lieu d'un médecin, le pape lui envoya un prêtre qui s'acharna à l'exorciser et à lui faire rétracter le serment qu'il avait prêté à la Constitution de 1791 !... 
La Vérité Sur la Question Romaine (1930)

\section{VI \\ Explosion du fanatisme religieux}

Tandis que, tour à tour souriant ou sinistre, Pie VI évoluait, d'un jour à l'autre, entre l'hypocrisie et le crime, ses prêtres, suivant un plan bien arrêté, " souffrant chez nous le feu de la guerre civile et préparant des poignards » (Gensonné). Dans le midi, l’Anjou, la Vendée, dont l'insurrection est dirigée par un Conseil supérieur où siègent les abbés Folleville, évêque (?) d’Agra, et Bernier, le fanatisme fait rage. Les plus forcenés gîtent dans ce couvent de Saint-Laurent-sur-Sèvres, à Montaigu, avec sa succursale féminine: les Filles de la Sagesse, sœurs grises qui écrivent et impriment une foule de libelles, d'appels à la révolte qu'elles répandent ensuite partout. Dumouriez, dans un rapport, juge " ces espèces de cénobites, mâles et femelles, très dangereux tant par leur propagande que par les énormes richesses n’ont d'abord pour but que de renverser la Constitution civile qui blesse leur orgueil et qui détruit leurs richesses volées à la nation. L’Église entend reprendre dans des flots de sang les domaines et les trésors qu'elle a perdus avec son pouvoir temporel. Elle n'épargne rien pour y parvenir. Les brefs, les monitoires pontificaux viennent fréquemment ranimer le zèle des conjurés lorsqu'il paraît faiblir. Dans un de ces documents, Pie VI exprime sa vive joie de la résistance, de l'élan hé- 
roïque, des prêtres et des vierges sacrées, ainsi que des fidèles laïcs, aux lois de la Convention, c'est-à-dire à la République. Il exhale aussi sa tristesse à propos des défections de certains prélats (Taleyrand et les évêques de Sens, de Viviers et d'Orléans). Il encourage, il excite cette révolte qui met à feu et à sang presque tout le territoire de la France. Ce qui n'empêche pas, aujourd'hui encore, les cléricaux d'oser qualifier de persécution cette sanglante période pendant laquelle l'Eglise et ses prêtres semèrent la discorde, la haine entre Français!

Les témoignages abondent de cette conspiration contre la Révolution, organisée et dirigée par le Vatican et les jésuites. La correspondance du Club des Jacobins de Paris est remplie d'adresses, de rapports des sections de province où sont relatés les moyens les plus odieux mis en œuvre - comme aujourd'hui d'ailleurs - par les prêtres réfractaires pour soulever les populations. On a retrouvé un cahier manuscrit et portatif, fort curieux et des plus instructifs à ce sujet, ayant appartenu à un prêtre réfugié à Munich et qui l'avait lui-même reçu du nonce du pape à Fribourg. Toutes les catégories d'obligations imposées aux prêtres comme aux fidèles non conformistes et relatives à la guerre faite à la Révolution s'y trouvent minutieusement réglées et commentées : " renchérissement du commerce par la défense à ceux qu'ils confessent de recevoir des assignats en paiement, afin d'accélérer la banqueroute de la France (on voit que le rôle criminel des banquiers christianisés et de leur soutien, l'Eglise romaine, ne date pas d'hier !) ; ordre de ne recevoir eux-mêmes en paiement que de l'or ou de l'argent, ce qui augmente l'agiotage ; menace de privation du Ciel pour l'éternité envers quiconque ne vient pas se confesser à eux ;... il faut persuader aux filles que leur mariage béni par des prêtres assermentés ne sera pas valable ; aux femmes, que la cohabitation avec les maris est un crime, etc., etc... » Un prêtre de la commune de Beausset, des environs de Toulon, conseilla à des enfants, dont le père et la mère étaient patriotes, de les empoisonner ; il leur fournit luimême le poison! Le fait est attesté par un procès-verbal rédigé et signé par toute la municipalité de Beausset.

Vraiment, il sied bien aux cléricaux de parler de persécution pendant la période révolutionnaire, d'exalter comme des soi-disant martyrs des prêtres du genre de celui-ci : «Qu'ils citent donc un seul prê- 
tre, mis à la question, en in pace, aux entraves sur le bûcher, à la roue, du 12 juillet 1790 au $1^{\mathrm{er}}$ janvier 1793, et ensuite !» (Robinet). Ceux dont ils glorifient la mémoire et qui furent fusillés ou guillotinés le furent en pleine action de révolte contre la Patrie qu'ils trahissent chaque jour pour rétablir la domination universelle de l'Eglise en ramenant la monarchie en France. Les catholiques, maîtres pendant des siècles de l'Europe centrale, y ont commis tous les crimes, imposé toutes les tortures, et, du jour où ils ne peuvent plus faire couler le sang et les larmes, ils osent parler de persécution !

En résumé : manœuvres de confessionnal ; conciliabules de sacristie et de couvents ; menaces de damnation pour empêcher la vente des biens d'églises, le paiement des impôts et la libre circulation des grains afin d'affamer la France; destruction des denrées de première nécessité ; ruine des finances publiques par l'agiotage ; accaparement, exportation du numéraire ; faux assignats ; embauchage pour l'armée des émigrés ; mauvais traitements et même assassinats des prêtres constitutionnels; émeutes suscités dans toutes les communes, d'accord avec les émissaires du pape, de la cour et de l'aristocratie, afin de rétablir le roi, les nobles et le clergé dans leur premier état, mise en œuvre de toutes les trahisons pour assurer le triomphe définitif de l'Eglise et de la royauté. Tels sont les faits prouvés, patents, indéniables, que nous avons tenus à rapporter, au risque de déborder un peu le cadre de cette étude, parce que ce bilan d'une époque que l'Eglise a voulue sanglante et dont elle garde, à la suite de bien des forfaits, l'entière responsabilité devant l'histoire, nous a semblé suggestif, sur bien des points, par rapport au temps présent. 
La Vérité Sur la Question Romaine (1930)

\section{VII \\ Le plan de la Papauté}

\section{Châtiment, expiation et pénitence imposés à la France de la Révolution}

$\underline{\text { Retour à la table des matières }}$

À toutes les époques, la Curie romaine a fait preuve d'un esprit prévoyant et méthodique, et s'il lui est arrivé souvent d'échouer dans ses entreprises contre la liberté des peuples, ce n'est que pour avoir sous-estimé leur énergie et leur force de résistance. Ainsi en fut-il dans la lutte de la papauté contre la Révolution. Même en inspirant et en dirigeant chaque épisode des révoltes dont elle avait établi un plan nettement défini et qui fut servi à la lettre par les émigrés et leurs alliés étrangers, elle s'occupait également d'organiser en France la restauration de l'ordre. Car on ne doutait nullement à Rome d'obtenir, avec ou sans l'appui du Ciel, la victoire pour la nouvelle croisade.

C’est l'abbé Maury qui avait été chargé de déposer aux pieds de Sa Sainteté Pie VI le programme détaillé des libéralités nouvelles et des bienfaits qu'il voulait bien accorder à la France définitivement vaincue! Prédicateur de carrefours comme nous en avons aujourd'hui encor de peu intéressants échantillons, cet abbé Maury s'était acquis quelque popularité par le procédé, classique chez ces sortes de gens, de la fausse bonhomie et de la basse trivialité. Député aux Etats- géné- 
raux, il avait pris peur et s'était enfui le soir même de la prise de la Bastille ; il avait reparu peu après à la Constituante, pour y défendre la royauté et les privilèges du clergé. Plus tard, jésuite à tout faire, il devait se rallier à l'Empire, au prix de l'archevêché de Paris, et finir, disgrâcié au retour des Bourbons, dans l'obscurité, après avoir été déchu de ses fonctions ecclésiastiques.

Comme introduction à ce programme, l'abbé Maury prévoyait le triomphe de la contre-révolution "avec une rapidité qui peut bien devenir incalculable ». Et cela, quelques semaines avant les grandes salvatrices victoires de l'an II, rejetant les coalisés, reprenant Lyon, Marseille, Toulon, Bordeaux, et l'écrasement des Vendéens à Savenay et au Mans! Mais, dans son impatience de voir l'abaissement de la France, il sollicitait du pape l'application, dès que possible, des mesures qu'il réduisait aux points suivants: bulle d'excommunication contre les prêtres assermentés; rétablissement de la monarchie, des ordres religieux et de la main-morte ; restitution au clergé de tous les biens qu'il avait avant la Révolution ; restitution d'Avignon au pape ; suprématie de la juridiction canonique sur la juridiction laïque en matière judiciaire, etc...

Les Français de l'an II, fort heureusement, ne se laissèrent pas entamer, et ils répondirent à ces menaces par de foudroyantes victoires.

Mais déjà la silhouette du « Corse aux cheveux plats » grandissait à l'horizon, et la brutalité d'un despotisme militaire allait accomplir, aux lieu et place de l'Eglise, et bientôt de complicité avec elle, la destruction de la liberté et de la République. 


\section{VIII \\ Napoléon et l’Église}

$\underline{\text { Retour à la table des matières }}$

Il fallut, en effet, toute la fortune inattendue d'un Bonaparte et toute la force d'un impérialisme nouveau pour faire rebrousser chemin à la Révolution «avec une rapidité incalculable » que prévoyait l'abbé Maury en juin 1793, dans la conclusion de son projet de restauration de la France qu'il soumettait au pape Pie VI. Les feuilles cléricales ont eu tôt fait de rapprocher Mussolini et Bonaparte. L'une d'elles a même laissé entendre que le « Duce » était en route... vers l'empire. Outre que le parallèle est excessif, il est encore presque injurieux pour la papauté, qui paraîtrait, s'être courbée, comme en 1802 et en 1813, sous une volonté « de fer ». Au regard du dictateur, il est tout simplement grotesque, et ce serait le cas de répéter avec Victor Hugo :

\section{L'acteur fut un héros et la doublure un drôle.}

Car, fils intellectuel et spirituel des philosophes du XVIII ${ }^{\mathrm{e}}$ siècle, Bonaparte faisait profession de mépriser tous les cultes, et, lorsqu'il cessa d'être le "soldat de la Révolution » pour devenir le despote aux sanglantes ambitions, s'il se tourna vers Rome, ce ne fut pas pour se vendre à l'Eglise, mais pour lui parler en maître, ainsi qu'aux jésuites qu'il exécrait et redoutait peut-être. Il se servit de la religion, « sans laquelle, disait-il, les hommes se battraient pour la meilleure poire », 
comme d'un instrument de règne. Mais il ne permit jamais au Vatican d'élever la voix au-dessus de la sienne et fit des prêtres et des moines eux-mêmes des fonctionnaires « caporalisés » comme tout le reste de la France.

La papauté essaya bien quelque résistance : Pie VII déclina d'abord l'offre du premier consul, au lendemain de Marengo, de lui rendre sous conditions ses Etats, dont le Directoire avait fait une République. Mais, lorsque Bonaparte eut conquis l'Italie, il accepta tout, même la formule de serment, d'un servilisme achevé, que les évêques et les curés devaient prêter au gouvernement, et qui contient cette obligation de mouchardage : «... Et si, dans mon diocèse ou ailleurs, j'apprends qu'il se trame quelque chose au préjudice de l'Etat, je le ferai savoir au gouvernement. " Aussi l'homme de Brumaire pouvait-il dire, au lendemain de son couronnement : "Avec mes gendarmes et mes prêtres, il n'est rien que je ne puisse faire. " Enfin, chose qu'on ignore généralement, il fit rédiger un catéchisme impérial que le Saint-Siège approuva et qui devint obligatoire par décret du 4 août 1806. La genèse des Concordats de 1804, qui mettait entre les mains du gouvernement les nominations ecclésiastiques, et de 1813, qui aggravait encore la dépendance de Rome vis-à-vis de Napoléon, est trop connue pour y insister. La papauté affecta de ne pas reconnaître le premier à cause des articles organiques, et le second, parce que, arraché par la contrainte. Car, dans l'intervalle, Pie VII ayant refusé d'adhérer au blocus continental, avait été enlevé de Rome et conduit à Gêne, puis à Savone et à Fontainebleau, tandis que ses Etats étaient annexés à l'empire. Il riposta par l'excommunication, dont la bulle fut secrètement introduite en France par les royalistes Mathieu de Montmorency et de Noailles, qui dirigeaient la congrégation de la Sainte-Vierge. En même temps, Pie VII rappelait l'affirmation de Grégoire VII et d'Innocent III sur la soumission à l'autorité et au trône de saint Pierre de la puissance impériale. Napoléon fit arrêter les membres de la congrégation et se contenta de simples évêques pour annuler son premier mariage et contracter avec Marie-Louise une union qui le faisait petit-neveu de Louis XVI. Sans les événements de 1814, le pape aurait sans doute payé cher ses rodomontades spirituelles.

Quant aux congrégations, et celles des jésuites en particulier, dissimulées sous le nom de Pères de la Foi, elle parurent vivre d'abord en 
bons termes avec Bonaparte. D’ailleurs, les gouvernements politiques ne sont à leurs yeux que des accidents, des formes passagères. La seule réalité, pour elles, c'est la théocratie universelle. Le principe politique n'existant pas, les révolutions, pour la Compagnie de Jésus, ne soulèvent que des questions de prudence et d'opportunité. Leur besogne positive, c'est la conquête de la terre au profit de l'Eglise. Avec une habileté extraordinaire, ils s'infiltrent partout, s'adaptent à tous les milieux, prennent tous les costumes, mettent tous les masques, essuient toutes les tempêtes, se redressent l'orage passé, et partout, en tous temps, en tous lieux, se retrouvent toujours et uniquement jésuites.

Ainsi furent-ils, sans cesser d'être l'âme de toutes les conspirations, de tous les complots royalistes contre Napoléon. Pris en flagrant délit d'espionnage au profit de la Prusse et de la Russie, un décret du 3 messidor an XII prononça une fois de plus leur dissolution. Mais ils ne se soumirent pas plus à cette décision qu'aux précédentes du Parlement, de Louis XV, et de Clément XIV. Cinq ans plus tard, ils avaient recouvré toute leur influence à la faveur de la réaction religieuse qui s'était produite à la cour impériale au lendemain du Concordat et du sacre, et aussi grâce à la mère de Napoléon, qui avait arraché à l'empereur se consentement au retour de quelques congrégations. C'était également l'époque où, dans une adresse d'une écœurante platitude, le clergé suppliait celui qui demeurait pourtant pour l'Eglise « l'usurpateur » d'instituer la Saint-Napoléon comme fête nationale.

Mais les choses se gâtèrent de nouveau et, le 12 septembre 1809, Napoléon, sûr de la connivence des divers ordres, et surtout des jésuites avec les Anglais, écrivait au ministre Bigot-Préameneu :

« Je ne veux point de mission en France... Je n'entends pas que des missionnaires fassent profession de prédicateurs errants, parcourant l'empire... Je ne veux plus de missions quelconques. J'avais permis un établissement de missionnaires à Paris. Je rapporte tout. Je me contente d'exercer la religion chez moi, mais je ne me soucie pas de la propager à l'étranger. Ces missionnaires, d'ailleurs, sont pour qui les paye, pour les Anglais, s’ils veulent s'en servir. 
«Présentez-moi un projet de décret là-dessus ; je veux en finir. Je vous rends responsable si, au $1^{\mathrm{er}}$ octobre, il y a encore en France des missionnaires ou congrégations. » 


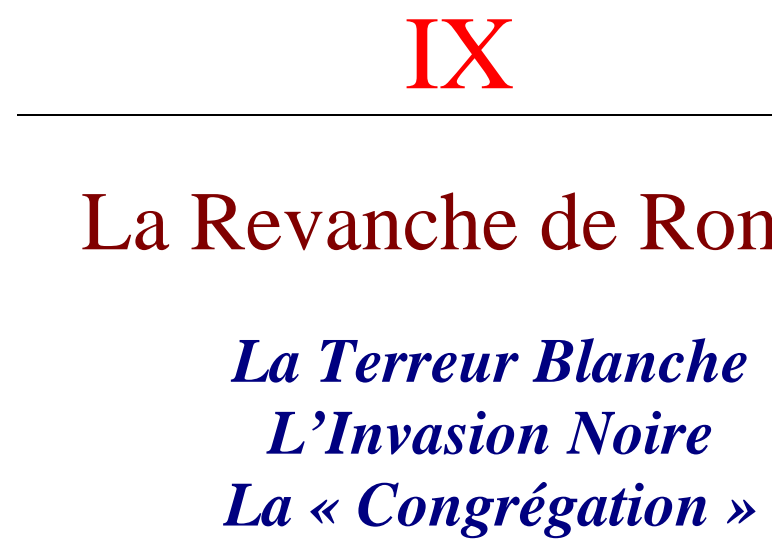

$\underline{\text { Retour à la table des matières }}$

La chute de Napoléon permit à l'Eglise et à ses milices monacales de reprendre l'exécution du plan de domination universelle que la Révolution avait arrêtée avec une si grande énergie et que l'Empire n'avait pu que paralyser momentanément. Il s'agissait d'abord de reconnaître la France selon le programme tracé par l'abbé Maury, en lui infligeant une invasion, mille fois plus terrible, parce que permanente, que celles de l'étranger : l'invasion noire.

Abolir le Concordat de 1801, refaire au clergé une fortune propre et indépendante, donner toutes les libertés aux congrégations, détruire l'Université, faire du catholicisme la religion officielle de la France, restituer à l'Eglise la tenue de l'état civil, abolir le divorce, rétablir pour le clergé une juridiction judiciaire spéciale, tels furent les principaux points à réaliser par l'Eglise romaine pour tenir la France sous sa tutelle. Elle y préluda dès la première Restauration par une série de massacres, d'assassinats individuels, qui organisèrent dans le Midi de la France la Terreur blanche. Enrégimentés par les Pères de la Foi, 
les Compagnons de Jehu, les Verdets, les Chevaliers du Brassard firent la chasse aux républicains comme aux bonapartistes. Ce fut la sanglante préface à l'œuvre de la seconde Restauration, où les diverses affiliations religieuses se fondirent dans la grande Congrégation, devenue rapidement une vaste conspiration englobant la France entière et qui, a écrit le vicomte de Montlosier, "fit plus de victimes qu'une des grandes batailles de la Révolution. »

Les origines de cette "Congrégation » sont intéressantes à savoir : En 1560, le jésuite Jean Léon, qui professait au Collège Romain, avait fondé une association de jeunes gens qui n'était en réalité qu'une filiale de la Compagnie de Jésus et qui devint le centre de beaucoup d'associations semblables et affiliées. Toutes disparurent, du moins en apparence, avec la dispersion des jésuites au XVIII ${ }^{\mathrm{e}}$ siècle. Mais, en 1801, l'une d'elles, la Congrégation de la Sainte-Vierge, affiliée autrefois à la congrégation du Collège Romain, se reforma ; elle compta parmi ses membres : Laënnec, Cauchy, Montmorency, etc...

Dissoute, on l'a vu, par Napoléon, elle s'était reconstituée dès les premiers jours de la Restauration et n'avait pas tardé à prendre un grand développement.

La Compagnie de Jésus, rétablie par Pie VII le 6 août 1814, prit la direction du mouvement. Les pères, se sentant tout-puissants, établirent à côté de la royauté un formidable gouvernement occulte qui osa même très souvent fonctionner à l'encontre des décisions royales. Les nouveaux jésuites s'installèrent à Montrouge, Saint-Acheul et Montmorillon. Les nobles émigrés, de retour, et les ex-dignitaires de l'Empire, devenus ultramontains par intérêt, leur confièrent l'éducation de leurs enfants. La dévotion régna aux Tuileries, les ministres durent assister aux offices, les grands corps de l'Etat suivre les processions. Il y eut pis encore : une loi du 22 novembre 1814 ordonna la fermeture le dimanche, pendant les offices, de toutes les boutiques, et que toutes les maisons soient tendues au passage des processions ! Mais Louis XVIII n'aimait guère les congrégations ; " ces corporations, disait-il, sont excellentes pour abattre et incapables de créer. » Seulement, il ne voulait et ne pouvait guère d'ailleurs les combattre. Leur triomphe ne fut complet qu'avec Charles $\mathrm{X}$, vieillard léger, têtu et libertin, et, comme Louis XIV, affilié aux Jésuites. 
C'est alors que se manifesta avec une violence inouïe la domination de l'Eglise sur notre malheureux pays. Des lois, comme celle du sacrilège, qui punit de mort avec amputation du poing droit la profanation des vases sacrés ou des hosties, deux milliards à l'Eglise en guise de restitution pour les biens vendus par la Révolution, un milliard aux émigrés, tels furent les dons de joyeux avènement du nouveau règne et de son ministre de Villèle. Sans compter la liberté de la presse et de réunion supprimée, tous les services publics, la poste, la police, l'administration, furent livrés aux jésuites. L'espionnage devint obligatoire : on dénonçait pour la sainte cause de la religion, pour sauver le trône et l'autel. L'audace du fanatisme ne connaissait plus d'obstacle. Aucun emploi n'était donné que par les ordres de la Congrégation. Il y eut à la Chambre de 1825 cent cinquante congréganistes.

Envahie par les ordres de toutes sortes, sans compter les jésuites à robe courte dont le nombre était - tout comme aujourd'hui - formidable, la France vit revenir alors presque tous les anciens moines.

On organisa des phalanges de missionnaires, telle la Société de Saint-Joseph, qui préchèrent une croisade contre les libéraux, c'est-àdire contre les républicains, titre qu'on n'osait pas alors employer, et pour cause. L'excès de cette réaction cléricale forcenée suscita les véhémentes protestations de deux journaux, le Constitutionnel et le Courrier Français, qui furent poursuivis pour « offenses à la religion de l'Etat ». La Cour royale, elle-même, acquitta les deux feuilles, tant étaient grandes l'indignation et la colère chez les esprits les plus pondérés en présence des fureurs de l'ultramontanisme déchaîné. Ce fut un royaliste, un émigré pourtant, le comte de Montlosier, qui se fit le porte-parole des consciences indignées en dénonçant publiquement ce vaste réseau d'affiliations religieuses et charitables qui couvrait toute la France. Pourtant, Montlosier avait défendu le clergé à la Constituante. Mais, royaliste jusqu'à l'exaltation, effrayé des progrès du jésuitisme et des congrégations, il fit paraître, en février 1824, son Mémoire à consulter sur un système religieux et politique tendant à renverser la religion, la société et le trône, qui eut huit éditions en peu de mois. 
Montlosier ne s'en tint pas là : il dénonça à la Cour royale de Paris les agissements et le but des congrégations. Celle-ci, tout en se déclarant incompétente, reconnaissait, dans son arrêt du 18 juillet 1826, le bien-fondé de la dénonciation, que tout le barreau de Paris appuya de sa consultation. Montlosier porta sa dénonciation à la Chambre des Pairs. A l'exemple de son illustre ancêtre, le chancelier Pasquier, qui défendit l'Université contre les jésuites en 1565, le baron Pasquier prononça contre ces mêmes ennemis de tout l'ordre social un vigoureux réquisitoire qui décida les pairs à voter le renvoi de la pétition au ministre pour toutes fins utiles. Les jésuites ripostèrent en obtenant de Charles X la dissolution de la Chambre des députés. Mais les élections de 1827 furent favorables aux libéraux, et, après une nouvelle enquête, accablante pour les congrégations, Charles $\mathrm{X}$ dut signer les ordonnances du 16 juin 1828, qui excluaient les jésuites et chassaient les congrégations de l'enseignement public. Sur l'intervention de Dupin, la Chambre des députés confirma ces décisions le 21 juin 1828.

Ainsi chassés pour la troisième fois par ordonnance d'un roi de France, les congréganistes se gardèrent bien de protester. Ils se cachèrent dans les ténèbres de la grande Congrégation, dont ils devinrent les directeurs on ne peut plus actifs, tandis que le dévôt Charles $\mathrm{X}$, comme s'il avait eu à cœur de se faire pardonner ses ordonnances, excitait la risée des Parisiens en prenant part, en habit violet, à pied et un cierge à la main, aux processions dans les rues de la capitale. 
La Vérité Sur la Question Romaine (1930)

\section{$\mathrm{X}$ \\ Nouvelle incarnation des Jésuites : La Société de St-Vincent-de-Paul}

Quelques mois après la Révolution de Juillet, les révérends pères rentraient clandestinement dans Partis et s'installaient sa,s le moindre bruit dans une sombre habitation de la rue des Postes, derrière le Panthéon. Leur premier acte fut la création, sous prétexte de charité, de la Société de Saint-Vincent de Paul, qui dépassa bientôt la Congrégation créée en 1828. Les accaparements et les dangers de cette société furent tels que dès 1843 la Chambre s'en occupait une première fois et, éventant la ruse des jésuites, réclamait contre la Société d'Ozanam l'application des lois les concernant. Thiers et Dupin exposèrent très énergiquement la situation. Guizot qualifia les jésuites de "malfaiteurs publics », de "pestilence morale », ce qui constituait autant d'accusations, justifiées d'ailleurs, contre les congrégations. Mais l'influence de la reine Amélie, dévote comme une Italienne, fit que Louis-Philippe laissa faire sans approuver ni condamner, et qu'on résolut de négocier avec le pape Grégoire XVI.

Quoique opposé aux tendances libérales de l’Europe, le pape n’était pas absolument partisan des jésuites. Ceux-ci n'attendirent pas un arrangement qui pouvait leur être préjudiciable. Grégoire XVI mourut. Pie IX, qui lui succéda, avait pris comme premier ministre le comte 
Rossi, lequel aurait certainement obtenu du pape un bref consentement approuvant l'application des lois françaises aux jésuites ; il périt assassiné, sans qu'on ait jamais pu découvrir le meurtrier. C’était, d'après la légende romaine, un monarchiste, mais ce monarchiste avait agi pour le compte de la Compagnie de Jésus. Ce double crime ne fit qu'irriter davantage, en Italie comme en France, tous les esprits clairvoyants contre les jésuites. Ce fut pour eux autant de gagné, car, plus puissants et plus riches que jamais, ils intensifièrent leur propagande, tandis que la loi demeurait impuissante à leur égard, du fait de la royauté, cependant prétendue voltairienne, de Louis-Philippe.

La Révolution de 1848 les trouva prêts à l'accueillir avec un faux enthousiasme. Louis Veuillot, rapprochant l'événement des premiers actes d'un libéralisme affecté de Pie IX, à Rome, salua la République de 1848 comme «un glorieux mouvement démocratique ». il osa écrire: "Le jésuitisme sympathise avec les institutions républicaines. » Autant de mots, autant de mensonges prémédités et savamment calculés. Ne fallait-il pas, dès les premiers jours, s'emparer du mouvement ou du moins le canaliser ad majorem dei gloriam ?

Ils bénirent avec empressement les arbres de Liberté, qui moururent presque tous.

Ils s'efforcèrent de compromettre aux yeux de la bourgeoisie la Révolution, en se faisant les promoteurs des doctrines sociales les plus exagérées, dans l'espoir qu'après des essais décourageants parce que irréalisables, ils établiraient peut-être leur domination en France comme au Paraguay.

Ils suscitèrent dans ce but les journées de juin 1848, travaillèrent pour la présidence du prince Louis-Napoléon dont l'élection devait marquer, — ils le pressentaient, — la fin de la République.

La réaction ultramontaine et jésuitique qui fit rage alors se montra ostensiblement par la résurrection de milliers de moines et religieuses sur tous les points de la France, préparant avec une sorte de fureur les élections de 1848, qui devaient sonner le glas de la République. 
La Vérité Sur la Question Romaine (1930)

\section{XI \\ La République de 1848 et les Jésuites \\ Les massacres de Juin \\ Le martyr par persuasion \\ L'expédition de Rome}

Retour à la table des matières

C'est surtout dans cette courte période de 1848 à 1852 que s'affirme nettement dans toute sa duplicité la tactique de l'Eglise romaine et des jésuites. La Révolution de 1848 ne fut pas la cause directe des divers mouvements qui éclatèrent alors en Europe. « En réalité, comme l'a écrit Emile Bourgeois, depuis huit ans, une crise générale - celle des nationalités opprimées - se préparait, dont l'éclat coïncida avec les événements de Paris. » Mais la papauté et ses perfides auxiliaires surent très habilement l'exploiter pour demeurer, la crise passée, les maîtres incontestables et absolus de la situation.

En France, où les reflets de la légende napoléonienne entretenaient encore, dans les campagnes l'idée monarchique; où des savants, des penseurs, dignes émules des encyclopédistes du XVIII ${ }^{\mathrm{e}}$ siècle, préparaient, eux aussi, l'avènement d'un ordre nouveau, basé sur la souveraineté de la démocratie et l'amélioration physique et morale de la classe prolétarienne, l'Eglise n'avait eu garde de laisser échapper l'occasion de s'installer dans la Révolution pour mieux la paralyser. Des prêtres, et, parmi ceux-ci, l'un des précurseurs du modernisme actuel, Lamennais, préconisaient l'alliance, impossible d'ailleurs, de 
l'Eglise et de la liberté, avec des alternatives de soumissions et de révoltes envers le pape Grégoire XVI, qui lui avaient valu assez de popularité pour aller siéger à la Constituante de la deuxième République. Un prêtre socialiste ! C'est le spectacle auquel le brave populo s'est toujours laissé prendre : l'éloquence d'un sermon ou l'énergie d'une période lui fait facilement oublier que l'auteur des Paroles d'un Croyant n'exalte les souffrances des humbles que pour mieux les exhorter à la résignation, c'est-à-dire à supporter in ceternum, au nom de la foi et par ordre de l'Eglise, en vue des futures joies célestes, leur misérable condition.

Un jésuite de robe courte, M. de Falloux, royaliste ultra sous LouisPhilippe et apologiste de l'Inquisition, mais devenu tout d'un coup fougueux démocrate, au lendemain de février 1848, saluant la République avec des transports d'allégresse et appelant tous les peuples à l'insurrection, avait reçu mission des jésuites de précipiter la chute du nouveau régime. Il s'en acquitta merveilleusement. D’abord, comme acteur très influent, bien que clandestin, dans les tractations diplomatiques qui amenèrent la chute de la République romaine, ensuite comme ministre de l'instruction publique, en livrant, par la loi qui a gardé son nom comme une marque d'infamie, tout l'enseignement de la France aux jésuites ; enfin, par une propagande intense en faveur du prince-président Louis Bonaparte, avec lequel, en compagnie de Montalembert, il parcourut la Bourgogne et une partie de l'Est de la France, le faisant acclamer partout par le clergé, par les moines, par les religieuses, par les frères ignorantins.

Nous ne nous attarderons pas à l'histoire du Second Empire. Il est cependant nécessaire d'exposer aussi sommairement que possible le rôle des légitimistes comme de Falloux, des ultramontains comme Montalembert, pour remettre la France sous la domination de l'Eglise, par l'intermédiaire d'un second Bonaparte dont la réaction cléricale, escomptant par avance la médiocrité d'esprit et les nuageuses rêveries, entendait se servir comme d'un instrument. Louis Bonaparte était, avant tout, celui dont on soupçonnerait le moins la complicité dans cette odieuse agression contre la République romaine devant laquelle Pie IX, qui avait succédé à Grégoire XVI, avait dû s'enfuir, après deux années d'une habile comédie de libéralisme dont les patriotes italiens Garibaldi et Mazzini n’avaient pas été dupes. En effet, en 
1831, son frère aîné, Napoléon-Louis, il avait combattu à Forli, dans les rangs des insurgés de la Romagne, et pour s'excuser de sa présence au milieu des révoltés contre l'Etat pontifical, il avait exposé, dans une longue lettre à Grégoire XVI, les desiderata du peuple italien, à savoir "la séparation du pouvoir temporel d'avec le spirituel »; il ajoutait que les forces avec lesquelles il se trouvait « étaient invincibles »; bref, il conseillait au pape, auquel on ne voulait, d'après lui, nul dommage, de céder et de «donner des lois et une représentation nationale à son peuple. »

Ce très curieux document fut publié in extenso (20 juillet 1849) par la Liberté, qui le faisait précéder de cette réflexion :

"Comment croire que l'insurgé de Forli ait pu associer son nom à la restauration du pape et de son pouvoir temporel ? »

Evidemment, la Liberté ignorait ou feignait d'ignorer que Louis Bonaparte, prince-président de la République, prenait le même chemin que son oncle pour renverser cette même République et se mettre à sa place : le chemin de Rome, par lequel ont passé, en quête d'une couronne ou d'une dictature, tous les aventuriers de l'Europe. Louis Bonaparte n'était pas l'homme des scrupules ; la gloire sanglante de son impérial prédécesseur lui permettait de risquer la partie, en rôdant, dans les sombres journées de juin 1848, autour du pouvoir.

\section{Et ce voleur de nuit alluma sa lanterne} Au soleil d'Austerlitz.

(V. Hugo, Châtiments.)

Tandis que, à la honte de la France républicaine, le général Oudinot se préparait à partir avec un corps expéditionnaire pour détruire la République romaine et remettre le pape en possession de ses Etats, M. de Falloux projetait l'écrasement en masse des forces prolétariennes qui, sur la foi d'un travail assuré par les ateliers nationaux, avaient afflué vers la capitale. Ce massacre des journées de juin 1848 entrait également dans l'infernal programme des jésuites. Par la dispersion des 120000 ouvriers auxquels un décret paru au Moniteur laissait le choix entre un retour forcé en province ou l'enrôlement obligatoire d'ans l'armée, la République provoquait chez ses meilleurs défenseurs une 
colère bien compréhensible et se les aliénait pour longtemps. Or, c'est sur un rapport de $M$. de Falloux que cette décision aussi dangereuse pour le régime que peu sensée avait été prise par le pouvoir exécutif. Il en résulta quatre jours d'émeutes sanglantes dans Paris et les mesures les plus rigoureuses qui frappèrent naturellement tous les républicains militants, au lendemain des «boucheries » du général Cavaignac, qui avait été chargé de rétablir l’ordre.

Ici encore, l'Eglise ne perdit pas l'occasion de jouer son rôle avec la mort théâtrale de l'archevêque Affre. On sait, par leurs casuistes, leurs théologiens d'immoralité divine, que les jésuites n’hésitent pas à « fabriquer des martyrs », lorsqu'ils estiment que l'intérêt de l'Eglise exige le sang d'un ou plusieurs des leurs. Leurs exemples abondent de ces fanatiques perinde ac cadaver qui, sur l'ordre du général, doivent aller se faire tuer pour que les simples d'esprit, frappés d'admiration, se courbent avec encore plus d'humilité dans la croyance. Peut-être n'y vont-ils pas toujours de bonne volonté. Tel paraît avoir été le cas de l'archevêque Affre, lorsque, le dimanche 25 juin, trois gardes nationaux, Frédéric Ozanam, le fondateur de la Société de Saint-Vincent de Paul, filiale des jésuites, Emmanuel Bailly et Léon Cornudet, tous trois jésuites, vinrent lui demander de se jeter dans la mêlée pour arrêter la lutte fratricide. " J'y songeais », leur répondit l'archevêque. Il avait eu, en effet, le temps d'y songer depuis trois jours que le combat des rues faisait rage. Mais quelques objections l'attardent encore. Les trois jésuites se font plus pressants, et Affre se décide... la Société de Jésus aura son martyr, qu'elle pourra faire canoniser plus tard. Deux vicaires généraux et un jeune homme portant une palme verte entourent le médiateur légèrement soucieux. Son arrivée, place de la Bastille, fait cesser le feu. Insurgés et soldats sont prêts à l'écouter, lorsqu'une balle perdue, venue on ne sait d'où, le frappe mortellement.

Ce récit, emprunté aux panégyristes du " sacrifié par ordre », appellerait bien des commentaires. Nous aurons l'occasion de les faire à propos d'un autre "sacrifié » du même genre, et, cette fois, avec des preuves matérielles qui ne laisseront aucun doute dans l'esprit du lecteur, même le plus croyant, s’il veut être de bonne foi.

Ainsi, la classe ouvrière décimée, et l'émeute ayant tourné comme l'entendaient les jésuites, la République romaine écrasée, Pie IX, dont 
nous avons retracé la sanglante histoire, immolant à sa colère plus de cinq mille républicains italiens, l'enseignement placé entre les mains de l’Eglise, telle était l'œuvre réalisée par l’Eglise et ses janissaires.

La voie était désormais libre pour faire du prince-président un nouvel empereur.

Les mêmes prêtres qui avaient béni les arbres de liberté en février 1848 chantèrent le Te Deum d'action de grâce en l'honneur du parjure de décembre 1852. Et, sous le signe bien religieux de la trahison et du mensonge, le pape et l'empereur scellèrent solennellement leur alliance.

Elle ne fut pas exempte de quelques petits froissements, et très souvent, dans ses multiples brochures, l'évêque Dupanloup reprocha avec aigreur au Second Empire les services rendus en 1851. Mais l'Eglise garda vis-à-vis du second des Napoléon une indépendance que le premier n'aurait certes pas tolérée, et elle eut l'art de l'associer dans ses tentatives de domination sur le Nouveau Monde, pour le malheur de la France qui y perdit un peu de son prestige et beaucoup de son crédit. 
La Vérité Sur la Question Romaine (1930)

\section{XII \\ Le Second Empire et les Jésuites}

$\underline{\text { Retour à la table des matières }}$

Résolue une première fois par la Révolution du le mode brutal d'Alexandre tranchant le nœud gordien, la question romaine devait revivre au lendemain du congrès de Vienne (1815), qui avait rendu à la papauté ses Etats et livré l'Italie au despotisme des Bourbons et de l'Autriche.

Ce n’était certes pas le césarisme démocratique, aux idées imprécises, aux formules lapidaires, appelant à la révolte "les nationalités » pour les abandonner ensuite, qui pouvait aboutir à une solution définitive du problème. Grisé par ses rêveries d'exil et de prison, Napoléonle-Petit se croyait destiné à réunir comme son oncle, mais par la force morale des traités et des alliances, l'Europe entière sous son arbitrage. Pour réaliser un tel projet avec la moindre violence, il fallait être d'un autre caractère que le maître d'une cour frivole et dissolue, qui, à défaut d'une alliance royale dédaigneusement refusée par ses pairs, avait dû se contenter d'une comtesse (?) espagnole, étrangement passionnée et dont l'influence néfaste devait coûter à la France deux provinces et cinq milliards, sans compter les morts.

Pour déjouer les fourberies de Pie IX, tour à tour italien et autrichien, et répondre au Syllabus, il eût été nécessaire que le second des Napoléon fît appel à l'énergie de son ancêtre et qu'il n'eût pas besoin, 
lui et son entourage, de l'appui calculé des jésuites et de la papauté pour affermir son pouvoir né d'un parjure et d'un crime.

L’Église devait avoir facilement raison de cette bande d'aventuriers, tels que les Morny, Maupas, Saint-Arnaud et Persigny, qui, dans une incessante orgie, exploitèrent la France pendant dix-huit années, et auxquels Gambetta lançait en 1870 sa célèbre apostrophe : «Vous avez commencé comme des jouisseurs et vous avez fini comme des traîtres!»

A l'intérieur, les jésuites publiaient dès 1853 un programme de restauration de l'Europe, comprenant le rétablissement des trois ordres : clergé, noblesse et le peuple, programme qu'avaient accepté la Bavière et l'Autriche, auquel devait souscrire plus tard le comte de Chambord en prêtant le serment d'obéissance au pape, et que le parti légitimiste reconnaissait publiquement comme sien dans une séance de l'Assemblée de Versailles (8 novembre 1875). Aux Tuileries, l'excuré de Ham, l'abbé Timache, devenu Monseigneur et évêque in partibus d'Adras, continuait à confesser et à absoudre Leurs Majestés, devant lesquelles les éléments les plus divers du clergé, prédicateurs de toutes nuances, chanoines du fameux chapitre de Saint-Denis réorganisé, papillonnaient et posaient à toutes les réceptions.

Les disciples de Loyola n'étaient pas tous des exclus de ces invitations. L'un d'eux, le jésuite Lefèvre, petit vieux rempli de souplesse et à la langue merveilleusement pendue, était l'un des coryphées les plus écoutés de cette basse-cour. Délégué par son ordre auprès de cette contre-façon de royauté, il s'acquittait de son office d' " observateur » avec une finesse et un savoir-faire dont chacun le louait. Mais, quelques années avant la guerre franco-allemande, la Montijo voulut avoir son aumônier, bel homme et discourant bien. Elle le trouva dans un sieur Bauer, Hongrois de naissance, transfuge de la religion israélite, puis d'un couvent de moines français. Le nouveau Monsignor, - aux ordres des jésuites, naturellement, - fit fureur à la Cour, et ses conseils et son influence jouèrent un rôle prépondérant dans les derniers événements qui conduisirent le Second Empire à Sedan et à la chute définitive du régime. 
A cette époque, il est vrai de dire que le despotisme et la réaction l'emportaient presque partout en Europe, et leur victoire profitait largement au cléricalisme. Les jésuites crurent toucher à leur but: l'asservissement de la société civile dans les pays catholiques ou prétendus tels. A la conférence réunie à Chieri, en Piémont, leur général, qui était alors le père Roothan, fit entendre ces paroles de triomphe et de menace :

"Vraiment, notre siècle est étrangement délicat. S'imagine-t-il que la cendre des bûchers soit totalement éteinte, qu'il n'en soit pas resté le plus petit tison pour allumer une seule torche ? Les insensés! En nous appelant jésuites, ils croient nous couvrir d'opprobre. Mais ces jésuites leur réservent la censure, un bâillon et du feu... Et un jour, ils seront les maîtres de leurs maîtres. »

On ne saurait être surpris, après un tel langage, des complaisances napoléoniennes et de la protection de l'impératrice Eugénie pour toute la prêtraille. Il en résulta un véritable débordement des congrégations réfractaires. Les hommes noirs se crurent alors assez forts pour faire de la France une vaste jésuitière ; le Panthéon fut rendu au prêtres ; l'enseignement à tous les degrés ; primaire, secondaire et supérieur, fut livré aux jésuites. L'université fut violemment attaquée par l'un d'eux, le père Combalot, qui l'accusa de former des intelligences prostituées qui vont chercher au fond des enfers la glorification du bagne, de l'inceste, de l'adultère et de la révolte. Après ce que l'on connaît de la morale et du code des jésuites, qui enseignent précisément tous les vices et poussent à tous les crimes, il faut reconnaître que rien n'égale l'impudence des disciples de Loyola renversant les rôles et chargeant leurs adversaires de leurs propres infamies. 


\section{XIII \\ L'accroissement formidable des Congrégations}

\section{L'unité Italienne - Les deux « Jamais »}

Les choses allèrent si loin, et l'audace des cléricaux s'accrut tellement, que certains conseillers de Napoléon III lui signalèrent les dangers de l'immense crédit des religieux. En effet, grâce à l'influence de la bigote espagnole des Tuileries, 1159 nouvelles maisons religieuses avaient été créées en France. Sept congrégations masculines enseignantes avaient été autorisées et reconnues, en vertu du décret-loi du 31 janvier 1852, d'utilité publique. Bien plus, le gouvernement avait imaginé cette escobarderie de déclarer illicites, en tant que congrégations, certaines corporations religieuses, mais de les déclarer licites en tant qu'associations enseignantes !

A Rome, où l'on suivait avec l'attention et la joie que l'on devine le développement considérable de l'influence des ultramontains, rien n'était négligé pour appuyer leurs efforts. Mais le sentiment des peuples devait une fois encore l'emporter sur la combinazione du Vatican : la Sardaigne, avec Charles-Albert d'abord et son fils VictorEmmanuel I ${ }^{\mathrm{er}}$, s’agitait de nouveau. 
La question d'Orient, qui pour un instant occupa le premier plan des préoccupations de l'Europe, fut pour le Second Empire l'occasion de témoigner de son zèle en faveur des chrétiens de Palestine et des lieux prétendus saints. Une querelle de moines de sectes différentes prétendant à la garde desdits lieux suffit pour amener la guerre de Crimée, au cours de laquelle le roi de Sardaigne s’imposa comme allié à la France et, la guerre terminée par le traité de Paris (1856), réclama instamment l'appui de Napoléon contre les Autrichiens. L'attentat d'Orsini précipita les événements, et, passant des encouragements secrets à l'aide ouvertement affirmée, l'ancien carbonari, le combattant de Forli, repris par son idée fixe : la libération des "nationalités », lançait son fameux appel en faveur de «l'Italie libre, des Alpes à la mer!»

Cet enthousiasme à retardement, qui avait d'abord rempli d'espoir le ministre Cavour, ne devait guère durer plus de trois mois. En plein succès, après Montebello, Magenta et Solférino, Napoléon III s'arrêtait net et offrait lui-même la paix aux Autrichiens. On a cherché bien des raisons à ce brusque revirement, qui était d'ailleurs dans le caractère de l'homme de Décembre. La cause était pourtant bien simple : l'Eglise romaine, avec la prescience pour elle du danger résultant de l'unité italienne, avait levé la main au-devant du vainqueur, et celui-ci avait dû s’incliner sagement.

Car, en France, les jésuites, les ultramontains, les chefs des conférences de Saint-Vincent de Paul, avaient poussé des cris de rage lorsque les Italiens s'étaient emparés des Romagnes et que la campagne préparée par Cavour avait mis en lumière toute l'impuissance du pape-roi. Ils protestèrent avec la plus grande violence en faveur du pouvoir temporel du pape.

La paix de Villafranca (1859) fut considérée comme une trahison par les Italiens, qui n'y gagnaient que la Lombardie, et VictorEmmanuel fit toutes réserves sur l'acceptation de principe d'une confédération italienne dont Pie IX serait le chef.

L'Empire essaya de faire subir aux cléricaux l'irritation de sa déconvenue. A la suite de plusieurs captations d'héritage par des congrégations, le Sénat fut saisi de diverses pétitions contre 
l'envahissement des congrégations religieuses et surtout des jésuites. On donna une très grande publicité au rapport qui fut fait de ces pétitions par le sénateur et procureur général Dupin, qui révélait l'existence en France de 7802 congrégations, tant d'hommes que de femmes, et qui étaient toutes entre les mains et sous la direction des jésuites et étaient riches à millions. Quant aux jésuites, leur fortune dépassait déjà un milliard en 1860, et ils faisaient construire, dans la suite, une luxueuse église, cachée au fond d'une cour, rue de Sèvres.

Ce temple fastueux, dont les profanes connaissaient à peine l'existence, possède plus de trente confessionnaux toujours remplis de pénitentes du noble faubourg. Car le menu peuple n'y a pas accès. De plus, ils avaient fait édifier, un peu partout dans les grands centres, de magnifiques collègues, notamment à Lyon et à Toulouse, les deux places fortes du jésuitisme et des dames du Sacré-Cœur.

Cette situation nettement définie impressionna tout de même le pseudo-César, d'autant que tous les fonctionnaires de province, préfets et procureurs, signalaient contre le régime des conspirations de sacristie. Malgré ces informations sûres, Napoléon hésitait à entrer en lutte avec les fils de Loyola. Le ministre Persigny se contenta d'une circulaire très modérée (16 octobre 1861) contre l'action et les actes odieux de la Société de Saint-Vincent de Paul. Ce qui lui valut d'être traité de nouvel Hérode par les cléricaux.

Très habilement, les jésuites rompirent les chiens en donnant ordre à leur presse d'attaquer la franc-maçonnerie ; et ils feignirent leur soumission et celle de la Société de Saint-Vincent de Paul aux ordres du gouvernement. Mais cette soumission était si peu sincère que, moins d'un an après (25 février 1862), M. Billault dénonçait au Sénat l'ingérence de ces deux sociétés dans la question romaine que venait de rouvrir le coup de main hardi de Garibaldi, secrètement encouragé par Cavour et... Napoléon III. Le résultat, ce fut la presque totalité de la péninsule (sauf Rome) aux mains du Piémont, la proclamation de l'unité italienne et celle de Victor-Emmanuel comme roi d'Italie, avec le désir non caché de compléter à bref délai cette unité par la conquête de Rome, où une garnison française protégeait encore ce qui restait au pape de son pouvoir temporel. 
On sait ce qu'il en advint par la suite : Cavour, avant de mourir, avait fait voter par les Chambres italiennes une déclaration platonique en faveur de Rome capitale et offrant, en échange, au pape, son indépendance spirituelle (1861). Sur le refus de Pie IX, Garibaldi, soutenu secrètement par Ricasoli, successeur de Cavour, voulut renouveler contre Rome la marche de l'expédition des « Mille ». Mais il fut désavoué presque aussitôt par le ministre et emprisonné à Aspromonte (1861), tandis que, toujours en quête d'une conciliation impossible entre le pape qui voulait conserver sa souveraineté et le peuple italien qui réclamait Rome, Napoléon III s’engageait à retirer la garnison française en échange de la promesse formelle par Victor-Emmanuel de respecter l'indépendance de Rome et du Saint-Siège, qu'il plaçait sous sa protection (15 septembre 1864). L'Italie ajournait une fois encore la réalisation de ses espérances et se contentait de Florence comme capitale (1865).

Mais le ministère La Marmora avait fait insérer dans ce compromis une clause aux termes de laquelle chacune des deux parties réservait sa liberté d'action pour le cas où le pape-roi serait incapable, n'ayant affaire qu'à ses propres sujets, de conserver sa souveraineté. Quelques années après, Garibaldi répétait sa tentative de 1861 et arrivait à 20 kilomètres de Rome, d'où les troupes françaises s'étaient retirées en 1866. Le pape appela Napoléon à son secours. Ecrasés à Mentana (3 novembre 1867) par le corps expéditionnaire français, les garibaldiens se retirèrent. Rome était encore perdue pour l'Italie, qui nous en garda une rancune d'autant mieux justifiée que deux phrases mortellement blessantes, même pour deux vielles amitiés, clôturaient cette odieuse intervention: L'une déclarait, dans un rapport militaire, que «les chassepots avaient fait merveille » à Mentana ; l'autre, prononcée peu après au Corps législatif par Rouher, affirmait, aux applaudissements des ultramontains, que «jamais l'Italie ne prendrait Rome ». Ce à quoi le général Menabrea, à la tribune du Parlement italien, répliquait que « jamais l’Italie ne renoncerait à son droit sur Rome ».

Ainsi, la politique à deux faces du second Napoléon, son criminel entêtement à défendre le pouvoir temporel de la papauté, aboutissait à nous aliéner l'Italie, devenue, évidemment un peu par notre aide, une grande puissance. Car l'expression : Italia fara da se était plutôt une noble vaillantise. Et, dans l'ombre de ces événements, selon 
l'expression d'un journal anglais, le Spectator : « On voyait s'avancer lentement, ténébreuse, et pourtant distincte comme un fantôme de théâtre, la figure du comte de Bismarck. »

La France, en effet, devait payer cher son titre de fille aînée de l’Eglise, que le criminel parjure de décembre entendait lui conserver. 


\section{XIV \\ La Double action des Jésuites \\ Le Syllabus \\ La menace romaine sur les deux Amérique}

Résigné en apparence aux événements qui diminuaient peu à peu les Etats de l'Eglise et lui faisaient prévoir la perte totale de son pouvoir temporel au premier grand choc, Pie IX affectait de se consacrer à une réorganisation de la hiérarchie ecclésiastique en Hollande et en Angleterre. Mais, en réalité, la compréhension très juste de la situation de l'Eglise, bientôt privée de la puissance territoriale et réduite au rôle d'une autorité morale de plus en plus discutable, occupait fortement ses pensées. Le temps était passé des persécutions sanglantes ramenant les peuples dans l'obédience du dogme, et les foudres de l'excommunication même majeure ne faisaient plus trembler les chefs d'empire.

Devant l'impérieuse nécessité pour la papauté de conserver à tout prix une suprématie que la milice noire elle-même ne suffisait plus à défendre, depuis l'entrée en scène presque partout des masses révolutionnaires, une double action s'imposait. Action morale pour le renforcement de la croyance en ajoutant de nouveaux dogmes aux anciens ; action matérielle par la création d'un grand empire latin entièrement inféodé à l'Eglise et à la fois point d'appui et contrepoids du 
catholicisme contre les forces progressives, particulièrement aux Etats-Unis, de l'orthodoxie protestante.

La première, l'action morale, qu'on pourrait dénommer plus justement immorale, faisait de la propagande deux parts : l'une gardait aux jésuites la tâche d'éduquer, de guider les classes "dirigeantes » et de les adapter aux conditions nouvelles du milieu social né de la Révolution, de remplir de leurs élèves l'armée, la marine, la magistrature, en un mot, toutes les fonctions d'autorité. Aux fils de Loyola, esprits subtils et sans aucune espèce de scrupule, il échéait d'imaginer une sorte de christianisme capitaliste et bourgeois, à l'usage des "gens du monde », d'une dévotion facile, mi-mensuelle, mi-spirituelle. L'autre propagande s'attaquait au peuple sans rien innover. C'était toujours, en effet, la spéculation sur l'ignorance des masses par la superstition et le miracle. Mais « l'effort de la démocratie pour se constituer dans la raison » exigeait de l'Eglise une activité plus violente. Multipliant les croyances obligatoires et offrant à la foule une religion matérielle, s'adressant à ses sens, à ses nerfs ; traduisant le symbolisme spirituel par de grossières images, elle fait de la légende de la prétendue Vierge "à la chair sans fragilité et aux sens sans rebellions ", d'après le pompeux Bossuet, une sorte de déesse vulgaire, dont l'Immaculée Conception (1854) atteindra dans son culte les bornes d'un grotesque achevé. La Passion, qui alimenta les admirables fantaisies de tant d'artistes, n’est plus que le fétichisme du Précieux Sang, et le SacréCour, « un viscère percé de coups, dégouttant de larmes sanglantes ».

Ce n'est même plus le mysticisme du $\mathrm{XI}^{\mathrm{e}}$ siècle que la misérable condition humaine à cette époque ennoblissait encore d'une grandiose souffrance, exploitée déjà par l'Eglise ; non plus celui du $\mathrm{XVI}^{\mathrm{e}}$ siècle que les querelles des sectes auréolaient aussi d'une fausse sincérité ; mais la séduction d'une religion abaissée au niveau des plus bas instincts de l'homme primitif, qu'avec une audace bravant ostensiblement le ridicule, l'Eglise entreprend de réveiller et de flatter la foule. Sans compter la collection de saints et de saintes appropriées à toutes les circonstances de la vie : tel saint Antoine de Padoue " pour retrouver les clefs et les cœurs perdus, garantir le succès au potache, le gros bénéfice au mercanti, la maternité aux femmes stériles, etc., etc... », bref, toutes ces superstitions que Joseph de Maistre appelait les ouvrages avancés et le remparts de la religion. 
Cette démagogie religieuse où par la vertu des apparitions, des sources magiques, des processions à grand orchestre, l'hystérie s'exalte jusqu'au miracle, à l'aide d'une mise en scène adéquate, a été jugée, avec raison, plutôt comme un signe de décadence de l'Eglise. Il est incontestable qu'une religion qui s'abaisse à de tels expédients, après s'être élevée aux plus hauts sommets de l'idéal, qui ressuscite le culte des fétiches et des idoles qu'elle combattit dès sa naissance, perd beaucoup de son empire sur les peuples. Encore faut-il que ceux-ci s'élèvent au-dessus de son niveau par une éducation rationnelle de l'intelligence et de la volonté, qui les instruise complètement de l'absurdité du dogme.

Aux termes des articles organiques du Concordat (art. III), le Conseil d'Etat avait dû examiner la bulle promulguant le nouveau dogme de l'Immaculée Conception, pour décider si réellement la mère de Ieschou l'avait conçu sans péché, aucun décret pontifical ou des conciles ne pouvant être publié en France à cette époque sans un visa du gouvernement. C'est le plus sérieusement du monde que, par trois voix contre deux, il déclara le dogme conforme à la vérité (!) historique et pouvant être imposé à la foi des sujets de l’Empire (1854).

Le couronnement de cette action morale s'affirmait bruyamment dix ans plus tard (8 décembre 1864), par l'encyclique Quanta cura condamnant la liberté des cultes et de la presse, ainsi que l'indépendance absolue de l'Etat à l'égard de la religion et de l'Eglise. Quatre-vingts propositions, élaborées et codifiées par les jésuites euxmêmes et connues sous le nom de Syllabus, étaient annexées à la lettre pontificale ; chacune d'elles clamait l'anathème contre un droit ou une liberté de la conscience humaine. Cet insolent défi à la raison, cet outrage au libre arbitre des peuples, parut tout de même dépasser les bornes d'une politique tolérante. La réprobation quasi universelle qui s'ensuivit ne permit pas au gouvernement impérial, malgré les intrigues des Tuileries, de braver l'opinion en accueillant favorablement, comme la précédente, cette seconde bulle. Défense fut même faite aux évêques de la reproduire dans leurs mandements.

La seconde action, l'action matérielle, fut, de beaucoup, la plus dommageable à la France. Il est certain que sans l'expédition du 
Mexique, la Prusse eût hésité à conduire l'Autriche à Sadowa (1866) et à soutenir la guerre contre nous en 1870, encore qu'elle n'en fut pas responsable, comme on le verra par la suite.

Il semble bien que, durant les deux années qu'il passa au Chili, en qualité de secrétaire du vicaire apostolique Muzzi, le futur pape «sanglant », Mastaï Perretti ait eu alors la pensée d'un grand empire latin aux confins des Etats-Unis, dont la forte sagesse des successeurs de Washington avait fait déjà une importante nation. Le moment était d'autant plus favorable à la réalisation de ce projet que l'Amérique du Nord venait d'être durement éprouvée par la lutte fratricide de la guerre de Sécession (1865) et que les Etats du Sud et du Centre, affaiblis par une suite ininterrompue de dissensions intérieures, n’opposeraient guère de résistance aux visées de l'Eglise. Les jésuites qui, aux premières époques de l'exploration et de la prise de possession de ces divers petits pays par la très catholique Espagne, étaient accourus pour évangéliser et surtout exploiter commercialement les indigènes de ces riches et primitives contrées vivant heureuses jusquelà, avaient déjà établi solidement leur influence sur presque toutes, et en particulier sur le Mexique, vers 1860.

Leur domination sur ce dernier pays avait abouti à la formation de deux grands partis : les escoceses (cléricaux) et les yorkinos (démocrates), toujours en lutte pour la possession du pouvoir. Une telle situation intérieure ne pouvait que favoriser les intrigues de la papauté pour tenter la conquête du Mexique. Faire naître un casus belli entre les Mexicains et une grande nation occidentale n'était qu'un jeu pour les jésuites. La grande nation était toute désignée : c'était la France, où, profitant de l'absence de l'empereur, pendant la campagne d'Italie, les jésuites s'étaient implantés aux Tuileries auprès de l'impératrice régente, la Montijo, dressée en Espagne à servir les desseins ad majorem dei gloriam. Restait à faire surgir l'occasion : ce ne fut guère moins aisé. 


\section{XV \\ L’expédition du Mexique}

\section{"La plus grande pensée du règne"}

En raison de sa descendance et de son affiliation d'autrefois aux carbonari, Napoléon III n'était pas sympathique au parti clérical qui, cependant, lui savait gré d'avoir vaincu l'anarchie, autrement dit d'avoir étranglé la République prolétarienne et socialiste de 1848 et de lui avoir substitué « l’orgie impériale ».

Victoire! il était temps, prince, que tu parusses. Les filles d'opéra manquaient de princes russes ! s'écriait, au lendemain du 2 décembre, le poète des Châtiments. Et, de fait, si, contrairement à l'affirmation de son chef, l'Empire n'était pas la paix (guerres de Crimée, d'Italie, du Mexique, etc...), c’était sûrement le régime de la " grande vie ». de l'alcôve au tripot, la haute société des Tuileries évoluait dans un luxe inouï, au milieu des dépravations de toutes sortes. Une situation économique forcément brillante, uniquement à cause des progrès de la technique commerciale et industrielle et de nouvelles découvertes scientifiques, mais sans rapport avec le régime, faisait se ruer vers les jouissances une foule d'individus pour lesquels les affaires et l'argent étaient le travail des autres. On n’ergotait pas sur les origines ; la fortune plus ou moins bien acquise tenait lieu d'antécédents. Les pires aventuriers côtoyaient fièrement des ministres dont ils alimentaient la caisse et les vices. Et c'est ainsi qu'un beau jour l'ancien commis de banque Jecker, suisse naturalisé français, agent secret des jésuites, 
quittait Paris (1856), pour aller fonder une banque à Mexico, se faire concéder des mines, signer avec le président Miramon, chef du parti catholique mexicain, une convention destinée à retirer de la circulation les bons de la dette intérieure et à les remplacer par une émission de 75 millions de titres garantis par la banque Jecker. L'opération était faite de compte à demi avec le duc de Morny (frère naturel de Napoléon III), auquel était réservé un bénéfice de $30 \%$. Mais Juarez fit suspendre l'exécution de la convention. Aussitôt, Jecker et Miramon de se rendre en France pour y réclamer aide et protection. C'était enfin l'occasion cherchée et quelque peu machinée par Rome et ses complices, les jésuites. Voici comment s'exprime le vicomte de BeaumontVassy dans son Histoire intime du Second Empire :

« L’expédition du Mexique est sortie, toute décidée, toute faite, du petit salon de l'impératrice. Ce fut un familier du cercle de Mme de Montijo, homme capable et séduisant, M. Hidalgo, qui la mit sur le tapis avec la combinaison de Maximilien. Mgr Labastida, évêque de Mexico, acheva ce que M. Hidalgo avait commencé. Juan Prim, le fameux général clérical espagnol, qui fut l'un des mauvais génies de Napoléon III, agissait dans le même sens. Malgré les plus sages conseils, Napoléon, une fois entraîné par le Gesu de Rome et d'Espagne et craignant d'être éclaboussé par le scandale des bons Jecker et la complicité du duc de Morny, persista dans cette œuvre insensée, et son ministre à tout faire, Rouher, osa même dire à la tribune que cette triste guerre était la plus grande pensée du règne!

Terre d'élection du Romanisme et de ses milices, le Mexique vivait alors sous le régime de la Constitution du 26 août 1843, ne tolérant d'autre religion que la religion catholique, apostolique et romaine, et avait concédé au clergé et aux ordres religieux tous les privilèges réclamés par eux. Notons, en passant, que le même esprit animait la Constitution de 1924 et qu'il fallu les pires excès de la part des prêtres et des moines pour que le peuple mexicain secoue, en 1926, la tyrannie du dogme, juste quatre cents ans après, et presque jour pour jour, la conversion forcée du pays au catholicisme par Fernand Cortez.

L'odieuse agression contre un peuple qui ne demandait qu'à vivre paisiblement sous la ferme et sage administration républicaine de Juarez se couvrit, pour l'Espagne et l'Angleterre, qui y participèrent, du 
prétexte des dommages causés à leurs nationaux, et pour la France du paiement des 75 millions dûs au banquier Jecker.

Le Vatican surveillait jalousement les résultats de l'intervention, dont le but principal, imposé par lui aux alliés, était la substitution à la République mexicaine d'un empire et d'un empereur tout dévoué aux ordres de l’Eglise.

Instrument quasi inconscient entre les mains des jésuites, Napoléon ne vit pas ou ne voulut pas voir le véritable caractère de l'aventure dans laquelle il s'engageait à l'instigation des politiciens diplomates de Rome qui infestaient la cour de Compiègne et de Tuileries. Ses alliés, que ne guidaient pas les mêmes intérêts inavouables, se hâtèrent de lui laisser toute la responsabilité de l'expédition en traitant séparément avec Juarez, qui très habilement avait accueilli leurs réclamations, dès l'arrivée en rade de Vera-Cruz de la flottille réunie par les trois nations, en vue d'une simple démonstration militaire. L'Espagne, où grondait déjà la révolution, n'était plus pressée de se tenir aux côtés de la France ; l’Angleterre, qui n’ignorait pas les projets de la camarilla du Vatican, n’entendait pas les servir. Napoléon, seul, s’entêta contre une nation qui, jalouse de son indépendance, avait fait l'union de tous ses citoyens contre l'envahisseur. Il en résulta d'abord de sérieux échecs et pendant quatre ans une lutte farouche entre le corps expéditionnaire et Juarez. La prise de Puebla, l'entrée dans Mexico, furent des victoires à la Pyrrhus, laissant les Mexicains toujours maîtres du Nord avec Juarez et du Sud avec Porfirio Diaz. Au général Forey, demi-victorieux, succéda le louche Bazaine, qui avait déjà la trahison dans le sang et projetait, paraît-il, marié à un Mexicaine, de renouveler envers la France la félonie d’Iturbide, ce général espagnol passé à l'ennemi et qui s'était fait proclamer empereur sous le nom d'Augustin I ${ }^{\mathrm{er}}$, aux premiers temps de l'occupation espagnole. S'il en eut l'idée, les Etats-Unis, redevenus maîtres de leur politique extérieure par la fin de la guerre de Sécession, ne lui laissèrent pas le temps de la réaliser.

Sur leurs instances presque menaçantes, Napoléon III rappela, par trois étapes successives, le corps expéditionnaire, abandonnant Maximilien, empereur éphémère, à son malheureux sort, mais quid, u 
moins, se sachant perdu, voulut quant même sauver la face, en continuant, après le départ des Français, une résistance impossible.

Quelques mois après, en effet, l'archiduc, victime, volontaire il est vrai, des intrigues romaines et de la politique aveugle d'un Napoléon, était pris et fusillé à Queratero.

Le Vatican avait échoué dans conquête du Nouveau Monde par la force, et l'Empire, qui avait englouti des millions de matériel et des hommes surtout dans cette lamentable odyssée, allait se trouver bientôt, démuni de tout, en face d'un ennemi contre lequel, changeant ses batteries, la camarilla jésuitique des Tuileries avait décidé de le faire marcher et, malheureusement, la France avec lui.

La tragédie mexicaine s'achevait par l'exécution de Maximilien d'Autriche et du général Miramon, le troisième protagoniste, le banquier Jecker, réfugié en France, devait subir le même sort. Les dommages subis par l'épargne française du fait des spéculations de l'association Jecker-Morny avaient valu, au premier surtout, l'exécration publique. Pendant la Commune, Jecker, sur le point de quitter Paris, fut reconnu, arrêté, et dut à la juste haine populaire d’être exécuté immédiatement.

Mais il y eut une quatrième victime, digne celle-là de tous les respects. Le président des Etats-Unis, Lincoln, qui venait de terminer heureusement la guerre de Sécession, et auquel Rome ne pardonnait pas, malgré les embarras de la nouvelle République à cette époque, d'avoir soutenu Juarez après le départ du général Forey, Lincoln, la noblesse et le désintéressement mêmes, le fervent antiesclavagiste, avait été assassiné le 3 avril 1865, d'un coup de pistolet, par un certain J. Wilkes, soi-disant pour venger la défaite du Sud esclavagiste. Or, des documents indiscutables, avec les pièces du procès à l'appui, ont nettement démontré que c'est sous l'impulsion des jésuites que l'assassin, un de leurs sectateurs, avait agi ${ }^{1}$. Les agents du Vatican espéraient ainsi paralyser l'aide de l'Amérique au Mexique ; ils en furent pour leur crime. Johnson, qui succéda à Lincoln, énergique et autoritaire certes, mais esprit aussi clairvoyant que son prédécesseur, déguisa à peine la menace brutale à la suite de laquelle le corps expéditionnaire français n'eut plus qu'à se retirer. 
La Vérité Sur la Question Romaine (1930)

\section{XVI \\ L’Amérique contre le papisme}

$\underline{\text { Retour à la table des matières }}$

Pour l'Eglise, échec n’a jamais été synonyme de renoncement. Elle ne négligea jamais de regagner par une activité diplomatique le terrain abandonné par contrainte, cherchant toujours à tirer le meilleur parti des conjonctures dans le dessein savamment dissimulé de diviser pour régner. La conquête religieuse des Amérique n’était qu'ajournée. Ce n’était pas d'ailleurs la dernière - que les jésuites entraient en contact avec le Nouveau Monde et y accomplissaient leur œuvre de sang et de haine contre tout ce qui n'accepte pas de se soumettre au catholicisme. Le manifeste de la fédération française de la Libre Pensée a fort opportunément rappelé (1929), à l'occasion des débats sur les congrégations, ce qu'ils firent au Canada, où ils arrivèrent en 1611 et dont ils devinrent les maîtres en 1628, dix-sept ans après, en chassant, avec l'assentiment de Richelieu, les protestants réfugiés à Québec. Un ouvrage, aujourd'hui épuisé, paru sous le titre : Les jésuites, marchands, usuriers et usurpateurs, et leurs cruautés dans l'Ancien et le Nouveau Monde, est rempli des manœuvres infâmes, des actes odieux par lesquels les défenseurs de l'Eglise romaine se débarrassaient de leurs adversaires.

Depuis cette époque, ce fut l'envahissement lent, mais progressif et surtout méthodique, grâce à l'immigration irlandaise et italienne des Etats-Unis. Et l'on a pu voir dans cette République, dont les fondateurs, de grands libres penseurs, Franklin Jefferson, Washington, Adam et d'autres encore, non moins illustres, eurent soin d'exclure la 
religion de toute participation au gouvernement, inscrire au budget national et sous la pression d'une minorité déjà menaçante de 18 millions de catholiques, des crédits pour les aumôniers dans la marine, dans l'armée ; au Congrès, les vastes propriété des églises exemptés d'impôts, de furieuses tentatives pour incorporer le dogme dans la Constitution des Etats-Unis sous la forme d'un serment de fidélité à la divinité chrétienne ; les scientistes chrétiens firent construire tout près de l’Université d’Harward l'une des plus belles églises d'Amérique, etc...

En 1866, l'évêque de Saint-Louis (Amérique) écrivait dans un journal, le Pâtre de la Vallée :

« Nous avouons que l'Eglise catholique romaine est inexorable, ce qui veut dire qu'elle emploiera tous les moyens qui sont en son pouvoir pour extirper l'hérésie ; mais son inexorabilité est la suite logique et nécessaire de son infaillibilité. Elle a le droit d'être inexorable parce qu'elle seule possède la vérité.

«L’Église supporte les hérétiques là où elle y est forcée, mais néanmoins elle les hait mortellement et elle emploie toute sa puissance pour assurer leur destruction.

« Lorsque les catholiques de ce pays auront une majorité considérable à leur disposition, la liberté religieuse de la République des EtatsUnis aura dit son dernier mot. »

Sans doute, la résistance à l'absorption catholique n'est pas ici uniquement le fait de la Libre Pensée. Celle-ci constitue, en effet, dans la lutte contre l'Eglise romaine, un modeste appoint qui, toutefois, n'est pas négligeable et procède, on s'en doute bien, d'un tout autre ordre d’idées que le protectionnisme.

Celui-ci a surtout pour but de «détrôner le pape de l'esprit des hommes ». La lutte contre le papisme était des plus vives avant la guerre. Les différentes sectes de la religion réformée osèrent installer jusqu'aux portes du Vatican des librairies où les ouvrages les plus agressifs contre la papauté, avec des titres injurieux, s'étalaient aux regards de tous les passants. Le fascisme triomphant et déjà préoccupé 
de satisfaire à son alliance secrète avec les jésuites, pilla et brûla ces boutiques. En réalité, substituer à l'autorité d'un homme divinisé par la bêtise humaine l'inflexible morale d'un livre divinisé par l'astuce des premiers individus qui furent assez habiles pour en imposer à leurs semblables moins intelligents, pour les libres penseurs, le pape ou la Bible, c'est toujours l'infection religieuse. On en a eu les preuves lors du procès ridicule intenté dans l'Etat de Pennsylvanie à ce professeur qui osait contre les " révélations » du Livre sacré accorder plus de créance aux théories de Darwin et de Lamarck.

Quoi qu'il en soit, la lutte entre les deux sectes est loin d'être terminée. Elle a pris en ces dernières années une très grande importance. Avec une clairvoyance à laquelle nous rendons hommage et devant l'invasion noire qui menace de les submerger, les Américains, chez lesquels les jésuites ont mis depuis longtemps en pratique - comme ils le firent en Asie - le système de la conquête des cerveaux par l'abêtissement des populations, ont décidé d'y mettre un terme. C'est là tout le fond de la prohibition et de la question du régime sec et du régime mouillé.

Il est bien évident, comme l’a écrit Gabriel Séailles, « qu’il n’y a rien d'impossible, à ne tenir compte que des lois de la nature, à ce qu'une foule abrutie par l'alcool s'enlise, et après des sursauts de colère se résigne à l'asservissement au dogme. » On comprend maintenant toute la violence de la dernière lutte présidentielle : il s’agissait, en réalité, bien moins du triomphe de la tempérance que de la conquête de la Maison Blanche par la Curie romaine.

L'alcool comme l'opium a servi, en effet, et sert encore la cause des jésuites, et ce n'est pas d'hier que leurs généraux ont utilisé même en Europe ces moyens de venir à bout des peuples. Nous avons rappelé, à l'occasion, il y a quelques années, les sollicitations secrètes dont, sous la Restauration (1823), les débitants de boissons en France furent l'objet de la part des bons pères. Non seulement on leur demandait de transformer leur comptoir en confessionnal en recueillant l'essentiel, pour le transmettre, des propos qui pouvaient les intéresser. Mais ceux qui consentaient à cette basse besogne et qui s'affiliaient par conséquent à leur ordre, recevaient gratuitement, en guise de prime de la délation, quelques barriques de vin. Les journaux de l'époque relatè- 
rent cette singulière et malhonnête méthode, dont s'indigna si éloquemment Michelet dans sa préface du livre Des Jésuites.

Il n'y a donc pas lieu de se montrer incrédule sur l'alcoolisation des Etats-Unis. À ces poisons d'un effet lent sur les générations anglosaxonnes fortement équipées pour leur opposer une longue résistance, la milice noire a ajouté la multiplicité des organisations catholiques dont elle a littéralement infesté les nobles fils de Washington. Et les hommes les plus éminents de la grande République n’ont pas vu sans un profond sentiment d'indignation, en 1926, l'immense revue des troupes catholiques passée à Chicago, à l'occasion du récent congrès eucharistique, avec reliques de saint Louis et cardinaux d'Europe en tête. Aussi, c'est vainement que les "Chevaliers de Colomb », cette société dont nous publiâmes jadis le serment prêté par ses membres " d'étriper tout ce qui n'est pas chrétien », ont insisté à diverses reprises pour l'intervention des Etats-Unis au Mexique. Le refus du président Coolidge de recevoir leur délégation à la Maison-Blanche a été considéré par eux comme un outrage infligé à leur propre Eglise. Les vingt millions de catholiques de l'Amérique du Nord parlaient déjà en maîtres, comme dans l’Amérique centrale et l’Amérique du Sud. 


\section{XVII \\ L’infaillibilité pontificale}

On nous pardonnera d'avoir interrompu un instant, à propos de l'Amérique, l'ordre chronologique de notre développement, d'autant qu'il ne s'agit pas, dans cette étude, d'une compilation de faits, sans relations entre eux, mais d'une vue générale d'événements dont la répercussion n'est pas toujours immédiate et qu'il importe cependant de marquer au passage si l'on veut en retenir la parfaite connexion.

Caractère plein de nonchaloir, se laissant dépasser ou prévenir par les événements, l'homme qui devait à son nom et surtout à l'audace de complices perdus de dettes et de débauches, d'être devenu le maître de la France, ne pouvait être autre chose qu'un jouet entre les mains de l'Eglise. Ses velléités de révolte contre l'invasion noire dont la circulaire Persigny, dès 1861, avait signalé l'intense péril, et que le Procureur général Dupin dénonçait au Sénat (1868) comme une "peste publique », n'empêchaient pas les jésuites et leur filiale la Société de Saint-Vincent de Paul de « travailler » la France sur tous les points. Ils avaient, d'ailleurs, une puissante alliée dans la Montijo, qui, dans les dernières années de son règne, inspira, si elle ne la dirigea pas complètement, la politique tant intérieure qu'extérieure du régime. 
L'insuccès du Mexique avait forcé Rome à modifier son plan d'hégémonie mondiale en abandonnant pour un temps la pénétration du continent américain. Revenant à l'Europe, le Vatican n'envisageait pas sans quelque inquiétude la situation. La nébuleuse mystique de Napoléon III avait abouti : $1^{\circ}$ à l'unité italienne avec pour toute protection au saint-Siège une petite garnison française expédiée à la suite d'une dernière tentative de Garibaldi ; $2^{\circ}$ à la formation de l'unité allemande sous l'égide de la Prusse (1866-1867), dont il avait notoirement favorisé la politique d'annexion aux dépens du Danemark et de l'Autriche.

Mais la Prusse était protestante et, par conséquent, peu disposée à seconder les vues de la Papauté. Déjà, au temps de Grégoire XVI, elle avait vu naître, en Westphalie, un esprit nouveau dont le docteur Hermes synthétisait nettement la tendance par sa théorie subordonnant entièrement la foi à la raison. Les Hermesiens étaient devenus en peu de temps un parti assez puissant et, chose plus grave au regard de Rome, l'archevêque de Cologne Spiegel s'en était constitué le protecteur. Condamnés par Grégoire XVI, les nouveaux philosophes chrétiens l'avaient été également par Pie IX. Naturellement, les jésuites les combattaient aussi, car ils n’ignoraient pas que Bismarck parlait déjà, dans les conseils de Guillaume $\mathrm{I}^{\mathrm{er}}$, de les chasser eux-mêmes d'Allemagne.

En France, où les élections de 1863 avaient manqué le réveil d'une opposition républicaine sérieuse et le début du déclin impérial, le gouvernement oscillait entre l'absolutisme et «l'empire libéral ». Ses concessions à l'opinion publique qui commençait à se ressaisir et à protester jusque dans la rue contre toutes les mesures attentatoires à la liberté de presse et de réunion, avaient amené le ministère Ollivier à pratiquer une politique de tolérance religieuse qui lui avait valu l'appui des catholiques libéraux, mais par contre l'hostilité des ultramontains, dont l'organe principal : L'Univers, rédigé par Louis Veuillot, déversait chaque jour des monceaux d'injures et de grossièretés sur les libéraux comme sur les républicains.

Et dans le même temps, comme un défi jeté au mouvement libéral et antijésuitique qui se manifestait un peu partout en Europe et qui s’était beaucoup accentué dans toute la France, Pie IX faisait procla- 
mer par un Concile œcuménique (18 juillet 1870) le dogme monstrueux de l'infaillibilité papale. Le texte du décret pontifical renforçant la discipline de l'Eglise romaine et donnant au chef de la secte chrétienne un absolu pouvoir de décision, vaut la peine d'être cité comme exemple hors de pair d'orgueilleuse sottise et d'insolente présemomption :

«Le pontife romain, lorsqu'il parle EX CATHEDRA, c'est-à-dire lorsque, remplissant la charge de pasteur et de docteur de tous les chrétiens, en vertu de sa suprême autorité apostolique, il définit qu'une doctrine sur la foi ou sur les mœurs doit être tenue par l'Eglise universelle, jouit pleinement, par l'assistance divine qui lui a été promise dans la personne du bienheureux Pierre, de cette infaillibilité dont le divin Rédempteur a voulu que on Eglise fût pourvue en définissant sa doctrine touchant la foi ou les mœurs, et, par conséquent, de telles définitions du pontife romain sont irréformable par elles-mêmes, et non en vertu du consentement de l'Eglise. »

Ainsi se réalisait le projet formé depuis longtemps par les jésuites de faire du pape une sorte de divinité terrestre. L'unification de l'Italie, le triomphe des idées nationales et les tendances libérales du roi Victor-Emmanuel furent autant de motifs qui les incitèrent à l'exécution de leurs desseins. Pie IX, à leur instigation, avait déjà proclamé le dogme de l'Immaculée Conception, contrairement aux doctrines, aux traditions de l'Eglise et à l'avis des docteurs, des théologiens, des prélats les plus célèbres par leur érudition. Ce premier pas franchi, les jésuites jugèrent le moment venu pour donner au pape un titre, une dignité qu'aucun de ses prédécesseurs n’avait ni demandée, ni même ambitionnée.

Les jésuites purent se dire : Nous avons fait le pape infaillible, nous sommes donc plus infaillibles que lui. Cette affirmation solennelle d'une autorité impliquant la perfection dans tous les actes, se produisant juste au moment où des scandales de toutes sortes surexcitaient l'opinion publique contre les méthodes de l'enseignement clérical. A Bordeaux, dans l'un de leurs séminaires, un élève avait été si maltraité que sa vie était en danger. Les pères La Judie et Commère, traduits en correctionnelle, avaient été condamnés à huit jours de prison. L'Univers, la feuille « la plus vile de toutes », selon l'expression de 
Montalembert, en avait profité pour faire, au mépris de l'indignation générale, l'éloge du fouet comme excellente méthode d'enseignement « pour former une génération virile ».

Les Jésuitesses de la Sainte-Union, de Douai, étaient aussi condamnées en la personne de plusieurs de leurs membres, convaincus d'avoir participé volontairement à un détournement de jeunes filles juives par des manœuvres fort scandaleuses. Enfin, Jules Simon, au Corps législatif, dans la séance du 25 janvier 1869, avait dénoncé les jésuites et l'exploitation odieuse des Maristes comme auteurs principaux du soulèvement des indigènes de la Réunion. 
La Vérité Sur la Question Romaine (1930)

\section{XVIII}

\section{La guerre de 1870-70}

\section{Rome reprise au Pape par les Italiens (20 Septembre 1870)}

$\underline{\text { Retour à la table des matières }}$

Tous ces faits, et bien d'autres encore, n'empêchaient pas la camarilla hispano-italienne qui trônait aux Tuileries de pousser Napoléon III à la guerre contre la Prusse. L'action de la Montijo, croyant servir, avec l'intérêt de l'Eglise, l'avenir de son fils et de la dynastie, a été résumée dans ce mot : «C’est ma guerre à moi, je la veux ! »

Il est hors de doute aujourd'hui que la candidature d'un Hohenzollern au trône vacant d'Espagne, la dépêche d'Ems falsifiée par Bismarck, du propre aveu de celui-ci, ou encore les quelques plaisanteries un peu roides de Guillaume $\mathrm{I}^{\mathrm{er}}$ sur

Badinguette,

D’un coup de baguette,

Devenue par hasard

Madame César,

Comme l'avait chansonnée Henri Rochefort, ne furent que les prétextes accessoires des véritables motifs : enrayer le mouvement libéral qui s'accusait de plus en plus en Europe et plus particulièrement en France, sauvegarder l'avenir de la dynastie des Bonaparte, mais sur- 
tout défendre le pouvoir temporel de la papauté : « Plutôt les Prussiens à Paris que les Italiens dans Rome », répétaient volontiers les familles de la Montijo.

L'aveu en fut fait d'ailleurs plus tard à l'Assemblée de Versailles par le prince Bonaparte, cousin de Napoléon III, qui représentait aux Tuileries l'élément anticlérical et participait, en compagnie de SainteBeuve et d'autres illustrations de l'époque, au banquet annuel du Vendredi dit sain.

« Il est incontestable, dit-il, que si nous avions eu des alliances, le résultat de la guerre eût été tout autre. Ces alliances existaient, mais une question les retenait: celle du pouvoir temporel de la papauté. Sans cette question, la France entrait en campagne avec six cent mille hommes de plus. L'issue malheureuse de la guerre de 1870 vient de l'occupation de Rome et le maintien du pouvoir temporel des papes nous a coûté l'Alsace et la Lorraine. »

C'est dans ces tristes conditions qu'Emile Ollivier annonçait à la Chambre des Députés, le 15 juillet 1870, D’UN CEUR LÉGER, « la déclaration de guerre à la Prusse, en ajoutant impudemment que son gouvernement la subissait ». Son prédécesseur, Rouher, n’avait-il pas dit avant lui qu'il n'y avait rien à redouter de l'Allemagne, « divinisée en trois tronçons »? Seulement, ces trois tronçons ne devaient plus faire qu'un seul et même peuple en marchant contre la France, dont l'armée était sans armes et sans munitions suffisantes, bien qu'au dire du maréchal Lebœuf, « il ne manquait pas un bouton de guêtre ».

On sait le reste ! Le désastre de Sedan, la République, proclamée, faisant face à toutes les rudes souffrances de cette année terrible, qui faisait dire au poète vengeur des Châtiments :

Si vous saviez combien on fut près de la fin !

L’Église, déçue de nouveau pour avoir misé sur le mauvais tableau des Bonaparte, était devenue silencieuse, et, comme en 1848, les jésuites avaient disparu après le 4 septembre 1870 . On devait les revoir bientôt à l'œuvre, plus nombreux encore et tout aussi dangereux. 
Le jour du départ de nuit de Rome, du dernier bataillon français (11 septembre 1866), le Comité National Romain disait dans un manifeste, avec une certitude commune à toute l'Europe : " Les jours du despotisme clérical sont désormais irrévocablement compromis.» C’était si bien l'évidence même, que sans l'intervention française un an après, à Mentana et Aspromante, contre l'expédition de Garibaldi, la prédiction se réalisait. Aussi, la guerre est-elle à peine déclarée à la Prusse que, suivant l'avis d'Emile Ollivier (ce renégat fils d'un proscrit de décembre et qui, on en eut la preuve depuis, s'était vendu à l'Eglise), Napoléon III, "repoussant toute alliance plutôt que d'abandonner Rome », informe les puissances qu'il est forcé de retirer momentanément ses troupes de Rome.

Ce n'était pas le moyen de faire naître des offres d'alliance : l'Italie n'avait plus rien à gagner de notre côté ; elle savait bien qu'au premier revers de la France, désorganisée par une politique incohérente, elle n’aurait qu'à mettre la main sur Rome, sans coup férir ; quant à la Russie et à l'Angleterre, de vielles rancunes, la crainte de contribuer à augmenter la puissance matérielle et morale de la France, les empêchaient de prévoir le grand danger pour l'avenir d'une Allemagne puissante, conduite au pas de l'oie par la Prusse et les menaçant à leur tour. 
La Vérité Sur la Question Romaine (1930)

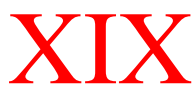

$\underline{\text { Retour à la table des matières }}$

Le 10 septembre 1870, le roi Victor-Emmanuel prévenait Pie IX, non sans une pointe d'ironie, « qu'il croyait nécessaire à la sécurité de Sa Sainteté de faire occuper par ses troupes certaines positions ». Le 20, à cinq heures du matin, un corps de 65000 hommes, sous le commandement du général Rafaelle Cardona - le père du général de la grande guerre - arrivait sous les murs de Rome, défendue par les fameux zouaves pontificaux qu'à l'instigation de Mérode, ministre des Armes du Vatican, Lamoricière avait recrutés un peu partout pour en former l'armée du pape. Après quatre heures de résistance, et sur l'ordre de Pie IX, le général Kanzler, un Suisse qui avait succédé à Mérode, faisait arborer le drapeau blanc sur les murs et au château d'Ange, et les Italiens entraient dans la Ville Eternelle par la brèche de la porte Pra, couronnant ainsi le travail d'émancipation qui avait duré un demi-siècle et affirmant le droit humain et social de tous les peuples de se libérer du despotisme théocratique.

Trente-quatre ans après (1904), les milliers de libres penseurs du Congrès International venaient apporter, de tous les coins du monde, leur hommage fraternel aux citoyens tombés dans cette mémorable journée où d'écroulait définitivement ce pouvoir temporel de la papauté que les accords de Latran n'ont pu ressusciter ni dans le présent ni dans l'avenir. 
De ce jour, en effet, la question romaine entrait dans la phase aiguë. A l'excommunication, aux protestations véhémentes (Encyclopédique Respicientes) adressées à tous les chefs d'Etat par Pie IX, le gouvernement italien répondit par une nouvelle affirmation de Rome comme capitale de l'Italie, et la promulgation (13 mai 1871) de la loi des garanties reconnaissant au pape les pouvoirs et les privilèges d'un souverain indépendant, une liste civile de 3 millions, la propriété du Vatican, de Sainte-Marie-Majeure et de Castel Gandaf. Ce modeste patrimoine était placé hors de la juridiction italienne et la personne du pape était déclarée inviolable.

Cette concession au sentiment catholique de la nation italienne était une faute, et nous dirons volontiers, avec l'historien Lavisse : « À quoi servait-il d'être à Rome pour qu'il y eût encore une question romaine ? " À notre avis, une situation nettement tranchée et sans retour possible au passé eût été cent fois préférable à ces accommodements que Tartufe recommande avec le ciel ou son représentant. Le patriotisme italien, exacerbé par les longs espoirs toujours ajournés, en était arrivé, malgré sa foi religieuse, à développer dans une même haine l'Autriche et son soutien intermittent, la papauté. Au lendemain de la journée à jamais mémorable du 20 septembre 1870, personne n'eût protesté, au-delà des monts, si Victor-Emmanuel II, parachevant son œuvre libératrice, n’avait laissé au pape Pie IX que sa tiare et les clefs de Saint-Pierre, sans attribution des prérogatives et privilèges d'un souverain... sans souveraineté.

C’était s'épargner d'abord le hautain et méprisant refus des faveurs octroyées par la loi des garanties, et, ensuite, ôter au chef de la secte chrétienne - qui réunit à peine $40 \%$ de la population en Europe et $16 \%$ pour tous les peuples de la terre - l'occasion de jouer au martyr. Trois immenses et luxueux palais avec des jardins splendides, trois millions de revenus auxquels s'ajoutaient ceux du denier du culte, soit une somme globale dépassant alors souvent 15 millions de francs, quel est l'homme qui n'accepterait pas une captivité aussi brillamment dorée ?

À en juger par les événements actuels, il semblerait que ce fut une grande habileté de la part de l'Eglise, de se replier pour ainsi dire sur elle-même ; de faire de son grand fakir un « réclusionnaire » volon- 
taire, s'isolant, lui et son entourage, de toutes relations avec les autorités italiennes, par le fait même de l'interdit qu'il avait jeté sur toute la péninsule et qui ne permettait aux catholiques italiens de prendre aucune part aux élections, ni comme électeurs, ni comme candidats ; enfin, chef d'Etat sans territoire, consignant aux frontières italiennes les chefs d'Etat catholiques et imposant aux autres qui voudraient lui rendre visite toutes sortes de formalités protocolaires.

Sans doute, la devise : « Le temps et moi », qu'affectionnait Mazarin, s'allie parfaitement au tempérament tenace, à l'action lente et sournoise de l'Eglise romaine. User par une résistance passive les hommes et les choses dont on ne peut venir à bout d'un seul coup, par la ruse ou par la violence, est le grand moyen des jésuites Mais si bien conduite soit cette ténacité, si forte paraisse cette passivité, les faits qui surviennent à la traverse en ont souvent raison. Et nous avons de bonnes raisons de croire que si le Vatican s'enorgueillit d'avoir gagné la première manche, la seconde lui échappera sûrement. Nous espérons le démontrer surabondamment dans la suite de cette étude. 
La Vérité Sur la Question Romaine (1930)

\section{XX \\ Le mouvement communaliste et communiste}

Tant que dura l'invasion allemande, les jésuites et l'Eglise affectèrent une demi-bienveillance envers la République ; mais, aussitôt la signature du premier armistice, en janvier 1871, ils réorganisèrent leur propagande. Ils le firent d'autant plus facilement que, pendant les dernières années de l'Empire, ils avaient, en quelque sorte, envahi toute la France avec la Société de Saint-Vincent de Paul et les autres corporations religieuses. C'est ainsi qu'ils purent faire élire une majorité cléricale et royaliste. Car, sur 750 membres que comprenait l'Assemblée nationale de Bordeaux, élue uniquement pour traiter de la paix, cent membres à peine étaient républicains ; les autres se composaient d'une douzaine de bonapartistes et d'un nombre respectable de légitimistes et d'orléanistes. Dès les premières séances tenues à Bordeaux, les hommes noirs agitèrent la question de savoir si l'on ne proclamerait pas la monarchie ; le généra des jésuites, consulté à ce sujet, répondit : "Le moment n’est pas encore venu, il faut laisser à la République tous les embarras de la situation. »

Mais quand l'Assemblée nationale se fut transportée à Versailles, après avoir nommé Thiers " chef du pouvoir exécutif », en attendant qu'il fût statué sur les institutions de la France - ce qui indiquait ouvertement que, pour cette assemblée élue dans un jour de malheur, la 
République n'était qu'un état provisoire qu'elle remplacerait par la monarchie - alors, la majorité royaliste, sur un mot d'ordre venu de Rome, déclara la guerre à la République.

Paris, exaspéré par cinq mois de siège, et que les privations, le chômage, la misère, les épidémies torturaient encore, Paris, dont un gouvernement de prétendue "défense nationale " avait gaspillé les suprêmes énergies en une série d'opérations qui se terminaient toujours par une retraite en "bonne marche ", même lorsque l'ennemi reculait ; Paris, conduit à la capitulation par un Trochu - « ce participe passé du verbe trop choir ", comme le stigmatisa le poète de l'Année terrible - qui faisait battre la garde nationale pour l'occuper et n'attendait la victoire que de ses prières à sainte Geneviève ; Paris n'ignorait rien des criminelles intentions de l'Assemblée de Versailles. Il eut conscience qu'une action décisive pouvait sauver la République. Et ce sera l'éternelle gloire du gouvernement révolutionnaire né, le 18 mars 1871, de la colère populaire, de cette "Commune de Paris » dont tous les protagonistes surent payer de leur liberté ou de leur vie leur dévouement à la patrie républicaine, d'avoir sauvé seule - car la province, abusée par Thiers, ne suivit pas - la France d'une nouvelle Restauration monarchique réalisée, comme en 1815, avec la complicité de l’invasion.

L'histoire de cette courte période de deux mois à peine ne nous intéresse, au regard de cette étude, que par le rôle toujours odieux de l'Eglise dans les discordes civiles, dont elle ne manque jamais de retirer un profit quelconque.

Il est hors de doute que le mouvement révolutionnaire du 18 mars 1871, débutant par la revendication pour Paris et toutes les villes de France des franchises communales, se poursuivit comme une manifestation nouvelle et plus violente de la souffrance sociale et que l'insurrection, communaliste d'abord, devint presque aussitôt, par la prédominance de l'élément blanquiste et des délégués de l'Internationale des Travailleurs, alors de fondation récente, à tendances communistes, bien qu'il ne fût pas même question de communisme parmi les quatre-vingt-six représentants de Paris qui siégèrent à l’Hôtel de Ville pendant les deux mois de tourmente. 
Mais il est non moins évident que cette révolution prolétarienne donna à la France républicaine le temps de se ressaisir, qu'en dépit des machinations de toutes sortes contre la République, elle imposa à Thiers l'engagement, vis-à-vis des délégués des grandes villes de France, de ne pas détruire la forme républicaine; que Paris y gagna d'avoir quand même sa loi municipale. Quant à la transformation économique, elle était noyée pour un quart de siècle au moins dans le sang des 35000 cadavres dont les «Versaillais » firent de sanglantes hécatombes emplissant les rues et les boulevards de la capitale. Car, du côté de l'armée de "l'ordre ", d'abord réduite à une vingtaine de mille hommes, puis augmentée des trois cent mille soldats prisonniers rendus tout exprès par l'Allemagne pour écraser la Commune sous le nombre, la lutte fut d'une férocité inouïe.

Et ici, ce n'est pas l'écho ou la reproduction des affirmations d'autrui, c'est notre propre témoignage que nous apportons, comme témoin oculaire des atrocités commises surtout pendant «la semaine sanglante » par la réaction victorieuse et qui sont demeurées parmi les plus terribles souvenirs de notre prime jeunesse. 
La Vérité Sur la Question Romaine (1930)

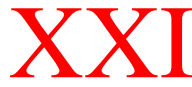

\section{Les véritables auteurs du massacre des otages}

\section{L’archevêque Darboy sacrifié par les Jésuites}

Ce qu'il importe surtout de savoir, c'est la part prise à ces massacres par l'Eglise romaine et en particulier par les jésuites, agissant prudemment sous le couvert du président Thiers. Ce que l'on ne saurait trop répéter, c'est que le massacre des otages, que des misérables comme un Maxime du Camp (de Satory) ou des esprits mal renseignés comme Claretie ont reproché avec tant de véhémence à la Commune, a été exclusivement le fait des cléricaux.

Les fils de Loyola ont vainement cherché à donner le change ; les faits parlent d'eux-mêmes pour dénoncer leur monstrueuse perfidie. Ecoutons-les.

Le 5 avril 1871, en réponse aux exécutions sommaires de tous les prisonniers faits par les Versaillais, la Commune décrétait l'exécution d'un nombre triple d'otages pour chaque victime de l'armée de la réaction. Or, ce décret resta lettre morte jusqu'au 22 mai, malgré que Versailles continuât à massacrer les fédérés qui tombèrent en son pouvoir. «Les otages, a écrit Camille Pelletan, n’ont pas été désignés 
par une cour martiale, leur nombre n’a pas été calculé d'après celui des exécutions de l'armée régulière. Si l'on veut chercher dans les massacres un effet précis du décret, c'est complètement inexact. Ce ne sont pas là des exécutions résolues d'avance. Si réellement la Commune avait pris ses mesures pour le massacre, elle n'aurait pas attendu, pour l'accomplir, que le rapprochement de l'armée permît aux captifs de résister avec succès, comme on l'a vu, à la Roquette. »

Mais voici le fait brutal contre lequel aucune légende ne saurait prévaloir.

Blanqui avait été arrêté le 17 mars et conduit à Clairvaux, par ordre du gouvernement de Versailles. L'archevêque de Paris Darboy et plusieurs autres prêtres, parmi lesquels Deguerry, curé de la Madeleine, furent peu après, en guise de représailles, arrêtés par la Commune et conduits à Mazas. Mais aussitôt des négociations avaient été entreprises pour l'échange des prisonniers. « Nous n’avons jamais voulu exécuter la loi des otages, disait Raoul Rigault, quelques heures avant d'être fusillé. Et pourtant c'eût été notre droit, depuis deux mois que les Versaillais fusillent tout sans pitié. Je ne tenais même pas à les garder à Mazas. Je ne voulais qu'une chose : avoir le vieux (Blanqui). Pour lui, je leur aurais donné tout : l'archevêque, Deguerry et les autres... J'aurais vidé Mazas, et j'aurais délivré des sauf-conduits pour Versialles à la prison entière ! »

Et, en effet, Flotte ancien compagnon de captivité de Blanqui, s'était chargé de cette mission. Il obtint de voir l'archevêque, qui lui proposa d'abord, pour l'accompagner auprès de Thiers, l'abbé Deguerry (14 avril 1871), puis son grand vicaire, l'abbé Lagarde. L'archevêque lui fit jurer de revenir, même s'il échouait dans sa tâche. Lagarde répondit: "Dussé-je être fusillé, je reviendrai! Du reste, pouvez-vous penser que je puisse avoir l'idée de laisser Monseigneur ici ?" — «Ne partez pas, lui dit encore Flotte, si vous n'avez pas l'intention de revenir. » Lagarde jura de nouveau et partit porteur d'une lettre de l'archevêque à Thiers, insistant pour qu'il consente à l'échange.

Cinq jours après, l'abbé Lagarde écrivait à son archevêque et à Flotte qu'il attendait une réponse définitive. Le 17, Thiers lui faisait 
savoir que le conseil des ministres — qui s'était décidé à l'unanimité moins une voix - refusait tout échange. Les jésuites, qui, avec les deux cardinaux Pie, Bonnechose, et l'évêque Dupanloup, multipliaient auprès des Prussiens encore sur le sol français leurs démarches en vue d'une restauration du pouvoir temporel du pape et d'une restauration monarchique en France, assiégeaient alors de leurs sournoises manœuvres le gouvernement de Versailles. Ils avaient le plus grand intérêt à l'écrasement de la Commune, que quelques-uns des leurs espionnaient pour leur compte. Tel ce citoyen Blanchet, qui se nommait en réalité Powelle, avait exercé les fonctions de commissaire de police à Lyon et à Paris et était entré comme novice dans deux couvents de capucins, à Brest et à Laroche. Tel encore Emile Clément, qui avait entretenu des rapports et des correspondances suivies avec le préfet de police de l'Empire. Tous deux d'ailleurs avaient été démasqués et arrêtés.

Il entrait dans les projets des disciples de Loyola que la répression fût d'autant plus terrible que les Versaillais auraient à venger des victimes appartenaient à l'Eglise. En outre, il leur fallait, pour la réussite de leurs criminelles entreprises contre la France, que les républicains soient mis pour de longues années dans l'impossibilité de les gêner. Or, s'il y avait autour de la Commune, il faut bien le reconnaître, des aventuriers sortis on ne sait d'où, et surtout des bonapartistes comme Jules Amigues et Hugelman, le gros des forces dirigeantes du mouvement ne comprenait que des républicains comme Ranc, Delescluze, Vermorel, Pyat, Millière, etc..., qu'il ne s'agissait pas seulement de vaincre, mais de détruire ad majorem dei gloriam, pour que le Vatican ne les retrouvât plus devant lui...

Le 17 avril, bien qu'il sût déjà à quoi s'en tenir, l'abbé Lagarde écrivait à l'archevêque « qu'il attendait toujours la décision ! " Le 18, nouvelle lettre : le vicaire général est désolé... mais « il lui faut encore attendre ». Du coup, l'archevêque et Flotte s'inquiètent, et le premier met en demeure son vicaire général de revenir à Mazas. L'abbé Lagarde réplique que « M. Thiers le retient toujours à Versailles ». Nouveau billet de l'archevêque. Cette fois, l'abbé Lagarde ne répond plus et a bien soin de ne pas revenir, malgré son double et solennel serment ! Il ne se sent pas de taille à jouer les Régulus... 
Plus tard, le nonce Chigi expliquait ainsi le triste rôle de ce grand vicaire: Thiers l'avait prié de remettre lui-même sa réponse à l'archevêque. Le peu courageux Lagarde avait refusé «sous prétexte qu'il ne pouvait porter une lettre cachetée en réponse à une lettre qu'il avait apportée ouverte ».

La vérité est tout autre : Lagarde, affilié aux jésuites, avait reçu de ceux-ci l'ordre de ne rien faire qui pût sauver l'archevêque. De cette façon, l'exécution de celui-ci et des autres prêtres justifiait l'effroyable tuerie qui pendant huit jours rougit la Seine et lui fi charrier de cadavres.

Et puis... l’Église compterait des martyrs de plus !

De nouvelles négociations furent tentées au début de mai. Darboy et Deguerry écrivirent à Thiers. Peine perdue. Le secrétaire général de la présidence, Barthélemy Saint-Hilaire, éconduisit brutalement les intermédiaires : "Les otages ? Qu'est-ce que vous voulez que nous en fassions ? Tant pis pour eux!» (Textuel.)

« Oseriez-vous encore soutenir, écrivait Rochefort le 8 décembre 1884, que l'exécution de l'archevêque et de ses compagnons de captivité, qui, tous, eussent été rendus contre Blanqui, n’a pas eu pour but d'exaspérer le cléricalisme et le bourgeoisisme français ? Quand on pouvait si facilement les sauver ! Et cela pour donner prétexte à l'égorgement de trente-cinq mille fédérés !

« C’est sur Thiers (instrument conscient des jésuites), c’est sur lui, c'est sur ceux qui l'ont soutenu et applaudi, que retombe la responsabilité des quatre-vingt-quatorze cadavres des otages. » 


\section{XXII \\ L’intrigue romaine en Europe de 1871 à 1880}

Avec la prise de Rome par l'Italie, la défaite de la France et la puissance grandissante de l'Allemagne, le rêve de domination universelle de la papauté s'estompait de plus en plus dans les brumes de l'avenir. C’était, en apparence du moins, le résultat anéanti de près de cinq siècles de luttes contre la conscience des peuples qu'elle était parvenue à bâillonner à la veille de la Révolution et contre le pouvoir civil qu'elle avait contraint à abdiquer un peu partout, devant la double suprématie des deux glaives : le spirituel et le temporel.

Nous disons : « en apparence ». Car, en réalité, défendue par la milice ded Loyola avec une application ingénieuse, patiente, obstinée, des fameux principes des Monita Secreta, usant de tous les accommodements comme elle le fit au temps de la Pragmatique Sanction et du Concordat de Bonaparte, comme elle vient de le faire au Latran, comme elle le fera demain encore vis-à-vis de la France, si les énergies républicaines et libres penseuses ne 's'y opposent rudement, l'Eglise, maniant les hommes avec une habileté consommée et les événements avec une rare souplesse, puise dans un étonnant mélange d'intrigue, d'audace et de modération simulée, la force considérable qui lui permet de retarder toujours l'heure de sa chute définitive. 
Au lendemain de la guerre de 1870-71, la situation politique de l'Europe exige, en effet, de la papauté qu'elle fasse front de trois côtés, contre les démocraties en plein éveil.

En Italie, l'ostracisme dont elle frappé $a b$ irato la monarchie qui a réalisé l'unité nationale, a pour conséquence presque immédiate de rallier à la royauté de Victor-Emmanuel II les partis de gauche dont les chefs Depretis, Crispi, Cairoli et Nicotera, subordonnant la religion à la patrie, gouvernent contre les menées sournoises d'un cléricalisme préparant chaque jour sa revanche. En Allemagne, l'instauration du pouvoir impérial centralisateur par le couronnement de Guillaume $\mathrm{I}^{\mathrm{er}}$ comme empereur de la Confédération germanique, et la poigne de fer de Bismarck, eurent tôt fait de déchirer la Constitution de 1850, qui assurait l'indépendance du clergé allemand vis-à-vis de l'Etat, et laissait ce même clergé maître de l'enseignement religieux primaire et des actes de l'état civil. Les professeurs de l'université et des gymnases refusèrent de souscrire au nouveau dogme de l'infaillibilité papale. Pie IX les excommunia, mais les excommuniés, qui formèrent dès lors, comme dans le même temps en Suisse et pour la même cause, le parti des " vieux catholiques », résistèrent, soutenus par le gouvernement. L'ambassadeur de la Prusse près du Vatican fut rappelé ; des prêtres, des évêques furent emprisonnés; des ordres religieux expulsés. De 1873 à 1875, une suite de lois dites « lois de mai » exigeaient des prêtres une éducation universitaire, soumettaient au contrôle de l'Etat les nominations ecclésiastiques, introduisaient dans le code allemand le mariage civil et rendait l'état civil obligatoire et soustrait à l'autorité religieuse. La lutte devait se poursuivre avec une vigueur égale de part et d'autre. Bismarck, bien décidé à ne pas "aller à Canossa », voyait disparaître Pie IX et s’apprêtait à garder vis-à-vis de son successeur la même attitude. Mais les jésuites avaient placé l'un des leurs, Windthorst, devenu le chef du parti catholique du centre, à la tête de la résistance à la politique du chancelier de fer, et l'esprit retors de l'ancien ministre du Hanovre en 1849, négociateur avisé, souple et inflexible selon les cas, devait, en fin de compte, venir à bout de l'intransigeance allemande.

En France, la situation était certainement plus favorable à la papauté. Et c'est précisément pour cette raison que l'Eglise s'acharna - le mot n'est que trop juste, hélas ! - pour reprendre chez nous, nonobs- 
tant la République de nom, sinon de fait, toute l'autorité dont elle avait usé et abusé aux temps de la Restauration et du Second Empire.

Trois prélats - deux cardinaux et un évêque - furent les acteurs principaux de cette tentative de restauration monarchique, en pleine invasion : l'évêque Pie, de Poitiers, l'archevêque de Rouen, de Bonnechose, et l'ancien confesseur de Talleyrand, Dupanloup, évêque d'Orléans, soit: un légitimiste, un bonapartiste, un orléaniste. L'histoire des démarches politiques de ces trois complices auprès des Allemands vainqueurs et dont ils recherchent l'appui et, au besoin, la protection contre la liberté de leur patrie, a été racontée tout au long par Stephen Pichon, l'ancien ministre des affaires étrangères dans son livre : La Diplomatie de l'Eglise sous la Troisième République (Paris 1892). Elle vaut la peine qu'on s'y arrête. On nous saura gré, pour l'éducation des générations présentes, ignorantes de tous ces faits, de la résumer sommairement.

Deux prétendants projetaient à leur profit le rétablissement, sur les ruines encore fumantes de l'invasion et de la guerre civile, du trône renversé en 1830 : le comte de Chambord, chef de la branche aînée des Bourbons, et le comte de Paris, chef de la branche cadette. Cette rivalité risquait de les éliminer tous les deux en présence du bloc compact que formaient alors les républicains au lendemain de la guerre franco-allemande. Les jésuites, qui avaient gagné la majorité royaliste, la dirigeaient, la dominaient même, imposèrent aux deux branches bourboniennes la fusion.

Déjà, sans attendre la fin de la guerre, en novembre 1870, l'évêque Dupanloup, recevant à Orléans le prince de Joinville, lui avait fait entrevoir comme une habile pensée politique « le groupement autour du prince (le comte de Chambord) représentant la légitimité, des membres de la famille d’Orléans apportant à la France la stabilité et la grandeur. »

Mais l'Eglise romaine entendait lier à cette restauration monarchique non seulement celle du rétablissement en France du clergé dans tous ses privilèges, mais aussi la reconstitution du pouvoir temporel de la papauté. La première partie du programme était d'une réalisation facile avec une assemblée nationale qui, élue pour faire la paix, s'était 
saisie du pouvoir constituant et dont la majorité était acquise au retour de la monarchie. Le seul obstacle sérieux, la Révolution du 18 mars, avait été brisé en quelques semaines, non sans compromettre, en le retardant par sa résistance héroïque, le succès qu’on croyait certain, des conservateurs. Il en restait un autre, celui du Président Thiers, qui s'entêtait à vouloir prolonger le régime provisoire en essayant par cet axiome : "La République sera conservatrice ou elle ne sera pas », de maintenir unis l'idéal démocratique du présent et l'esprit rétrograde du passé. Sous le prétexte que « la République était le gouvernement qui divisait le moins », Thiers, tenu aussi par sa parole de ne pas détruire la forme républicaine, ainsi qu'il l'avait promis aux délégués de province au début de la guerre civile, aurait voulu faire de ce provisoire un état définitif au cours duquel la réaction eût peut-être trouvé l'occasion de relever le trône. Mais, outre l'impatience de la majorité royaliste, il lui fallait compter avec les inquiétudes des républicains auxquels ce " provisoire » ne disait rien qui vaille et qui réclamaient énergiquement qu'on en terminât par la proclamation officielle de la République comme le seul gouvernement légal du pays. Tant et si bien que, le président fut obligé d'inviter l'Assemblée à se prononcer sur l'organisation de la République, dont l'étude fut confiée à une commission de trente membres. En même temps, et prenant ombrage d'un remaniement ministériel qui avait donné des portefeuilles à quelques républicains modérés, l'Assemblée lui signifiait « d'avoir à suivre une politique résolument conservatrice ", c'est-à-dire de préparer les voies et moyens au rétablissement de la monarchie. La réponse à cette mise en demeure, ce fut la démission de Thiers, et le même jour, dans la même séance, l'élection par l’Assemblée saisissant « la balle au bond », du maréchal de Mac-Mahon à la présidence d'une République encore purement nominale.

De leur côté, les agents de Rome n'étaient pas restés inactifs, et leurs efforts s'étaient surtout portés sur la question romaine, dont le seul et unique article définissait tout le caractère : la délivrance des Etats de l'Eglise et le rétablissement du pouvoir temporel du pape. Les ultramontains comprenaient fort bien que cette tâche qu'ils imposeraient à la France, une fois maîtres de ses destinées, se heurterait à certaines oppositions européennes, et en particulier à celle de l'Allemagne protestante et victorieuse. Aussi, Bonnechose, Pie et Dupanloup multiplient les démarches pour s'assurer, sinon l'appui, au 
moins la neutralité des Allemands. C'est tour à tour Manteuffel, le général entré à Rouen "au milieu d'un morne silence et d'une profonde stupeur ", puis le duc de Mecklembourg, Bismarck, à Versailles, et ce même jour de janvier 1871, le prince royal, le grand-duc de Bade, gendre de Guillaume $\mathrm{I}^{\mathrm{er}}$, auxquels le cardinal de Bonnechose rend visites sur visites pour leur arracher un consentement au moins tacite à l'action éventuelle de la France contre l'Italie. Il n'en recueille que des approbations mitigées, des protestations de respect pour Sa Sainteté Pie IX, des formules de politesse, bref ce que l'on est convenu d'appeler - et c'est ici vraiment le cas — de l'eau bénite de cour, qu'il prend, pourtant, comme argent comptant.

Ce sont ensuite les visites à Thiers, finement réservé, à Jules Simon dont l'accueil onctueux "le touche profondément », à de Rémusat « qui lui laisse grand espoir ». Ces allées et venues prolongées jusqu'en Italie, auprès de Pie IX, ne lui suffisent pas ; il y joint le geste public d'une protestation contre l'envoi d'un ambassadeur à VictorEmmanuel II, la rédaction de mandements à son clergé en faveur du pouvoir temporel.

De son côté, l'évêque Dupanloup, à l'Assemblée nationale, ne restait pas inactif. À son instigation, c'était une pluie d'adresses et de pétitions contre «l'invasion de Rome par les Piémontais ». D’accord avec M. de Corcelles, notre ambassadeur au Vatican, il prépare un violent discours contre l'envoi d'un représentant de la France auprès du quirinal et pose la fameuse thèse reprise de nos jours par le Bloc nationalo-réactionnaire "de l'identité des intérêts catholiques et des intérêts français ». Or, dans le même moment — singulièrement choisi, on en conviendra ! - le prince royal de Prusse, Frédéric-Charles, flirtait avec le roi d'Italie; tous deux ébauchaient des projets d'alliance visant la revendication de Nice et de la Savoie, Au dernier moment, le fougueux prélat hésite et se contente d'une courte intervention à la tribune, le 22 mars 1872, pour affirmer que l'ajournement subit de la restauration du pouvoir temporel « réserve intacts les droits imprescriptibles du Saint-Père. »

Quant au cardinal Pie, évêque de Poitiers, hostile à l'Empire qui l'avait poursuivi, il représente, dans cette trinité de monseigneurs faisant assaut de platitudes devant toutes les portes, l'extrême-droite de 
l'Assemblée de Versailles. C'est surtout l'éternel candidat à l'Académie, à l'archevêché de Paris, et à la barrette cardinalice que la République, bonne fille, devait lui décerner huit ans plus tard. Son rôle semble se borner exclusivement à « la fusion » des deux prétendants en un seul. Pour lui, le rétablissement de la monarchie en France est pour l'Eglise "une affaire", quelque chose comme le meilleur placement d'un père de famille, le canal de Suez du cléricalisme. Et pour « enlever » cette affaire, il fait la navette entre le Vatican et Versailles et Paris : il voit Thiers, le nonce, l'archevêque, les hommes influents, les chefs de congrégations, la grande presse et naturellement: l'Univers, l'Union et la Semaine religieuse. Au pape, il apporte l'offrande annuelle de dix mille francs en or, du comte de Chambord ; aux autres, les résultats de ses pérégrinations qu'il croit décisives. 


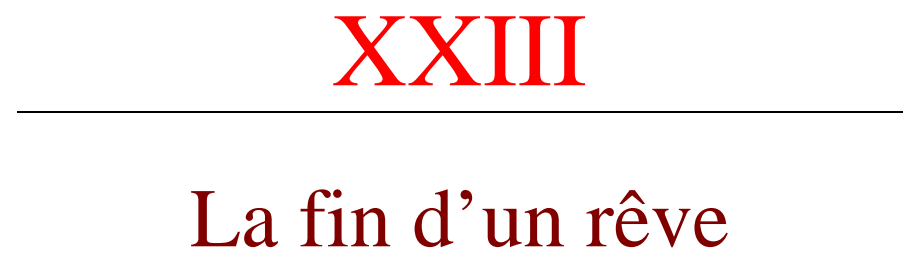

$\underline{\text { Retour à la table des matières }}$

Mais cette conspiration à ciel ouvert, que Thiers avait légèrement traitée et que Mac-Mahon n'avait écoutée que d'une oreille, réservait à ses auteurs un cruel réveil. Alors que tout semblait marcher au gré de leurs désirs, que le comte de Paris et ses enfants se préparent à faire amende honorable devant le chef de la maison de France, chassé des Tuileries et dépouillé par ses ancêtres, le comte de Chambord se souvient qu'il est avant tout le fils aîné de l'Eglise et prépare un manifeste retentissant sur la "question du drapeau », qu'il veut garder blanc et substituer comme de juste au drapeau tricolore. C'est un premier avortement de la fusion : les royalistes sont navrés. Le 5 juillet 1871, le manifeste paraît. " C'est le suicide de M. le comte de Chambord ! » s’écrie Dupanloup, presque pleurant. Mais il ne se tient pas pour battu; ses instances amènent enfin l'orléanisme aux pieds de la légitimité : «Un drapeau n’est pas un principe ! » dit-il. Et, après la réconciliation du comte de Chambord et du comte de paris, il suggère l’idée de « fleurdeliser » le drapeau tricolore !

Le renversement de Thiers, la présence de Mac-Mahon à l'Elysée font du gouvernement le chef occulte de la conspiration. Mais l'obstacle du drapeau, que Chambord s'entête à vouloir blanc, subsiste plus que jamais. Rien ne peut vaincre cette obstination. Pourtant, au lendemain de l'entrevue des deux comtes, le ministre Beulé apprend que Chambord a fait visiter par son maître d'équipages les écuries de 
l'empereur au Louvre. C'est donc qu'il cèderait sur le drapeau et s'apprêterait pour le retour triomphal. Et le ministre de Broglie est délirant de joie le 27 octobre $1873 \ldots$ Or, le soir de ce même jour, paraissait la lettre adressée à $\mathrm{M}$. Chesnelong et dans laquelle le comte de Chambord affirmait sa volonté irrévocable d'imposer à ses partisans le drapeau blanc. C'est l'écroulement du rêve ! C'est la déception amère pour l'Eglise. Car il ne faut pas songer à imposer à la France le drapeau blanc : les chassepots partiraient tout seuls !

Le désarroi des monarchistes fut terrible : les uns voulaient proclamer la lieutenance générale du prince de Joinville, les autres une dictature militaire en attendant... des temps meilleurs pour la cause. Finalement, on s'arrêta à la prorogation des pouvoirs du maréchal de Mac-Mahon pour sept années.

Avec le septennat s'établit véritablement le gouvernement des curés. L'Église romaine n'avait pu nous imposer la monarchie de droit divin ; elle allait tyranniser la France au nom du «droit divin » tout court.

Après avoir fait la guerre aux institutions républicaines, c’est à la République elle-même que l'Eglise va sen prendre, sous tous les gouvernements qui vont se succéder pendant près de quarante années. Sa diplomatie flegmatique et patiente s'affirme à haute voix, sous les diverses assemblées à majorité républicaine qu'élira à partir de 1876 le suffrage universel, comme indifférente aux " causes changeantes » et aux intérêts humains. Subtile avec Thiers, pathétique avec MacMahon, adroite avec Grévy, elle se prosterne à la même heure aux pieds du comte de Chambord ou du comte de Paris, en même temps qu'elle ébauche avec l'homme de Sedan, relégué à Arenberg, un plan de restauration impériale. Elle défend, selon la devise de Richelieu : une loi, un roi, une foi, mais se hâte de protester de son respect det de sa soumission aux lois de la République. «La duplicité de l'homme est si visible, a dit Pascal, qu'il y en a qui ont pensé que nous avions deux âmes. " Ces deux âmes, l'Eglise les possède admirablement. Ce sont les deux faces du mensonge religieux, l'une reflétant toutes les convoitises terrestres, l'autre tournée vers le ciel, comme pour y chercher l'inspiration de toutes ses fourberies. 
La monarchie ajournée ad infinitum, le septennat restait, comme la garde à Waterloo, "suprême espoir et suprême pensée ». Le maréchal de Mac-Mahon n'est pas évidemment l'homme qu'il faut aux jésuites pour remplacer par un coup de force la reculade du comte de Chambord. Ils l'avouent du reste. L'évêque Pie se félicite presque de l'avortement du complot monarchiste. « Si, écrit-il ; la monarchie s'était faite dans les conditions arrangées par le libéralisme, notre dernière ressource religieuse et nationale était perdue. " Pourtant, il représente la France comme "une pauvre infirme » atteinte du «mal caduc ", et il ajoute : "Quel bon peuple qui se sent mourir, qui agonise, et qui s'entend dire qu'il doit être content, puisque sa maladie durera désormais sept ans!»

Dupanloup prend son parti de la prorogation des pouvoirs du maréchal ; quant à de Bonnechose, qui n'a jamais cessé d'être bonapartiste, mais qui jugeait prématuré le retour de l'empire, il lui semble maintenant que ce retour pourrait devenir une chose possible. 


\section{Le gouvernement des curés}

Au fond, cette indifférence simulée en présence de l'illusion détruite est conforme au plan que s'est tracé l'Eglise romaine. Ce qu'il lui importe avant tout, c'est d'avoir en Europe une base avant tout, c'est d'avoir en Europe une base d'action entièrement soumise à son influence. Or, à cette époque, aucune puissance occidentale n’offre de meilleur point d'appui que la France, d'où la papauté irradiera sur toutes les parties du monde. Avec ou sans monarchie chrétienne, le Vatican poursuit son œuvre, les royalistes sans le roi, c'est encore la réaction. C'est même mieux, car, à l'instigation des trois personnages dont les manœuvres vont continuer pour étrangler la "gueuse ", selon l'expression de Changarnier, l'Union conservatrice a mobilisé sous ce nom tous les partis de droite : bonapartistes, légitimistes, orléanistes communient ensemble dans une même haine contre la République, mais sans abandonner leurs prétentions respectives. Aussi les prises de becs sont fréquentes dans cette "union ", qu'un organe orléaniste s'oublia, un jour, jusqu'à qualifier de « mascarade où les dupes semblent descendre la Courtille avec les fripons ». Ces brouilles intermittentes n’altèrent pas la sérénité des adversaires du régime. Peu leur importe qu'en se donnant la main, légitimistes et bonapartistes « mêlent des taches de sang ". Leur union sous un drapeau sans couleur, « ou plutôt dans lequel, selon l'expérience célèbre de Chevreul, le mélange de toutes les couleurs aboutit à un blanc neutre et sale », les 
conduira jusqu'au déshonneur, c'est-à-dire jusqu'à la honte de l'aventure boulangiste.

Quant à l'Eglise qui dirige la bataille, son premier soin est de préparer de nouveau les voies à une restauration quelconque, et surtout de garder la maîtrise du pouvoir aussi longtemps que l'Assemblée nationale retardera le vote du statut constitutionnel de la République. Le choix par Mac-Mahon du duc de Broglie comme président du Conseil autorise désormais toutes les hostilités contre la démocratie. Profondément dévoué aux jésuites, qui, on l'a vu dans l'affaire Paredes, gardent encore parmi leurs dirigeants l'un de ses descendants, de Broglie, de retour exprès d'une ambassade à Londres, était venu se mettre à la tête de l’opposition cléricale qui força Thiers à la retraite.

Mais, malgré toutes les mesures de dictature, les actes les plus arbitraires pour assurer «l'ordre moral » dans la nation, le gouvernement ne pouvait empêcher « le glissement rapide de la France vers la République et surtout vers le radicalisme » qui, selon l'expression de Dupanloup, "s'identifiant avec l'irreligion ». Chaque élection partielle était un succès républicain, et les élections municipales de 1874 ne permirent plus de douter que la France, écœurée des luttes des partis monarchiques, étant presque complètement acquise à la République.

Cependant, les jésuites n’avaient rien épargné pour arrêter ce " glissement » en ranimant la foi et l'obéissance à l'Eglise. Le 24 juillet 1873, à la requête de M. Guibert, archevêque de Paris, l'Assemblée nationale votait la fameuse loi déclarant d'utilité publique l'érection d'une église sur la colline de Montmartre, pour « la France pénitente et repentante ». C'était vouloir biffer par un vote ignominieux tout ce qui avait été fait depuis 1789. En choisissant la butte Montmartre pour y élever un temple au Sacré-Cœur, les jésuites poursuivaient un double but. D'abord consacrer par un édifice grandiose le souvenir de la vieille chapelle dans laquelle Loyola fonda leur compagnie, ensuite prendre en quelque sorte possession de la patrie de Voltaire. Ils espéraient ainsi gagner Paris au pape-roi infaillible et faire de ce foyer de civilisation, qu'est et restera malgré eux la Ville-Lumière, un grand centre religieux vers lequel convergeraient les pèlerins de tous les points du monde catholique. C'était également l'application de cette constitution monarchique que l'évêque Pie avait soumise au pape, au 
moment où les jésuites escomptaient avec tant d'assurance le retour de la royauté en France, et qui disait dans l'un de ses articles : «La religion catholique, qui est pour les Français la religion de quatorze siècles dans le passé et de 35 millions de citoyens sur 36 millions dans le présent, est la religion du pays et de ses institutions. »

Depuis 1873, trois assemblées républicaines ont voté l'abrogation de ce vœu prétendu «national » et de la loi honteuse qui a autorisé pareil outrage à la France de la liberté de conscience. Un motif de procédure a rendu caducs ces votes, que le Sénat n’a pu ratifier.

Dans un jour très prochain, la Fédération française de la Libre Pensée demandera au Parlement de se prononcer pour la quatrième fois. Et, à ce moment, il faudra bien que les masques tombent complètement et que la République sache à quoi s'en tenir sur le degré de sincérité de ceux qui, tout en se déclarant partisans des lois laïques et les proclamant intangibles, ont pourtant voté contre elles, dans l'affaire des congrégations. Il ne s'agira plus alors d'équivoquer sur " l'influence française à l'étranger », mais de se prononcer nettement et sans détour contre la superstition et l'idolâtrie.

L'activité cléricale ne se bornait pas à des manifestations de ce genre ; elle organisait en même temps et pour la première fois, dans le grand style, l'exploitation de la question sociale, par la création des Cercles catholiques d'ouvriers qui devaient devenir vingt ans plus tard, entre les mains des comédiens du Modernisme et du Sillonisme, de puissants moyens de propagande, et que nous retrouverons alors pénétrant et dissolvant les Syndicats ouvriers par leurs agents, tous incorporés à la Société de Jésus. Mais ce n’était alors, sous l'impulsion de l'ex-capitaine de cuirassier de Mun, l'un des massacreurs de la Semaine sanglante, qu'une sorte d'essai de retour aux corporations moyenâgeuses sous la férule de l'Eglise. Ce furent encore les missions dans chaque village, les pèlerinages, les conférences, qui faisaient de la France une vaste capucinière. Le souci de demeurer maîtresse des destinées de la France n’empêchait pas la papauté de diriger entre temps les clameurs de ses évêques et des cléricaux vers les nations voisines, et en particulier vers l'Allemagne à propos de Kulturkamp, et vers l'Italie pour la mise en vente des couvents sécula- 
risés, au risque l'allumer un incendie dont notre pays aurait naturellement fait les frais.

Tant d'efforts, de peines, de violences, d'attentats contre la liberté devaient se briser contre l'inflexible volonté de la nation qui, à chaque consultation nouvelle, accordait à l'idée républicaine des suffrages de plus en plus impressionnants. Chaque fois, l'opinion publique réclamait avec une insistance devenue menaçante que l'Assemblée instituât enfin dans les formes légales le gouvernement de la République au lieu de ce provisoire qui durait depuis 1870 et que l'habileté des jésuites prolongeait afin de laisser toujours la porte entr'ouverte à la monarchie. L’Assemblée nationale, sentant l'orage gronder et redoutant l'insurrection, s'y résolut enfin, tandis que le ministère de Broglie faisait place à un ministère de coalition à la dévotion des orléanistes. 


\title{
XXV \\ La République « légalisée »
}

\author{
Le Coup d'État du 16 Mai 1876
}

Rêver longtemps à la monarchie et réaliser la République semble avoir été pour les cléricaux de l'Assemblée de Versailles une rude pénitence que leur bon dieu leur infligeait. Du moins, firent-ils tous leurs efforts pour en atténuer la rigueur. L'essentiel, pour les visées futures, c'était d'exclure de la Constitution la consécration légale de la République, par une de ces déclarations préalables qui, généralement en tête d'un statut constitutionnel, constate juridiquement le fait existant avant d'en régler les modalités.

Aussi, l'amendement Laboulaye : "Le gouvernement de la République se compose de deux Chambres et d'un président » fut-il rejeté à 23 voix de majorité. Mais celui que proposa Wallon pour tourner la difficulté : "Le président de la République est élu à la pluralité des suffrages par le Sénat et la Chambre des députés, réunis en assemblée nationale ; il est nommé pour sept ans ; il est rééligible », fut tout de même adopté par 353 voix contre 352, c'est-à-dire à une voix de majorité (25 février 1875).

Ceux qui ont vécu cette minute angoissante, où « d'un texte banal en apparence » dépendait la destinée de la France, ont gardé le vivant souvenir de la proclamation du résultat, au milieu d'une poignante 
émotion. Le mot « République » officiellement inséré en tête de la loi constitutionnelle, c'était, malgré la réaction, l'équivalent de la déclaration : "La République est le gouvernement légal du pays. » Peu importait la suite des articles de la loi où, comme on l'a dit très justement, «l'assemblée mit le plus de monarchie et le moins de république possible ", la souveraineté populaire se chargerait bien d'en corriger, en toute occasion, les tendances réactionnaires. Et de fait, cette Constitution, que les partis de droite s'étaient laissé arracher, pour ainsi dire, et qu'ils espéraient réviser à leur profit, dès qu'un prétendant sérieux surgirait, est parvenue jusqu'à nous sans retouches importantes, ce qui ne veut pas dire qu'elle soit parfaite.

Quoi qu'il en soit, la République avait désormais une naissance légale, et les royalistes, qui avaient répété maintes fois qu'ils se contenteraient « d'une voix » de majorité pour ramener la royauté, auraient eu mauvaise grâce à chicaner sur ce point la République.

Mais, comme pour bien marquer que ce nouvel échec de la réaction ne devait changer en rien l'orientation politique du gouvernement, le maréchal de Mac-Mahon remplaçait, à la présidence du Conseil, de Cissey par Buffet. C'était plutôt une aggravation, et l'on s'en aperçut bien vite dès que l'Assemblée nationale eut fixé le terme de son existence et la date des élections générales au 20 février 1876.

Celles-ci furent un triomphe pour les républicains, au nombre de 340 sur 350 députés. Il ne restait plus à la réaction qu’à tenter un coup d'Etat ; mais elle n'a à compter que sur le maréchal et le Sénat ; c'est plus qu'insuffisant. Elle s'efforce pourtant d'y réussir, et, aux premiers rangs de ceux qui l'encouragent, nous trouvons naturellement les trois champions du droit divin: Pie, Bonnechose et Dupanloup, qui conseillent au maréchal d'employer tous les moyens pour sauver le pays. Mac-Mahon n'en tient guère pour la résistance. Il essaie cependant, surtout après l'interpellation du 4 mai 1877 sur « l'agitation des évêques en faveur de Pie IX et du pouvoir temporel ",, au cours de laquelle Gambetta, interprète de l'immense majorité des Français, a caractérisé la situation en ces quatre mots : «Le cléricalisme, voilà l'ennemi ! » Douze jours après, Jules Simon, qui avait remplacé Dufaure comme président du Conseil, était congédié plus brutalement 
qu'un laquais par l'hôte de l'Elysée. Le mois suivant, c'était le tour de la Chambre, dissoute après avis du Sénat.

C'était alors, pendant près de deux années avec le ministère de combat que dirigent de Broglie et de Fourtou et l'appui des jésuites et de l'Eglise, le despotisme le plus effréné qui règne en France : tout ce qui est républicain parmi les fonctionnaires, les instituteurs, ou encore dans l'armée, la magistrature, bref dans toutes les administrations, est sauvagement traqué, chassé et remplacé par des royalistes. On va chercher jusque dans l'arsenal du Moyen Age — telle la loi de sacrilège qui fut appliquée à un jeune artiste, aujourd'hui membre de l'Institut - des armes contre la liberté d'écrire et même contre la liberté de pensée : 6000 maires, 5000 fonctionnaires, la plupart des instituteurs et institutrices soupçonnés de tiédeur religieuse, sont révoqués. Ce sont tous les jours des hécatombes formidables de braves gens, de familles entières, que le " gouvernement des curés » sacrifie à la cause de "l'ordre moral » que le maréchal, dans de nombreuses randonnées à travers la France, prétend défendre.

Mais les pires actes d'arbitraire ne prévalent pas contre ce dilemme : "Se soumettre ou se démettre ", que Gambetta, dans le programme de Romans, a posé au pouvoir personnel mis au service de l’Eglise.

En novembre 1877, une majorité républicaine accrue sort des urnes. Cette fois, c'est l'écrasement définitif. Malgré les objurgations les plus véhémentes des évêques, Mac-Mahon se « soumet » d'abord, en rappelant Dufaure aux affaires ; peu après, le renouvellement triennal du Sénat, avec aussi une majorité républicaine, lui impose de se « démettre $»$.

Nous n'entreprendrons pas de refaire l'histoire de la France républicaine à partir de cette époque. Ce serait d'ailleurs hors de notre sujet. Si nous nous sommes étendus sur la formation de la Troisième République, c'est que l'action de l'Eglise en cette période faillit étouffer le peu de liberté si chèrement acquise par notre démocratie.

La suite vaudrait certainement qu'on s'y arrête un peu longuement, tant elle est pleine d'enseignements dont la génération actuelle pour- 
rait faire son profit au regard de l'assaut de plus en plus furieux que les jésuites et l'Eglise romaine - deux forces sous la même tiare livrent depuis la grande guerre à la seule nation qui a osé leur résister depuis plus d'un demi-siècle et s'émanciper de l'odieuse tyrannie du dogme.

L'avortement du coup d'Etat du 16 mai fut un tel échec pour les cléricaux que l'évêque Dupanloup en mourut de dépit. Il eut cependant encore a force, peu de temps avant ses derniers jours, d'arracher au dernier ministère du maréchal un blâme contre le Conseil Municipal de Paris, qui s'était associé à la fête du centenaire de Voltaire. Les cléricaux, vaincus, continuèrent sournoisement la lutte. D’abord en disputant pied à pied le terrain qu'à la faveur de l'Empire ils avaient reconquis au détriment des libertés publiques. Puis par une campagne des libertés publiques. Puis par une campagne de dénigrement systématique du régime auquel ils rattachèrent avec une perfide habileté nombre de scandales qui pour la plupart étaient leur œuvre: tel l'écroulement de l'Union Générale, grande banque dont le but était de grouper et transformer en moteur d'action les capitaux catholiques pour venir en aide au coup d'Etat du 16 mai.

Fondée en 1876, avec le marquis de Plœuc, l'ancien gouverneur de la Banque de France, elle échouait en 1882 en correctionnelle avec cinq ans de prison aux deux pères jésuites qui la dirigeaient alors : Bontoux et Féder. Telle encore l'affaire des Décorations, avec un royaliste de marque, le général comte d'Andlau, condamné par contumace. Telle enfin, pour ne citer que ces trois-là, l'affaire du Panama, que la presse cléricale et le clergé avaient l'audace d'exploiter contre la République, alors que tous les journaux réactionnaires s’étaient repus des "mensualités » qu'ils imposaient à la Société du Canal, et que, sur les cent quatre parlementaires soupçonnés, une dizaine seulement appartenaient plus ou moins à la majorité républicaine. Tous le autres étaient de la minorité. N'importe : le discrédit moral couvrait d'abord les personnes, puis les institutions qu'elles défendaient. C'était tout ce que demandaient les jésuites. Par accroissement successif, la boue religieuse devait finir par former un barrage où viendrait s'enliser la République. Telle fut l'une des causes de l'aventure boulangiste (1886), qu'un général de roman commandité par une duchesse déjà sur le retour, et à sa suite le bloc monarchiste, reconstitué par l'ordre de l'Eglise et grossi de mécontents abusés sur 
la vertu du sabre, tentèrent de faire prendre au sérieux. La triste fin de l'aventurier, semblable à celle d'un sous-off qui aurait mangé la grenouille, couvrit de honte les conspirateurs et leurs zélarices du noble faubourg. L'énergie des républicains au pouvoir, Tirard, Floquet, Constans, avait su faire tourner en comédie burlesque ce qui semblait s'annoncer comme une grande crise nationale. 


\title{
XXVI
}

\section{La République se défend}

\author{
L'affaire Dreyfus \\ La nouvelle tactique de la Papauté \\ Léon XIII et le ralliement
}

Parallèlement à l'action par la calomnie et l'outrage, les fils de Loyola poursuivaient de leurs objurgations tantôt hypocritement doucereuses, tantôt quasi-menaçantes, le nouveau président Grévy, qui, par antipathie contre les radicaux et surtout contre Gambetta et Clemenceau, prêtait une oreille complaisante à leurs impudentes réclamations. On en trouve la preuve dans le Temps du 7 janvier 1892, qui a révélé l'incorrection du premier magistrat de la République correspondant directement et à l'insu de ses ministres avec le nouveau pape Léon XIII. Ce qu'il y a de certain, c'est que l'œuvre de Jules Ferry pour la création de l'enseignement laïque est à peine esquissée que l'archevêque de Bonnechose averti l'Elysée d'un pétitionnement dans chaque province contre les « lois Ferry »; que c'est à l'instigation des cléricaux que le Sénat, après un discours du faux libérâtre Jules Simon - que le provincial des jésuites avait visité la veille - refuse de voter l'article 7 de la loi sur l'enseignement supérieur, qui exclut du droit d'enseigner les congrégations non autorisées - en fait les jésuites. La riposte des républicains, c’est l'exécution des décrets du 29 
mars 1882, exécution peu sérieuse. On s’en explique maintenant la raison: Grévy avait promis au cardinal de Bonnechose d'en atténuer les effets ; celui-ci, de concert avec le pape Léon XIII, avait rédigé un accord garantissant aux congrégations le droit de continuer à exister en France, par tolérance. Ainsi, cet ancien Constituant de 48, esprit aussi étroit que parcimonieux, solennel et prud'hommesque, s'était cru obligé, en prenant cette présidence qu'il avait voulu supprimer autrefois, de devenir l'ami de l’Eglise.

Malgré toutes les embûches, les républicains qui, à chaque renouvellement de la Chambre et du Sénat, s'accroissaient de telle façon qu'on avait le droit de ne plus les considérer comme un parti, mais comme s'identifiant avec la France elle-même, continuaient avec toute la vigueur désirable la grande tâche d'assainissement laïque qui constituait la principale clause de leur programme et qui restera comme l'un des meilleurs titres à la reconnaissance de tous les Français affranchis de la superstition religieuse.

En présence du danger sans cesse renaissant, la majorité républicaine forma, de 1899 à 1909, ce que Clemenceau appela « le bloc républicain ». Socialistes, radicaux et radicaux-socialistes furent désormais fortement unis pour appuyer les ministères " de défense républicaine » qui se succédèrent avec Waldeck-Rousseau, Combes, Sarrien, Clemenceau. L'affaire Dreyfus - dont ce n'est pas trop dire que de constater qu'elle ébranla le vieil édifice social de l'humanité - machinée de toutes pièces, et surtout de pièces fausses, par les Jésuites auxquels les autres ordres, entre autres les Assomptionnistes, avaient prêté leur malhonnête concours, avait révélé aux républicains toute la scélératesse d'une Eglise toujours prête à tous les forfaits. L'exploitation de l'antisémitisme, fondé et développé en France par Edouard Drumont, Morès et quelques autres affiliés, avait paru une arme merveilleuse contre la République, que déjà une presse cléricale répandue à profusion dans toutes les provinces combattait avec le système de Basile. Faire d'un juif un traître à la patrie n'était qu'un jeu avec la complicité d'officiers supérieurs élèves des jésuitières, comme le colonel Henry, qui se tua dans sa prison après avoir avoué être l'auteur de l'un des principaux faux qui avaient fait condamner Dreyfus. Il y eut aussi des hommes comme le général de Pellieux, qui 
démissionna parce que «dupe de gens sans honneur, et de ses chefs qui l'avaient fait travailler sur des faux. »

De 1894 à 1899, les jésuites s’acharnèrent à susciter jusqu'au sein des familles les plus vifs débats et à accuser un innocent d'un crime commis sur leur ordre et par un des leurs, l'aventurier Estherazy, qui avoué lui-même plus tard n'avoir agi qu'à leur instigation, afin de créer dans le pays une agitation telle que, selon l'expression d'un jésuite, « la République mange du juif jusqu’à en crever ! »

Cette deuxième crise, due tout entière à l'infernale tactique des fils de Loyola, laissa, bien lois de l'affaiblir, la République plus forte et plus résolue que jamais à résister aux manœuvres criminelles de la milice noire. On peut même dire que cette « affaire Dreyfus » marqua chez tous les peuples un réveil de la conscience humaine, en même temps qu'elle augmentait leur haine contre l'Eglise romaine et la gente monacale. Déjà, à l'exemple de la France, des pays catholiques, comme le Portugal et l'Espagne, préparaient des expulsions de moines. En France, la loi de 1901 et quelques poursuites correctionnelles parurent suffisantes. Les événements actuels ont démontré l'inefficacité de la première ; quant aux poursuites, il y a beaux jours que, sous prétexte de tolérance, on laisse les lois laïques en chômage.

La politique du pape Léon XIII qui, depuis 1878, avait succédé à Pie IX, avait entrepris le "redressement des affaires romaines », fortement compromises un peu partout par l'attitude altière de son prédécesseur et les violences maladroites des jésuites. Ancien élève des jésuites Joachim Pecci réprouvait les luttes inutiles. Toute son action était basée sur l'acceptation des faits accomplis, devant lesquels il affectait de s'incliner ou de se résigner, mais non sans les avoir commentés, analysés, avec toutes les conséquences qu’il entendait en tirer pour le plus grand profit de l'Eglise. C'est le pape qui a écrit le plus d'encycliques sur toutes espèces de choses.

Vis-à-vis de la France, Léon XIII, admirablement secondé d'ailleurs par le cardinal Rampolla, fait preuve d'une francophilie de circonstance. Il s'agit d'amadouer le gouvernement républicain, et dans ce but, d'accord avec le cardinal Lavigerie, il autorise celui-ci, lors d'un banquet après l'inauguration d'une église à Bône, à dénon- 
cer l'adhésion nette à la République, avec accompagnement de la Marseillaise par la musique des Pères Blancs du Sahara. Il confirme quelques jours après cette adhésion par une lettre au clergé de France. Dans le même temps, il lance l'encyclique Rerum Novarum, sur le mouvement social, alors que précisément se développe en France la propagande socialiste et syndicaliste dont le citoyen Millerand quantum mutatus ! - est l'un des plus ardents animateurs.

Les cléricaux s'extasient volontiers devant cette longue dissertation latine, qui n'apporta au débat entre patrons et ouvriers aucun argument nouveau, mais qui, au contraire, se conformant à la politique traditionnelle de l'Eglise romaine, se terminait par l'invitation aux riches « d'user avec bienveillance de leurs richesses » et aux ouvriers « de se résigner avec patience et modération au sort que le dieu des chrétiens leur avait fait ». Cette solution simpliste de la question sociale n’était guère compromettante. Dans tous les cas, cela n'empêcha pas le Vatican d'établir chez nous, au siège de la nonciature, avec le nonce Lorenzelli, un vaste système d'espionnage, d'encourager secrètement les modernistes catholiques dans leur propagande en faveur du « socialisme chrétien », créé par Mgr Beigni, directeur et fondateur de la Correspondance de Rome, puis de condamner ce même modernisme dans la Civita Cattolica, dirigée par le même Benigni. De cette façon, et avec le concours des cercles catholique ouvriers, on organisait et l'on brisait des grèves, on jetait le trouble et la désunion dans les véritables organisations syndicales ouvrières, on créait des syndicats d'ouvriers catholiques, on pourrissait tous les rouages de notre administration. Et les mêmes hommes accomplissant cette odieuse et perfide besogne osèrent et osent encore aujourd'hui reprocher aux républicains comme Combes, Pelletan, le général André, d'avoir voulu protéger la France contre le guet-apens savamment organisé par l'Elise en établissant le repérage de tous les espions romains dont la république était et est encore envahie. Le système des "fiches ", comme on l'a dit fort justement, est indispensable dans un pays où l'élément catholique aux ordres d'un chef étranger trame la perte du pays qui lui donne l'hospitalité. Nous verrons, sous le successeur de Léon XIII, c'est-à-dire à trois ans de distance, le ministère Clemenceau n'hésitant pas à faire perquisitionner à la nonciature, où n'était resté après la rupture des relations avec le pape (1904), qu'un auditeur, le Monsignor Montagnini. La saisie de 3300 pièces de toutes 
natures, que l'imprévu de l'opération n'avait pas permis de faire disparaître, fournit les preuves irréfutables de l'existence d'une vaste entreprise de "mouchardage » dirigée aussi bien contre les républicains que contre les catholiques militants, qui, ainsi que leurs évêques, étaient soumis à une étroite surveillance de l'agent officiel du Vatican. 


\title{
Le Pape des « conciliations opportunes »
}

\author{
Bismarck à Canossa \\ Le Vatican vers la Triple Alliance
}

La politique de Léon XIII ne fut pas toujours du goût des jésuites, et le cardinal Rampolla, secrétaire d'Etat, qui l'inspira fréquemment, devait payer de la tiare d'abord et de la vie ensuite son audace d'avoir osé leur résister. Cette politique au regard de la France peut se résumer ainsi : recherche d'un accord avec la démocratie, préoccupation sociale, reconnaissance du régime consacré par la volonté nationale, et républicain de toute solidarité avec les régimes déchus.

Mais, en admettant même que la papauté fût, par extraordinaire, sincère dans ses tentatives, la presse catholique française, et en particulier la Croix et son directeur, le P. Bailly, affectèrent de l'ignorer, et par l'intempérance de leur langage et la violence de leur action, ils en détruisent intentionnellement à l'avance les résultats escomptés par le Vatican. C'est à ce moment précis où la lutte entre les cléricaux et la République est à l'état aigu que Waldeck-Rousseau, s'étant retiré après les élections législatives de 1902, le bloc républicain eut l'intuition qu'une main énergique était résolument nécessaire au gouvernail, si l'on voulait briser la tempête formidable que, nonobstant 
les avances de son chef, l'Eglise avait déchaînée contre la France et ses institutions laïques, et que Léon XIII, décédé le 20 juillet 1903, semblait avoir prévue, mais sans pouvoir l'empêcher.

En Italie, l'action du pape des Encycliques, pendant ses vingt-cinq années de pontificat, se heurta à la garde vigilante montée autour du pouvoir par tous les Italiens qui avaient combattu pour l'indépendance et ne se souciaient pas de lui avoir sacrifié en vain le meilleur de leur sang. Mais, ainsi que Zola l'a constaté dans Rome, les grandeurs de leur histoire passée vivent au cœur des Italiens de toute classe et de tout parti, une sorte de mégalomanie maladive et ancestrale. La France, l'Italie et l'Angleterre avaient dû intervenir en Tunisie, chacune avec l'appétit aiguisé de ses financiers coloniaux, sous prétexte de sauvegarder les droits des derniers créanciers de la Régence, où le gaspillage régnait seul. Après dix années de luttes d’influences, une histoire de khroumirs incursionnant en Algérie (comme plus tard les histoires de Boxers en Chine) avait servi de prétexte aux mercantis français pour obtenir une action militaire du gouvernement et s'emparer de la Tunisie. La fureur des Italiens qui convoitaient la même proie s'était affirmée du coup par une extrême gallophobie d'abord, et ensuite, pour apaiser leur soif d'expansion, par une tentative contre l'Abyssinie. La papauté n’eut garde de négliger la double occasion qui lui était offerte d'exploiter la colère des masses contre le gouvernement italien par les désastres successifs de l'expédition en Ethiopie et la crise économique qui en résulta, pour user de toute son influence dans le but d'amener un rapprochement entre l'Allemagne et sa rivale d'hier l'Autriche, et entre celle-ci et son ancienne vassale l'Italie. L'aboutissant de cette réconciliation, qui, avec bien d'autres, valut à Léon XIII d'être appelé le pape " des conciliations opportunes », ce fut la Triple Alliance, dirigée surtout contre la France. Ainsi, estimant que la République française, irréductible sur la question cléricale, ne pouvait plus désormais rester, comme au lendemain de 1871, « la fille aînée de l'Eglise », sur laquelle celle-ci pensait pouvoir compter pour réaliser son rêve de domination universelle, le Vatican déplaçait de nouveau l'axe de sa politique, au profit des empires centraux et en hostilité avec la France, dont, à partir de ce moment, il préparait « le baptême de sang » pour 1914. 
Entre temps, les cléricaux romains avaient repris quelque espoir d'un rapprochement entre le Quirinal et le Vatican : Crispi, qui exerça un pouvoir quasi dictatorial de 1881 à 1896 dans la péninsule, accueillit presque leurs suggestions en vue d'une réconciliation comme celle d'aujourd'hui. Mais, aux premiers bruits de ce genre, les protestations s'élèvent du sein de toutes les organisations politiques de gauche et les conversations engagées avec le Saint-Siège n'eurent pas de lendemain.

Une seconde tentative, sous forme d'action directe en mai 1898, ne fut pas plus heureuse. Les troubles agraires de la Sicile et des Marches, ainsi que l'insurrection de Milan qui avait toutes les sympathies de l'archevêque, furent réprimés avec une énergie féroce. La preuve fut faite que le clergé italien n’était pas demeuré étranger à ces émeutes, les œuvres et cercles catholiques furent dissous. Mais le Vatican y gagna la chute de Crispi, en lequel il n'avait pas trouvé l'homme assez habile pour le seconder, et salua d'une joie discrète le général de Pelloux, son successeur, un « ami » de l'Eglise qui gouverna nettement à droite (1898-1900).

Ce changement de direction, très mal accueilli par le peuple, fut encore une occasion pour les jésuites de perpétrer l'assassinat à Monza du roi Humbert $\mathrm{I}^{\mathrm{er}}$, en août 1900. Evidemment, l'assassin était un anarchiste, Gaetairo Bresci. Il avait des complices, c'est certain. Mais un épais mystère enveloppa toujours le criminel et ses inspirateurs, et c'est ici peut-être que jamais le cas de rappeler le vieil axiome : Is fecit cui prodest. Léon XIII doit-il être tenu pour responsable, ou bien le Sacré Collège, quelquefois rétif à ses instructions, de la semiopposition qu'il fait à des obsèques religieuses, en proscrivant la prière composée par la reine, parce qu'il estimait impropre le mot de " martyr » appliqué au roi défunt ? Nous penchons d'autant plus pour la seconde hypothèse que l'extrême réserve du clergé en présence de la grosse affluence du peuple à l'enterrement ne fut certes pas très habile.

En Allemagne, Léon XIII avait remporté, il faut bien le reconnaître, un réel succès. Ici encore, les circonstances l'avaient servi à souhait. La formation de l'empire allemand s'était accomplie sous le double signe du nationalisme libéral et du libre échange excluant toute inter- 
vention de l'Etat dans les questions sociales. Mais le « centre catholique », dirigé en réalité par les jésuites que représentait Windthortst, occupait les principales firmes de l'industrie naissante et de la métallurgie allemande. On reconnaît bien là cette façon, toujours la même de la part des fils de Loyola, de s'emparer d'abord des sources de production es pays qu'ils veulent subjuguer; parce que, possesseurs comme en France actuellement, de tout ou partie de la richesse nationale, ils tiennent à leur merci les peuples et leurs gouvernements par la simple menace de serrer les cordons de la bourse, si on résiste à leurs prétentions.

Des droits protecteurs étaient nécessaires pour affronter la concurrence étrangère. La vie du nouvel empire en dépendait. Dans le même temps, Léon XIII notifiait son élévation à Guillaume $\mathrm{I}^{\mathrm{er}}$ (20 février 1878) — comme à tous les chefs d'Etat, du reste - et la réponse tardive mais courtoise de l'empereur contenait l'invite au nouveau pape d'user de son influence sur les catholiques allemands pour leur recommander la fidélité à l'empire. Le 17 avril, le pape s'y engageait en échange de l'abrogation du kulturkampf (lois de mai). Bismarck n'admettait pas qu'on lui posât des conditions. Un silence s'ensuivit. C'est le pape qui le rompit par une lettre de condoléances à l'occasion d'un attentat manqué contre l'empereur, et c'et le prince impérial qui répondit au nom de son père convalescent, pour lui exprimer le désir d'une prochaine paix avec l'Eglise. Ce fut au tour du chancelier de fer d'en rédiger les clauses. À les lire, il n'est pas douteux que leur auteur, en imposant au Vatican de désavouer le parti catholique et d'approuver les lois de mai, rêvait à la création d'une sorte de religion d'empire, d'essence purement luthérienne, qui eût fait de Guillaume $\mathrm{I}^{\mathrm{er}}$ un souverain analogue au tsar de Russie.

Léon XIII ne fut pas dupe de la manœuvre. Il savait que les nécessités économiques à l'extérieur et la crainte du socialisme grandissant à l'intérieur lui livreraient pieds et mains liés son redoutable partenaire. Il suffisait de laisser traîner les négociations, et le temps accomplir son œuvre, pour que Bismarck, malgré sa brutale habileté, abandonnât ses exigences.

Et de fait, après deux ans de tractations diverses, le chancelier, désireux de masquer sa reculade aux yeux des autres nations, acceptait, 
sans que rien l'eût fait prévoir, l'arbitrage du pape au sujet des îles Carolines que l'Espagne disputait à l'Allemagne. Par une sentence que Salomon n'eût pas désavouée, Léon XIII accordait la possession à l'Espagne, mais reconnaissait à l'Allemagne le droit à un dépôt de charbon et la liberté entière du commerce dans l'archipel. C'était tout ce que voulait l'Allemagne, en quête de stations commerciales un peu partout (1885). Moins d'un an après (9 mai 1886), une loi mettait fin au kulturkampf. Bismarck avait sauvé la face en donnant à sa défaite l'apparence d'un échange de bons procédés entre Rome et Berlin.

Les chancelleries furent peu après nettement fixées à ce sujet, lorsque, en janvier 1887, elles apprirent la démarche de Bismarck auprès du pape pour obtenir le vote du centre catholique et que celui-ci eût voté en effet le régime protectionniste, le rachat des chemins de fer, et toute une législation ouvrière sur les accidents, la maladie, la vieillesse, etc..., qui allait devenir aux mains du chancelier d'empire un sérieux instrument de propagande pour annihiler les forces croissantes du socialisme.

Mais cette démarche inconsidérée, cette intervention sollicitée et à laquelle un véritable homme d'Etat s'étant juré de ne pas aller à Canossa ne se serait jamais résigné, c'était bien l'aveu d'impuissance d'une logique de fer... blanc, incapable de briser les fils retors de la politique pontificale.

A dater de cette époque, la papauté ne cessera de surveiller attentivement ce qui se passe de l'autre côté du Rhin. C'est elle qui, lors d'une rupture du ministre avec le centre catholique sur la question coloniale, imposa de nouveau l'union des partis libéraux et conservateurs allemands, en prévision d'une guerre franco-allemande que l'on croyait imminente à cause d'incidents de frontière (affaire Schnœbelé, meurtre d'un chasseur français, etc...), et aussi de la crise boulangiste alors à son apogée.

Cette union, Léon XIII, subissant malgré lui peut-être l'influence de la Curie romaine où les jésuites commençaient à parler en maîtres, la considérait comme indispensable au plan d'une plus grande union entre les peuples de l'Europe centrale, dont lui ou ses prédécesseurs de- 
vaient préparer la croisade contre la France athée, l’Angleterre hérétique et la Russie schismatique.

Mais l'idée de cette réalisation, pour laquelle il prêchait aux Irlandais et aux Polonais la résignation provisoire, aux Uniates le calme et la patience, n'allait pas jusqu'à l'inciter à se confier aveuglément à la Triple Alliance. Et lorsque, en 1898, l'empereur Guillaume II, chef du plus grand Etat protestant, vint « en équipage féerique et vêtu en Lohengrin colonial » visiter Jérusalem et que, fort de l'amitié turque, il sema sur les ruines immenses du passé une foule d'œuvres protestantes ; quand, tout ce bluff accompli, il demanda à Léon XIII de transférer en sa personne à l'Allemagne la protection des catholiques d'Orient jusqu'alors confiée à la France, le pape, gardant le sourire, dissimula cependant mal une grimace à la pensée qu'un pontife luthérien pourrait devenir le protecteur des lieux prétendus saints et surtout catholiques, et, par une lettre publique au cardinal Langérieux, il reconnut le droit à la France de garder le protectorat d'Orient.

En Russie, Léon XIII poursuivait l'union de l'Eglise orthodoxe russe avec l'Eglise romaine et marquait nettement, du point de vue spirituel, son but : l'unité de l'Eglise et l'unité du monde par l'Eglise. Et cet autre but inavoué : faire renter sous l'obéissance de la papauté quelques millions d'êtres dont la conversation serait l'écroulement du tsarisme religieux.

Au fond, la Triple Alliance ne le satisfaisait qu'à moitié, à cause de l'une de ses premières clauses qui confirmait la possession de Rome à l'Italie unifiée. Et la conclusion d'une alliance franco-russe avec la possibilité d'y introduire la fin du schisme de Photius eût été plus conforme à ses aspirations.

Mais l'illusion n'était pas de mise sous l'œil des jésuites, dont la politique excluait les sentiments et les scrupules entendait faire de la Triple Alliance l'instrument des revendications de l'Eglise en faveur du pouvoir temporel, et qui se substituaient de plus en plus, à Rome, au pouvoir spirituel de la papauté dans la direction du catholicisme. Leur crainte était plutôt de voir l'orthodoxie russe ravir à Rome tous les chrétiens d'Orient, surtout si la Russie parvenait à mettre la main sur Constantinople, que de voir la Russie rentrer elle-même dans le 
giron de l'Eglise romaine. Aussi, quelque désir qu'il en eût, Léon XIII ne put jamais installer un nonce à Moscou et faire comprendre au Sacré Collège que la lutte ne pouvait plus être entre Byzance et Rome ; il la voyait bien plus grave, et s'en inquiétait davantage, entre croyants et incroyants.

C’est cette perpétuelle inquiétude qui dicte tous les actes de sa politique, dont on ne saurait contester, à défaut d'une absolue franchise, la très grande habileté et la remarquable activité.

Partout on le retrouve, insinuant, prévenant, accablant de lettres, de cadeaux, tous les chefs d'Etats catholiques ou non catholiques, se gardant bien de prendre parti dans les crises intérieures des nations, ou ne le faisant qu'avec une modération dans la forme ou dans le geste qui lui permet d'échapper à toute suspicion. C'est ainsi qu'en Angleterre, après avoir défendu aux Irlandais les quêtes pour Parnell à la porte des églises, il veut consacrer à Rome même le docteur Walsh comme évêque catholique de Dublin ; c'est encore dans le même esprit qu'il entame des négociations pour résoudre la question de validité des ordinations anglicanes qui dure depuis trois cents ans, ordinations considérées comme nulles par l’Eglise romaine.

Dans la catholique Espagne, il n'est pas seulement le médiateur de l'affaire des Carolines, mais aussi l'appui sérieux d'Alphonse XII en lui rattachant les évêques espagnols et en empêchant l'élément religieux de prêter son influence morale au prétendant don Carlos.

En Belgique, il obtient la reprise des relations diplomatiques avec le Vatican en 1885, quatre années après une rupture due au cabinet libéral et à $\mathrm{M}$. Frère-Orban, que renversent des élections nouvelles à forte majorité catholique. En Turquie, il ramène à Rome les Eglises chaldéennes et arméniennes, qu'en avait écartées le dogme de l’infaillibilité.

En Suisse, c'est également la rentrée au giron de l'Eglise du parti " vieux catholique », né de la même cause que ci-dessus.

En Hollande, lors de la première conférence de La Haye (15 mai 1898), les catholiques intriguent, à son instigation, pour que la papau- 
té y soit officiellement représentée. Mais, ici, Léon XIII se heurte au veto formel de l'Italie, qui menace de se retirer de la conférence si l'on rend même de loin hommage à la coopération qu'il a eu l'air d'imposer aux nations en déclarant publiquement, quelques jours auparavant, qu'il prenait la conférence sous sa protection. Cette nouvelle victoire de l'Italie sur la papauté apprenait au monde que la question romaine existait encore, tandis que, avec son astuce ordinaire, Léon XIII espérait la faire oublier et continuait à tenir le rôle d'un souverain temporel jusqu'au jour où, la force de la tradition l'empotant sur le fait accompli le 20 septembre 1870, un nouveau congrès de La Haye aurait restitué la papauté dans ses anciens Etats.

Aux Etats-Unis, de généreuses offrandes et des lettres d'encouragement accéléraient la marche continuellement ascendante du catholicisme comptant 46 diocèses en 1886 et 75 en 1888, et dont le clergé était passé de 2000 à 10000 prêtres dans le laps de temps.

En Turquie, Léon XIII trouva dans la duplicité du khalifat un obstacle qu'il espéra tourner par la fondation d'un collège de clercs arméniens en 1883 ; mais c'est en vain qu'il réconcilie les Turcs avec les Arméniens et par l'élévation au rang de cardinal de l'évêque Hassoun donne à ceux-ci toute satisfaction. Le sultan, qui l'en a remercié par le don d'un magnifique anneau, n'en continue pas moins à exciter au massacre des Arméniens sa propre police.

En Perse, il nomme grand-croix de Pie IX les deux fils du schah pour leur tolérance envers les catholiques ; il fait de même au Japon, en Chine, dont les empereurs reçoivent de longues épîtres de congratulations.

Il n'est pas jusqu'aux Indes où, pour faire face à la propagande protestante, il ne crée, en 1886, un patriarcat d'Hindoustan.

Cette activité prodigieuse, ce désir insatiable de tout concilier ne mériteraient que des éloges, si l'on ne savait qu'ils masquent avec tout le soin possible le projet de réunir en un seul troupeau soumis à la servitude dégradante du dogme catholique tous les peuples de la terre et d'abolir à tout jamais chez les peuples la conscience de leur propre dignité et l'amour de la liberté. 
La Vérité Sur la Question Romaine (1930)

XXVIII

\section{La Curie Romaine.}

\section{Les Jésuites préparent "la grande saignée régénératrice "}

L'histoire n'a guère justifié les prophéties de saint Malachie sur les papes. Son livre, d'une authenticité douteuse, d'ailleurs, pour les pontifes qui ont occupé le trône de saint Pierre jusqu'au seizième siècle, annonce qu'aprè Léon XIII, quakifié de "Lumière dans le ciel » (lumen in cœlo), viendra un pape qu'il désigne sous le nom d'Ignis ardens. Or, Sarto, qui fut, à son insu peut-être, l'élu de la combinazione des Austro-Allemands et des jésuites, et pontifia sous le vocable de Pie X, de 1903 à 1914, apparaît bien pâle et presque nul, par comparaison avec son prédécesseur.

Les conditions dans lesquelles se fit l'élection du nouveau pape (4 août 1903) révèlent tout de suite aux esprits avertis que le Vatican passait ouvertement et complètement sous la puissance des jésuites, et que l'Eglise romaine allait désormais être gouvernée par eux seuls et, successivement, par leurs trois généraux : les PP. Martin, Wernz et Ledochowski.

Lors de l'élection, et après plusieurs scrutins, le cardinal Rampolla, candidat des évêques français et italiens, obtenait 24 suffrages ; Gat- 
ti,candidat des Austro-Allemands, 5 voix, et Sarto, illustre inconnu, 5 voix. Avant le dernier tour de scrutin, le cardinal Puzyna demanda la parole, au nom de son auguste maître, « le très-puissant et très-pieux empereur d'Autriche », et prononça fort distinctement les paroles suivantes :

" $\mathrm{Au}$ nom de S. M. François-Joseph, empereur d'Autriche, je déclare que mon illustre maître met le veto de l'Autriche à l'élection éventuelle de S. E. le cardinal Rampolla. »

Celui-ci retira sa candidature et le dernier scrutin se répartit ainsi : Sarto 50, Rampolla 10, Gatti 2. Jamais Sarto n’aurait cru que sa nullité même serait son principal titre à la tiare. Jusqu'alors, il ne s'était guère signalé que comme un réformateur de la musique sacrée, s'évertuant à chasser les allegri profanes du sanctuaire et à rédiger un code de la musique liturgique, qu'il devait rendre obligatoire plus tard, par son motu proprio. Mais les jésuites avaient tablé précisément sur cette intelligence obtuse, entêtée, plus que modeste, pour garder toute leur liberté d'action derrière la Curie romaine, peuplée de leurs créatures et qui avait fini pas se calquer entièrement sur la Société de Jésus.

Et, dès lors, apparaît non moins nettement le plan ourdi par cette dernière, en plein accord avec l'Allemagne, l'Autriche-Hongrie — et même un moment avec l'Italie - contre la France, pour la punir de son impiété et la reconquérir à la foi. Mais, avant d'aller plus loin, quelques mots d'explication sur cette Curie romaine sont indispensables. Divers ouvrages l'ont suffisamment étudiée et caractérisée avant nous pour que nous nous contentions de les résumer ${ }^{1}$ :

Dans son livre : Le Baptême du Sang, l'abbé Daniel, qui fut l'un des secrétaires de cette redoutable organisation et pour lequel le Vatican, à la veille de la grande guerre, n'eut guère de mystères, en raison des devoirs de sa fonction, expose la formidable puissance de cet organisme dont la volonté mit l’Europe à feu et à sang :

« Il y a, dit-il, deux pouvoirs dans l'Eglise : $1^{\circ}$ le pape, devant lequel tout croyant obéit, s'incline respectueusement et se taît ; $2^{\circ}$ les bureaux. 
« Nécessaires pour étudier les affaires ecclésiastiques, les bureaux constituent à côté du pouvoir des Clefs, qui n’appartient qu'au pape, le pouvoir des paperasses, des formules, des timbres, c'est-à-dire cette formidable machine bureaucratique où se nouent les intrigues, où les intérêts matériels dévorent les intérêts spirituels, où les passions grouillent sur des ronds-de-cuir et entourent la volonté du pape d'une enceinte fortifiée, de tranchées, de fils barbelés, de nuages asphyxiants, lesquels font que l'on n'obéit pas à Dieu, mais à des ficelles ecclésiastiques... La Curie n'est pas réformable; ses abus sont éternels... Cette armée de scribes, procureurs, notaires, pronotaires, de gratte-papiers chamarrés d'or et de broderies, gras, épais, rondelets, pieux et fainéants, rabâcheurs de formules sacrées et repus de bons dîners, c'est ce que l'on appelle la sainte, la sacro-sainte hiérarchie qui a le pas sur les évêques eux-mêmes et constitue les familiers du pape, qui les comble de biens et d'honneurs, eux et leurs créatures. La Curie romaine devrait être internationale comme la catholicité ; elle est nationaliste, c'est-à-dire italienne... Elle a grandi peu à peu ; elle a tout englobé, même le pape. Elle ne devait être rien, elle est devenue tout...

«...Enfin, derrière la Curie romaine, il y a les jésuites, dont l'influence à Rome et dans le monde entier est considérable, les jésuites qui devaient compter autrefois avec les autres ordres et dans lesquels ceux-ci sont fondus aujourd'hui. Ils sont maintenant l'Eglise elle-même...

« Cette influence était passée, à la veille de la guerre, aux mains des jésuites allemands ou autrichiens... Quiconque n'est pas avec eux est contre le Christ. Ils sont l'orthodoxie. »

Pie X, qui était tout le contraire d'un diplomate et suivait par tradition la politique instaurée par son prédécesseur vis-à-vis de l'Italie et de la France, aurait bien voulu y apporter quelques ménagements. C’étaient, par tempérament, un ennemi de la lutte. Mais les jésuites, qui avaient déjà dressé leurs batteries, veillaient à l'accomplissement inéluctable de leurs criminels desseins. Auprès du pacifique Sarto, ils avaient pris soin de faire accepter pour secrétaire d'Etat un prélat jeune, actif et intrigant, l'un des leurs d'ailleurs, le jésuite espagnol Merry del Val, esprit chargé de haine contre la France, et qui fut l'un 
des plus acharnés protagonistes de la préparation de la grande guerre. Lui et le P. Martin d'abord, puis, à la mort de celui-ci (1906), le P. Wernz, ne laissèrent pas un instant de répit à leur " pupille ». Si l'on considère que le $\mathrm{P}$. Wernz était encore membre des trois congrégations les plus importantes : l'Index, le Concile et le Saint-Office, autrement dit l'Inquisition, on peut ainsi juger de la situation de Pie X, qu'une perpétuelle contrainte amenait toujours, par toutes sortes de ruses et d'intrigues, à seconder les vues des jésuites.

On a noté, dans la presse, à l'époque de son élection, ses appréhensions d'une fin tragique en se voyant investi de la dignité pontificale. L'avenir devait pleinement les justifier. Pie X fut, en effet, le pape prisonnier des jésuites, puis révolté contre l'odieuse besogne qu'ils attendaient de lui, et finalement assassiné par eux.

Se tenant discrètement et comme dans une demi-obscurité au second plan, le P. Ledochowski, regardé cependant depuis longtemps comme le plus puissant génie malfaisant de la Compagnie de Jésus par tous ceux qui «vivaient » pour ainsi dire la politique vaticane dans cette période de 1903 à 1914, personnifie en quelque sorte le sinistre prologue de la tuerie mondiale. Galicien d'origine polonaise, ayant un frère général de division dans l'armée autrichienne, Ledochowski jouissait auprès de l'empereur François-Joseph d'une très grande influence, dépassant même les ministères de la monarchie austro-hongroise. Il le devait surtout à sa profonde connaissance de l’imbroglio balkanique.

On sait quel volcan à foyers multiples constituait alors, et même encore aujourd'hui, la péninsule balkanique. Un pêle-mêle de races et de religions dont trois traités (Paris, 1856, San-Stefano et Berlin, 1878), n'avaient pu satisfaire les aspirations nationales ou religieuses ; des conflits sans cesse renaissant entre la Turquie et la Russie, que surveillaient jalousement la France et l'Angleterre, tandis que l'Autriche-Hongrie, située aux confins du catholicisme, des religions réformées et de l'islamisme, poursuivait inlassablement (avec une population de $80 \%$ de catholiques en Autriche et de $50 \%$ en Hongrie) le rattachement à l'Eglise romaine des peuples orthodoxes ; les affaires de Bulgarie et de Crète compliquées au possible ; celles de la Macédoine inextricables; partout le grondement des révoltes; partout 
l’âpre désir de la part de ces multiples Etats ou principautés d'une prochaine indépendance. Telle était alors la situation que les jésuites, fervents adeptes de l'intrigue, trouvaient excellente pour la réussite de leurs projets. Car, le jour où il leur plairait, selon la devise de leur fondateur inscrite au dôme de leur Eglise à Rome, « lettre le feu partout », la moindre allumette jetée sur le foyer balkanique embraserait toute l'Europe.

Ainsi Ledochowski, usant d'une habileté consommée, avait réussi à ramener presque tous ces peuples schismatiques dans le giron de l'Eglise romaine en les détachant un à un de l'influence russe. Les empires centraux s'en étaient trouvés fortifiés d'autant pour entreprendre la lutte contre les puissances occidentales. D’autre part, la constitution d'un grand empire orthodoxe, projetée par la Russie, aux dépens de la Turquie, n’était pas réalisable.

$\mathrm{Si}$, vis-à-vis de la monarchie italienne, Pie X demeura obstinément ferme sur le terrain des protestations et des mesures d'ordre spirituel instituées par le pape Pie IX, il leva cependant pour certains cas la défense faite jusqu'alors aux catholiques de s'occuper des affaires politiques et de prendre part aux élections. On ne saurait pourtant faire un mérite à la papauté de cette attitude nouvelle.

La vérité, c'est que, depuis le retour des gauches au pouvoir, avec les cabinets Zarnadelli et Giolitti (1903-1912), le parti socialiste avait grandi dans toute la péninsule et particulièrement à Milan. Mais jamais pris de court, les jésuites, selon la tactique employée déjà en France, avaient aussitôt créé une "Union Populaire », dont les membres « se mettaient promptement et sans hésitation entre les mains du pape comme des instruments dociles et empressés pour la grande œuvre de restauration sociale. »

Plus tard (1918), la grande guerre terminée, ce parti, avec le moine dom Sturzo comme animateur, deviendra le " parti populaire italien », avec un programme qui n'est qu'une contrefaçon des revendications socialistes... mais la dictature en plus, dont il est, du reste, le fourrier.

En France, la crise arrivée à l'état aigu, une fois encore, révélait la ferme volonté des républicains non seulement de n'accepter aucun 
compromis avec l'Eglise romaine, mais même de déchirer purement et simplement le Concordat, afin de faire la situation nette et de couper court, une fois pour toutes, aux velléités de réconciliation dont un « esprit nouveau » cherchait l'occasion chez les modérément républicains.

La lutte revêtit alors un caractère d'une exceptionnelle gravité. Nous tenons à la préciser dans tous ses détails, car elle démontre avec une aveuglante clarté que l'EGLISE ROMAINE est la SEULE RESPONSABLE DE LA GRANDE TUERIE MONDIALE, et que les jésuites en ont préparé avec une extrême et criminelle minutie toutes les phases. 


\section{La Séparation}

\section{L'action perfide du socialisme chrétien \\ L'attitude des partis de gauche en face du péril clérical}

Quelque peu ébranlée par l'affaire Dreyfus, la coalition des partis de gauche, qui marque le début d'une nouvelle période - celle du «bloc républicain » — dans l'histoire de la Troisième République, s'était cependant suffisamment disciplinée pour faire aboutir, avec le cabinet Waldeck-Rousseau, la loi du $1^{\text {er }}$ juillet 1901 sur les associations. Les élections de 1902 avaient apporté à cette politique une majorité de 360 républicains contre 220 réactionnaires. Emile Combes, ; qui succéda à Waldeck-Rousseau, appliqua sans défaillance, comme c'était son devoir, les prescriptions de la loi de 1901. il fit rejeter les demandes de congrégations et voter la loi du 7 juillet 1904, supprimant l'ensemble de l'enseignement congréganiste, dont le plus clair résultat était, comme l'avait dit Waldeck-Rousseau, de « former une jeunesse séparée par son éducation de la jeunesse formée par les maîtres de l’Université et de perpétuer ainsi de génération en génération un conflit des plus dangereux pour l'avenir de la démocratie. » Deux faits d'ordre différent allaient accroître l'attitude déjà passablement hostile du Vatican envers la France. En avril 1904, le président Loubet, sans se soucier de la défense de la papauté aux chefs d'Etat leur 
interdisant de venir à Rome, aussi longtemps que durerait la situation créée en 1870, était venu au Quirinal rendre au roi d'Italie la visite qu'il en avait reçue en France. Pie X (ou plutôt les jésuites) considérèrent cette visite comme une offense et adressèrent à tous les chefs d'Etat une protestation secrète en apparence, mais que toute la presse reproduisit avec force commentaires. Répondant du tac au tac, le ministère Combes rappela notre ambassadeur auprès du Vatican, ne laissant qu'un simple chargé d'affaires. Dans le même temps, la Curie romaine citait devant le tribunal du Saint-Office - alias la congrégation de l'Inquisition - trois évêques qu'en vertu du droit qu'il tenait du Concordat, Emile Combes avait nommés sans prendre l'avis du pape. Le gouvernement se plaignit alors de n'avoir pas été prévenu alors de n’avoir pas été prévenu de cette citation, conformément aux prescriptions dudit Concordat en la matière. Mais Pie X blâma les trois inculpés d'avoir trahi un secret de l'Eglise en faisant connaître leur citation à un laïc. Combes n'était pas de ces ministres qui froncent le sourcil et... vont à Canossa. Notre ambassadeur fut définitivement rappelé et, le 10 novembre 1904, le projet de séparation des Eglises et de l'Etat tait déposé à la Chambre. A vrai dire, le Vatican, en agissant avec autant de rudesse, avait eu plutôt à cœur de maintenir dans une étroite dépendance le clergé français, dont quelques membres étaient suspects de sympathie envers la République, que de chercher une mauvaise querelle au ministère.

C’était, en effet, le temps où le Saint-Office, prenant une part prépondérante dans la conduite de l'Eglise romaine, sous l'impulsion de Merry del Val, au froid et cruel faciès d'inquisiteur médiéval, prodiguait chaque jour, à l'instigation de la Curie romaine, les condamnations et les anathèmes. C'est le règne de l'interdit et de la terreur à la Cour pontificale: les évêques tremblent sur leur siège épiscopal : « Malheur à qui ne se soumet pas, il est bien vite foudroyé !»

Les trois évêques s'étaient soumis. Mais le geste insolent de la papauté avait eu pour heureux résultat de mettre enfin à l'ordre du jour la séparation d'avec l'Eglise, réclamée de toutes parts comme la seule solution pratique du débat chaque jour plus envenimé entre la République et l'Eglise romaine. Tous les libres penseurs sincères attendaient des quatre coins de l'horizon cet acte libérateur de la France, et deux mois auparavant, au Congrès international de Rome, tenu le 20 
septembre 1904, au jour anniversaire de la reprise, en 1870, de la Ville Eternelle par ses légitimes propriétaires, une foule immense entourant les plus illustres représentants de l'intelligence mondiale acclamait frénétiquement l'aurore d'une ère nouvelle se levant enfin sur des siècles de forfaits, de souffrance et de misère, dont l'Eglise chrétienne avait accablé l’humanité !

Mais déjà les jésuites avaient accompli leur besogne délétère. À l'aide d'une foule de fondations s'inspirant soi-disant d'une étroite sollicitude pour la classe prolétarienne, ils avaient, ils avaient réussi, en se faufilant à travers les masses ouvrières, à les détourner peu à peu de la lutte contre le péril clérical. Sous le prétexte, absolument faux d'ailleurs, que la question sociale n'avait rien à voir avec la question religieuse, alors qu'on n'arrivera jamais à résoudre la première sans s'être débarrassé d'abord de la seconde, leurs affiliés s'efforçaient d'aiguiller le mouvement socialiste uniquement contre le capital et de leur faire oublier que c'est à la crédulité et à l'ignorance des masses que l'on doit aujourd'hui encore, comme hier et toujours, l'asservissement des peuples aux puissances d'argent.

On n'insistera jamais trop sur le mal énorme que les modernistes, sillonistes et autres disciples de Basile et de Tartufe ont fait aux dépens des démocraties laborieuses, en tous les pays, en créant perfidement cette indifférence au sein des populations pour la question religieuse, afin de les maintenir plus étroitement que jamais dans la dégradante servitude du dogme, source de toutes les misères et de toutes les souffrances humaines. Cette manœuvre, qui s’affuble du nom de " socialisme chrétien ", est un double outrage à la logique et à la vérité. Car le véritable socialisme exclut tout article de foi et le Jésus des prêtres fut tout le contraire d'un socialiste.

Cette manœuvre, disons-nous, s’affirma hypocritement pour la première fois au congrès socialiste d'Amsterdam. Le résultat escompté par les jésuites qui l'inspiraient dans les couloirs du congrès ne tarda pas à se manifester : le ministère Combes, attaqué par les catholiques et les conservateurs, le fut également par des " progressistes » de la même farine que les " socialistes chrétiens ». Quant au parti socialiste, il affecta dans on ensemble de ne plus soutenir avec la même vigueur les radicaux-socialistes contre le parti clérical. La guerre aux 
" partis bourgeois », que lui avaient soufflée, comme tactique nouvelle, les fils de Loyola, permettait à bon nombre de ses adhérents de se couvrir du maque aisé de la tolérance : manger du curé la semaine et aller à l'Eglise le dimanche était devenu le fin d'une suprême habileté que, dans nombre de partis qui s’intitulent « de gauche, on pratique encore aujourd'hui. Le résultat? ce fut, le 18 janvier 1905, la chute du cabinet Combes, qui, plus soucieux de sa dignité que certain président du Conseil de notre connaissance, refusa de rester au pouvoir avec six voix seulement de majorité. Le résultat? c’est aujourd'hui, pour les mêmes raisons et sous l'influence des jésuites dont les élèves détiennent toutes les administrations, la tactique du laissez faire et du je m'en fichisme qui rouvre toutes grandes les portes de la France à ses pires ennemis, tandis qu'à l'horizon, au delà des monts alpins, monte déjà la lueur sanglante de nouvelles et prochaines hécatombes.

Quoi qu'il en soit, force nous est bien de reconnaître en toute impartialité, par les enseignements mêmes de l'histoire, que de tous les partis de gauche, le parti radical et radical-socialiste, dont on peut discuter la doctrine politique, a toujours été le seul parti qui n'ait jamais eu peur du cléricalisme et qui lui ait souvent infligé de rudes défaites. Tandis qu'en Allemagne, Bebel et Liebneckt — le fait est rapporté dans les mémoires de Prolès - avouaient, au début du règne de Guillaume II, « qu'il était dangereux de s'attaquer à l'Eglise, que les jésuites étaient un bien gros morceau à avaler », et qu'en France, malgré Jaurès, beaucoup de socialistes partageaient et partagent encore cet avis ; le parti radical, et c'est son grand honneur, faisait toujours face crânement à l'Eglise romaine. Un moment peut-être, il a paru faiblir, sous la poussée de jeunes arrivistes, inventeurs d'une nouvelle tactique prétendant le rajeunir en le confinant dans "l'économique." Cette autre manœuvre, à laquelle les jésuites ne sont pas non plus étrangers, paraît déjouée à l'heure actuelle. Les libres penseurs avertis ne s'y sont pas laissé prendre. Souhaitons-leur de veiller avec vigilance et souhaitons aux sincères des autres partis de gauche de se ressaisir également. L'heure n'est plus aux équivoques et aux compromissions. La France a déjà payé de près de deux millions de ses enfants et de la ruine des trois quarts de son territoire l'abandon de la lutte contre le Vatican à la veille de la grande guerre. Qu'on médite la leçon si l'on veut éviter un nouveau massacre. 
Ce fut au ministère Rouvier, remplaçant Combes, que l'on dut le vote de la loi de Séparation (9 décembre 1905). Aussitôt après le vote de l'article 4 concernant l'organisation des sociétés cultuelles, notons deux mots désormais historiques : «La séparation est faite ! » dit Jaurès. « La séparation est morte ! » riposta de Mun* . Ces deux jugements également vrais, puisque, si la loi de Séparation existe légalement, on ne l'a jamais appliquée, nous dispensent d'une plus longue appréciation. Et, du reste, la condamnation de la loi par Pie X (11 février 1906), sa défense aux fidèles de constituer des associations cultuelles,puis les manifestations violentes qui accompagnèrent les inventaires impressionnèrent à ce point la Chambre qu'elle renversa par une coalition de droite et d'extrême gauche le cabinet Rouvier. N'est-ce pas la justification de ce que nous disions plus haut? Un ministère Combes aurait courageusement fait face à l'ennemi, et poursuivi quand même les inventaires. Car les jésuites savent reconnaître la supériorité de la poigne, lorsque l'on se donne la peine d'en faire usage à leur égard. Sans doute, il s'en vengent tôt ou tard par un nouveau crime. Mais, en attendant, on y gagne quelques années de tranquillité, et en l'espèce le temps est tout.

Malheureusement, le premier acte du ministère Sarrien fut de suspendre partout où se produiraient des difficultés les inventaires des biens volés autrefois à la nation et que la République avait le droit strict de récupérer. On pense avec quelle joie non dissimulée les cléricaux accueillirent cette reculade. Cependant, un courant formé par ceux que l'on appela les " cardinaux verts », parce que tous ou presque, prélats et laïcs, appartenaient à l'Institut, proposaient d'essayer des cultuelles. Au nom du droit canonique, Pie X s'y opposa par son Encyclique Gravissima officii (10 août 1906), et les choses restèrent en l'état jusqu'au jour où, au mépris d'une loi existante et du Parlement, mais que la veulerie des gouvernements avait rendue inapplicable, on imagina l'illégale et malhonnête invention des Diocésaines, que par un artifice de procédure on fit consacrer législativement dans un additif au budget. 


\section{XXX \\ Espionnage et diffamation de la France par la milice noire}

L'opposition du Vatican aux cultuelles et aux diverses mesures d'application de la loi de Séparation imposait au gouvernement de se montrer plus énergique qu'il ne l'avait été jusqu'alors et de compléter la loi du 9 décembre 1905 par deux autres lois : celle du 2 janvier 1907 et celle du 13 janvier 1908, réglant, à défaut d'associations cultuelles, l'attribution des biens ecclésiastiques. En outre, en l'absence des biens d'associations cultuelles, le clergé et les fidèles devaient subvenir à l'exercice public du culte en usant de la loi du 30 juin 1881 sur la liberté de réunion, à charge de déclaration préalable annuelle. Le pape repoussa cette condition qui assimilait les cérémonies du culte à des réunions publiques. Ce refus a eu pour conséquence de constituer le clergé et les fidèles comme des occupants sans titre juridique des édifices cultuels. Un jurisconsulte catholique, M. de Guntz, dans une étude publiée à Paris en 1917 et préfacée par un Monsignor, camérier secret du pape, a reconnu cette précarité de jouissance qui autorise, en vertu de la loi de séparation, à retirer aux prêtres, du jour au lendemain, les églises. L'auteur s'en inquiétait et souhaitait vivement que cette occupation sui generis fût réglée le plus tôt possible, tant il redoutait qu'un gouvernement, résolu à appliquer la loi de 1905, laissât les communes en disposer à leur gré, comme elles en ont toujours le droit, n'en déplaise aux juristes de sacristie, 
habiles à expliquer en sens inverse les textes les plus formels. Il n'est pas jusqu'à M. Guiraud, dans la Croix, qui n'ait jeté le cri d'alarme contre cette situation. Il y a bien, il est vrai, une lettre du $1^{\mathrm{er}}$ décembre 1906, de M. Briand, qui recommande aux préfets de ne pas tolérer les fermetures arbitraires. Cette instruction ministérielle n'a que la valeur d'une interprétation de circonstance. Et, ainsi que l'établit plus tard une consultation juridique avec formules de délibérations à l'usage des conseils municipaux, rédigée au nom de la Fédération Française de la Libre Pensée (Bulletin juin-juillet-août 1920), le droit desdits conseils reste intact ; ils peuvent en user aujourd'hui encore, malgré les Diocésaines. Celles-ci en effet, constituent une modification illégale à la loi de 1905, en ce sens que l'avis du Conseil d'Etat et le décret-loi qui a suivi ne sauraient se substituer au pouvoir législatif qui, dans notre droit français, a seul qualité, qu'on le veuille ou non, pour établir ou modifier un texte de loi.

Tandis que l'Eglise se refusait à tout accommodement, nonobstant l'excessive timidité du gouvernement dans l'application de la loi, les jésuites poursuivaient leur œuvre de division par la double réaction du " parti démocratique chrétien " et des "démocrates catholiques ». Leurs agents, s'insinuant dans les organisations syndicales, travaillant les congrès socialistes par leurs mouchards, parvenaient à dissocier les efforts du prolétariat, à le couper en deux (socialistes unifiés et réformistes), et à atteindre leur but : la dislocation de l'ancienne majorité du bloc républicain par le retrait des socialistes unifiés de la délégation des gauches, qui, jusque-là, avaient soutenu fidèlement les ministères de « défense républicaine » contre la réaction cléricale.

On sait, mais on ne saurait trop le répéter, que la Société de Jésus a pour principal facteur l'espionnage universel. Tous ses membres n'espionnent pas seulement les profanes et les adversaires, ils s'espionnent encore les uns les autres. Le régime des jésuites a pour idéal un vaste ministère de la police universelle. Les papiers saisis à la nonciature confirmèrent cette assertion. Ils prouvaient encore que la Curie romaine essayait de la corruption pour acheter les consciences avant d'en venir à la guerre. L'argent d'abord, le sabre ensuite. La père Rouvier était chargé par le Vatican de recueillir le plus possible d'or pour payer toutes les trahisons, satisfaire à toutes les vénalités. N'était-ce pas l'époque où, dans un banquet, un général jésuite disait à 
Rome, à un rédacteur du Petit Journal : « De la République française, nous ne craignons ni les hommes, ni les lois, dont nous pouvons régler nous-mêmes l'exécution et l'interprétation avec quelques millions. »

Au lendemain de la Séparation de l'Eglise et de l'Etat, le pape, toujours docile aux ordres de la Curie romaine, avait rappelé le nonce Lorenzelli. Mais le cardinal Merry del Val, qui dirigeait une vaste entreprise d'espionnage et de diffamation, non seulement contre le clergé de France, mais encore contre la nation française, ne voulait pas perdre le contact avec notre politique. Il s'arrogea le droit de maintenir à la nonciature un auditeur de l'ex-nonce, le Monsignor Montagnini. Les agissements de cet espion furent tels que Clemenceau, alors président du Conseil en remplacement de Sarrien, décida le 2 décembre 1906 de perquisitionner l'hôtel de la nonciature. Cette perquisition eut lieu le 11 décembre, et le soir même Montagnini était reconduit à la frontière. L'affaire fit grand bruit ; la Chambre nomma une commission de vingt-deux membres pour dépouiller le dossier qui, comme nous l'avons dit, comprenait 3300 pièces.

Mais on sait que le plus clair résultat d'une commission d'enquête parlementaire, c'est, par tradition, un enterrement de première classe. Le pape, d'ailleurs, protesta, menaça même de révélations " scandaleuses » Peut-être y eut-il entre le gouvernement et Pie X échange de bons procédés, autrement dit un accord tacite pour ne pas pousser les choses... Toujours est-il que l'enquête en resta là, et que depuis des esprits curieux, comme l'abbé Daniel, ayant voulu savoir ce qu'était devenu le formidable dossier, ont été renvoyés du ministère de l'intérieur à la Sûreté générale, et vice versa. Le dossier et ses 3300 pièces ses sont volatilisés ; impossible, même avec l'appui de deux sénateurs et d'un député, de mettre la main dessus. Personne ne sait où ils ont passé !

Cependant, Merry del Val ayant fait commencer une campagne contre le ministère Clemenceau par les journaux à sa solde, on peut juger par les quelques extraits suivants du genre de diplomatie de l’Eglise romaine en France. 
Montagnini écrit dans ses notes à Merry del Val : « La publication de ces documents sera honteuse, mais elle sera aussi une justification pour le Saint-Siège. » (Le Matin, 8 avril 1907.)

« M. Ribot parlera aussi à M. Leygues. Mais Piou dispose d'autres moyens auprès de Leygues. Il sait que ce dernier a 300000 francs de dettes. » (Autorité, 5 avril 1907.)

Un télégramme adressé au Vatican dit : «Clemenceau est méchant, mais son secrétaire Sarraut est plus méchant encore. » (Petite République, 31 mars 1907.)

Un autre télégramme au Vatican relate, comme très important pour l'Eglise, le fait que «le P. Maumus a dîné chez Mme WaldeckRousseau ». (Autorité du 8 avril 1907.)

Montagnini écrit encore : «Au moyen de sommes d'argent, on pourrait peut-être, selon Piou, obtenir que Clemenceau soit disposé à ce que l'on laissât toutes les églises aux catholiques et qu'il travaille contre les associations cultuelles, mais Piou m'a dit qu'il faudrait une somme trop forte. » (Le Figaro, $1^{\mathrm{er}}$ avril 1907.)

Voici maintenant comment fonctionnait l'espionnage de la nonciature :

$1^{\circ}$ Fiches sur les évêques et les archevêques ;

$2^{\circ}$ Fiches sur les ecclésiastiques divers ;

$3^{\circ}$ Fiches sur les hommes d'Etat et de gouvernement ;

$4^{\circ}$ Fiches sur les catholiques et divers.

L'une signale Amette comme partisan d'accepter la loi de Séparation, mais il est mécontent qu’on ait réclamé l'avis du cardinal Richard (dont il n'est encore que le coadjuteur), et avec lequel il n'est pas d'accord au sujet de la déclaration préalable.

Une autre blâme l'archevêque Fuzet, auquel Montagnini reproche de "parler comme un Jaurès ou un ennemi de l'Eglise ». Elle le signale comme ne versant plus la quête habituelle au Comité de Terre Sainte (?) 
Une autre mentionne la protestation d'obéissance du cardinal Richard et blâme l'évêque de Toulouse pour une déclaration importune.

Telle était l'œuvre de mouchardage du représentant du Vatican en France, et nous ajoutons sans craindre de démenti, telle elle est encore aujourd'hui. Sa demeure n'est qu'un foyer d'intrigues. C'est là que « les mensualités, les pots de vin, le système des concessions dont vivent nombre de politiciens, s'établissent sur une vaste échelle. » Les marchandages se concluent sous forme de gratifications, de chèques et de billets bleus. D’où pour les profiteurs du régime la nécessité de maintenir des relations avec le Vatican. La dernière campagne cléricale en faveur des articles 33 à 43 a coûté plusieurs millions au trésor de guerre des jésuites. Mais, avec cent vingt milliards de capital, on peut perdre pour la cause une centaine de millions par an.

Pour en revenir à l'affaire Montagnini, la campagne des petits papiers cessa comme par enchantement. Mais Merry del Val la continué sous une autre forme, avec le journal La Correspondance de Rome, que les Débats qualifièrent «d'entreprise de diffamation nationale ». Une série d'articles dûs à l'inspiration du haineux cardinal traînait dans la boue la France et la République.

2 janvier 1908 : Appétit jacobin. La Correspondance se fait annoncer de Paris : "Le gouvernement français va mettre la main sur les biens de l'Institut, à cause de ses embarras financiers. »

10 janvier 1908: L’accord anglo-franco-espagnol est représenté comme une menace contre l'Allemagne et la Russie ; l'Entente cordiale, qu'il appelle « le bloc libéral occidental », lui paraît dangereuse pour les autres puissances.

20 avril 1908 : Merry del Val s'en prend à l'Angleterre, qu'il représente comme l'agent des juifs contre la Russie.

Le 10 juillet 1908, dans un article intitulé Bizance agonisante, la France est socialement tombée si bas qu'elle est comparée aux plus mauvais jours du bas Empire. 
14 août 1908 : À propos de l'échauffourée de Draveil, le gouvernement est qualifié d'assassin du peuple.

15 décembre 1908 : Il dénonce le gouvernement français comme soutien en Italie de l'agitation irrédentiste.

18 octobre 1909 : La Correspondance insinue que la France soutient l'anarchie en Espagne et en Russie. Elle prophétise un coup antiespagnol et antirusse, etc., etc...

Et la campagne continue sur le même ton, avec autant de mauvaise foi dans le fond que d'insolence dans la forme.

Enfin, ces lignes trouvées dans les papiers Montagnini laissent échapper l'aveu de la préméditation du crime contre la France et la civilisation que les jésuites s’apprêtent à commettre :

« Nous sommes à un tournant de l'histoire universelle, écrit Merry del Val à son agent d'informations; il s'agit de toutes les forces du mal, de la Maçonnerie internationale contre l'Eglise, et, dans cette lutte, La France servira d'exemple à tous !»

Ainsi, l'Eglise poussait les catholiques allemands au pangermanisme comme elle poussait les catholiques français à la revanche et au nationalisme. Le pape ne perdait aucune occasion de manifester sa bienveillance aux deux empereurs, leur adressant de temps à autre la bénédiction du " Tout-Puissant » pour eux, pour leur famille et pour leur œuvre. 


\section{XXXI \\ L’intrigue Romaine en Russie : le pope Gapone et le moine Raspoutine agents des Jésuites}

Tandis qu'en France l'action dissolvante des fils de Loyola subissait un temps d'arrêt, du fait des mesures énergiques du gouvernement, elle s'intensifiait, au contraire, chez les nations que le « Gesu » avait décidé de jeter les unes contre les autres. La Russie, avec son peuple innombrable (plus de cent trente millions d'habitants à l'époque), bénéficiait d'un prestige de force auquel les événements, à commencer par la guerre russo-japonaise, devaient infliger un cruel démenti. La puissance tsariste, toute en façade, était faite surtout de l’ignorance absolue des masses, théoriquement libérées depuis le manifeste du 19 février 1861, par Alexandre II, mais en réalité toujours esclaves, et du caractère religieux de l'autocratie qui réunissait dans la personne du tsar la direction suprême de l'Eglise orthodoxe et le gouvernement sans contrôle d'un immense empire.

Cette prétendue force, qui devait faire pencher la balance du côté où elle se porterait (triple Alliance ou Triple Entente), de quel «bourrage de crânes » ne fut-elle pas le prétexte, lorsque, de 1891 à la veille de la grande guerre, la Russie n’ayant récolté par le triple jeu de Bismarck que leurres et duperies du côté de Vienne et de Berlin, Alexan- 
dre II daigna revenir de ses préventions envers la France républicaine et rechercher son alliance contre la Triplice !

Et ce brave peuple français, qui en était resté au cri de « Vive la Pologne ! » qu'en juin 1867 Floquet, sur les marches du Palais de Justice, jetait à la face d'Alexandre II ; cette jeunesse des écoles qui, en d'ardentes réunions présidées par le vénéré Blanqui, défendait au gouvernement hésitant de déshonorer l'hospitalité française en rendant à la Russie les nihilistes réfugiés sur notre sol ; cette foule enthousiaste du noble geste de Séverine concourant à sauver de l'échafaud français ou de la potence russe Padlevski, le meurtrierjusticier du général Seliverstoff, ce grand-maître de la police russe, organisateur de faux complots terroristes; toutes et tous, enfin s'égosillèrent à crier pendant plus de vingt années : "Vive la Russie ! Vive notre alliée ! Vive le tsar! » cependant que marins français à Cronstadt (1891) et marins russes à troulon 1893) tiraient ensemble de fraternelles bordées ; que star et présidents de la république de 1896 à 1902 se rendaient de mutuelles visites. Cette confiance inouïe dans une alliance qui se bornait à l'échange de deux lettres entre les cabinets russe et français (21-27 août 1891) trouva sa plus stupide expression dans le bluff de lord Kitchener. Massacreur des Egyptiens en 1898, mais vaincu par les Boers en 1900, le fameux sirdar-pacha clamait à tous les échos : "Vous allez voir ce que vous allez voir avec le rouleau compresseur de la Sainte Russie!»

Le Vatican était-il aussi dupe de cette illusion de force compressive suffisante pour barrer la route aux Empires centraux et sur laquelle presque tous les diplomates, même de carrière, se méprirent singulièrement ? Avec des agents aussi bien renseignés que les jésuites sur les moindres faits et gestes des chefs d'Etat, il est permis d'en douter. La Russie, malgré le ralliement à l'Eglise romaine de populations dites " uniates ou grecs unis », parce qu'elles participent comme les Ruthènes (petite Russie) à la fois à la confession romaine et au rite grec,est toujours pour la papauté l'orthodoxie rivale. Pie IX, au lendemain de la répression sanglante de l'insurrection polonaise (1864), avait rompu nettement avec la Russie. Léon XIII, plus habile, nous l'avons vu, avait renoué dès son exaltation en 1878. Une suite de procédés gracieux de part et d'autre (envoi de légats aux fêtes officielles, intervention officieuse en Pologne, reconnaissance des apôtres slaves, etc...), 
le style nouveau de la papauté évitant les expressions : schisme et hérésie, à l'égard de la Russie orthodoxe, amenèrent une réelle détente, On prétend même que Léon XIII pensait persuader le tsar qu'il s'enlèverait un souci, sans rien perdre de se force, en cessant d'être chef d'Eglise et en " passant la main au point de vue spirituel à une autorité plus haute que le Saint-Synode fondé par Pierre-le-Grand ». Le pape entrevoyait naturellement des répercussions profitables à l'Eglise sur les Polonais d'abord et sur la France à la foi (chancelante ». La réalisation d'un tel projet plaçant sous l'autorité morale du Vatican un empire de plus de 130 millions d'êtres, c'était l'alliance franc)-russe à la discrétion du Saint-Siège. Donnant, donnant : ou la République française répudierait les lois laïques, et la Russie serait à ses côtes contre la Triple Alliance ; ou la France de la révolution persistait dans son œuvre de laïcité, et ce serait alors son écrasement par les empires centraux — avec la Russie même, peut-être ? — à la voix de la papauté.

Léon XIII n’eut pas la satisfaction de vivre ce rêve. Mais, sous ses successeurs, les jésuites n’ont rien négligé pour en faire une réalité. De même qu'en France, ils avaient utilisé l'importance croissante prise par les questions sociales pour rallier à l'Eglise les masses prolétariennes, par des solutions exclusivement inspirées de l'esprit religieux, c'est-à-dire confirmant le capital dans tous ses privilèges et continuant à lui asservir le travail sous l'autorité de la foi. Ainsi, en Russie, ils se servirent du mouvement nihiliste d'abord et, plus tard, de l'agitation ouvrière et paysanne, lorsque, sous la pression des désastres de la guerre contre le Japon, Nicolas II se vit obligé, par crainte d'une révolution que tout le monde pressentait, d'établir un semblant de régime constitutionnel.

Leur but était bien simple : il s'agissait d'entretenir le vaste empire des tsars dans un perpétuel état de révolte qui l'anémie peu à peu et rende illusoire le concours que la France, crédule, croyait pouvoir en attendre, dût la révolution en sortir avec l'écroulement du tsarisme. Or, c'est exactement ce qui arriva.

Trois hommes, tous trois chers aux jésuites, furent les principaux agents exécuteurs de ce plan conforme à la tactique des disciples de Loyola. L'écrivain russe Tolstoï, auquel le snobisme a fait une re- 
nommée que ne méritait pas certes son naturisme mystique, mais que lui valurent surtout les condamnations artificieuses du Saint-Synode et la propagande du "tolstoïsme » organisée par les jésuites dans toutes les nations. On peut admettre, à la rigueur, que « ce grand sentimental, plus grand naïf encore, sans culture scientifique et sans esprit critique, sorte de poète religieux ne pouvant que mettre les évangiles en roman ", ainsi que l'a défini Emile Hureau, fut de bonne foi, mais à ce titre plus dangereux encore. Dans tous les cas, il est peut-être l'homme qui a contribué le plus aux divers échecs de la révolution russe jusqu'en 1917, tant il est vrai qu'il ne suffit pas de broder de belles phrases et de douces maximes archi-connues pour délivrer un peuple, et que cette littérature qui fleure l'encens et se déroule comme un cantique, endormit plutôt les masses par sa puérile morale, qu'elle n'aida à leur affranchissement. C'est en se réclamant de cette mystique aux allures patriarcales que le pope Gapone, un aventurier celuilà, qui émargeait à la fois - la preuve en est faite - à la caisse de la Curie romaine et à celle de la police russe, créait dès 1904 des sociétés ouvrières et jouait absolument, en Russie, le même rôle que nos « sillonistes » en France. Au début de 1905, il menaçait le gouvernement d'une grève générale, et, passant de la parole à l'action, adressait aux ouvriers un violent appel pour aller porter une supplique au tsar. Mais lorsque, le 22 janvier 1905, à la tête d'une foule énorme, Gapone approchait du palais impérial, une rafale de mitrailleuses fauchait des milliers de victimes, tandis que le pope Gapone s'enfuyait... jusqu'en France.

Le misérable qui avait livré au massacre cette foule d'honnêtes travailleurs, pour affaiblir d'autant les forces révolutionnaires, osa revenir en Russie et conseiller aux ouvriers d'accepter le rescrit impérial du 30 octobre 1905, par lequel Nicolas II instituait une Douma ou assemblée législative avec quelques bribes de liberté. Mais, malgré la cynique audace avec laquelle il jouait son rôle, le parti révolutionnaire acquit la preuve de ses relations avec la police et les jésuites dont il avait été l'élève, et, le 10 août 1906, attiré dans une villa hors de Saint-Pétersbourg, il était jugé et étranglé par quatre hommes qui l'accrochèrent ensuite au plafond de la salle. Juste fin d'un traître qui avait abusé les socialistes de tous les pays, et dont Jaurès lui-même, avec cette candeur qui s'apparente souvent aux nobles et hautes consciences comme l'était la sienne, avait magnifié l'action dans plusieurs 
articles. La Civita Cattolica, organe de la procure des jésuites à Rome, qui fournit au pape son confesseur, et le Saint-Synode, qui avaient partie liée, durent bien rire de l'emballement d'un tribun français.

Le troisième personnage, le moine Raspoutine, est encore aujourd'hui pour bien des gens un être de mystère, dans lequel ils verraient presque une victime.

La vérité, c'est que Raspoutine et Gapone eurent les mêmes patrons et obéirent à la même consigne : le moine s'était réservé la Cour et l'aristocratie, sur lesquelles ses pratiques étrangères, ses vices effroyables, devaient jeter le plus possible de discrédit. Gapone avait la tâche de soulever le peuple, de le mener à la boucherie à l'occasion. Tous deux remplirent leur office en conscience, si pareille expression peut être de mise avec de tels misérables. Et tandis que le moine, se croyant invulnérable, entraînait dans la pire abjection l'impératrice, le tsar et leur entourage, les caisses publiques se vidaient, les arsenaux restaient sans munitions et sans armes, les intrigues faisaient succéder les disgrâces aux disgrâces; l'armée n'était plus qu'un troupeau d'hommes sans cohésion, et, au premier choc, ce fut, malgré quelques succès secondaires, le refoulement, la débandade, et... la paix de Brest-Litovsk, qui mirent la France et ses alliés à deux doigts de la défaite.

Les jésuites pouvaient être satisfaits, ils avaient encore bien travaillé ad majorem dei gloriam. 


\title{
XXXII \\ Au seuil de la grande guerre
}

\author{
Le plan du « Gesu » en 1911
}

Nous abordons une période (1911 à 1918) d'une tragique ordonnance, et il est à prévoir que les jésuites d'abord, et aussi les braves gens pour lesquels tant de forfaits paraissent invraisemblables, se refusent à y croire.

Aux protestations des premiers nous ne ferons pas l'aumône d'une réponse. C'est leur rôle, comme ils l'ont fait pour les Monica Secreta, de nier l'évidence même ; mais aux seconds, nous leur demanderons de noter que cette étude exclut tout travail d'imagination, qu'elle produit des preuves irrécusables pour toutes les affirmations qu'elle énonce, et qu'elle en indique les sources. A moins d'être volontairement sourds et aveugles, tous ceux qui nous font l'honneur de nous lire ne pourront, si peu que ce soit, incriminer notre bonne foi. Ce n'est pas de l'histoire romancée, c'est l'histoire tout court que nous livrons à leurs méditations.

Avant d'en arriver à l'acte décisif auquel ils étaient résolus, malgré Pie X et Rampolla, si d'autres moyens ne leur réussissaient pas, pour déclancher la guerre, qu'ils voulaient à tout prix, les jésuites mirent tout en œuvre contre la France pour faire naître l'acte ou le geste hostile qui aurait été le signal de la conflagration européenne. Humilia- 
tions, provocations, bravades, rien ne lui fut épargné, à leur instigation. Tantôt, c'était l'Autriche, dont le sénile François-Joseph, qui fut toute sa vie le pantin des femmes, affectait d'ignorer officiellement l'un de nos très hauts personnages consulaires, parce que celui-ci avait dédaigné la bénédiction religieuse ; tantôt, c'était l'Allemagne, qui, après n'avoir fait aucune objection, selon la déclaration même du chancelier de Bulow, à l'accord hispano-anglo-français du 8 avril 1904, nous laissant les mains libres au Maroc, envoyait à deux reprises différentes (31 mars 1905 et 1911) l'empereur Guillaume II à Tanger d'abord et Agadir ensuite, sous le prétexte d'une croisière contre l'action de la France, qu'il accusait d'avoir transgressé les accords de 1904 et d'Algésiras 1906. Puis c'étaient les incidents de la légion étrangère à propos de l'arrestation de quelques déserteurs allemands, etc., etc...

Chaque fois, avec le souci d'éviter la catastrophe que l'Eglise s'efforçait de rendre inévitable, la République, sous les ministères Briand (1909-1911), Monis (1911), Caillaux (1911-1912), dédaigneuse de l'injure, se refusant à prendre au sérieux la provocation allemande ; allait jusqu'à s'amputer largement d'une partie du Congo par le traité du 4 novembre 1911, pour satisfaire aux exigences de l'Allemagne réclamant une compensation au protectorat marocain qu'elle voulait bien ne plus disputer. La guerre !... Certes, les peuples ne la voulaient pas. C'est avec une résignation douloureuse, parfois avec consternation, qu'elle était redoutée de la foule des travailleurs français, et même en Allemagne il existait des « forces de paix, mais inorganisées et sans chefs populaires ». (Livre Jaune 1914, $\mathrm{n}^{\circ}$ 5.) Scheidemann et Kautsky, en 1908, mettaient le monde en garde contre la mauvaise foi «traditionnelle dans la maison des Hohenzollern ». Il est vrai que, six ans après, le parti socialiste en majorité se ralliait à la politique de guerre.

On nous objectera que mettre au compte de l'Eglise seule la responsabilité de la guerre de 1914, c'est méconnaître tout à la fois la situation politique et économique de l'Europe en 1913 et l'état d'esprit des peuples des empires centraux à la même époque. Nous convenons volontiers que la formation et le développement de la Prusse avaient fait d'elle un organisme «condamné à l'agression constante ou à la disparition ; que l'unité allemande, ce résultat d'une 
rigide soumission à une administration sans souplesse », avait abouti à cet immense orgueil de voir dans le peuple allemand « le peuple élu de Dieu » et de mettre "l'Allemagne au-dessus de tout ». De là à convoiter l'exploitation de l'Univers, avec un chef impulsif et mégalomane dangereux, il n'y manque que l'excitation constante d'un complice dont l'unique préoccupation est de faire son profit du crime auquel il aura poussé les autres. Or, tel fut - comme nous ne cesserons de le témoigner par les témoignages les plus accablants et que rien, absolument rien, n'est venu jusqu'ici détruire ou seulement atténuer - tel fut le rôle de l'Eglise romaine et des jésuites qui la dirigeaient sous Pie $X$ et la possèdent aujourd'hui tout entière sous Pie XI, profès des trois vœux de la Compagnie de Jésus.

De même que la guerre de 1870-71 fut décidée au Concile du Vatican en 1869, de même la guerre de 1914 fut résolue au Congrès eucharistique de Vienne en 1912, où le légat du pape, tel un souverain traitant de puissance à puissance, prit aux côtés de François-Joseph la place d'honneur, et où, tant au-dedans qu'au-dehors du Congrès, les propos les plus désobligeants, enveloppés de cette ironique courtoisie diplomatique spéciale à nos Talleyrand modernes, furent tenus contre la France, « la fille impie de l’Eglise, qui avait mérité tous les châtiments ».

Mais l’impartialité nous oblige à reconnaître que la prévision du conflit sanglant qui devait ruiner l'Europe était accueillie avec une joie odieuse par la presse cléricale et nationaliste française. Les inspirations qu'elles puisaient auprès de la Civita Cattolica laissaient entendre qu'un bain de sang était encore ce qu'il y aurait de mieux pour « régénérer la France et la débarrasser de la laïcité ».

L’Église a si bien voulu la guerre qu'elle avait pris toutes les mesures les plus rigoureuses pour empêcher toute action individuelle ou collective de manifester pour la paix ou de chercher à abréger les hostilités.

Elle redoutait le mouvement d'émancipation qui soufflait alors sur le monde, et mettait son influence en péril. Son but a été l'écrasement de la démocratie grandissante, et surtout l'anéantissement du socia- 
lisme, qui portait ombrage aux autorités de ses chers fidèles, les capitalistes.

Non seulement elle conçu, préparé, et nous oserons même dire, conduit la guerre, mais encore elle en a réglé d'avance les résultats qu'elle en escomptait. Dès 1911, pendant la période du Carême, un monsignor anglais, Hugh Benson, prélat domestique du pape, publiait à Rome un livre intitulé : " La grande guerre européenne de 1914 (The great European War of 1914). Confident des plans et des espoirs du " Gesu », il les révélait ainsi :

« La France vaincue, réduite à n'être plus qu'un très petit pays ( $a$ very small country), sera, par compensation, redevenue la fille aînée et désormais docile de l'Eglise, sous une monarchie intensément catholique et vouée à la gloire de Notre-Dame de Lourdes. Le pape sera devenu le souverain temporel de l'Italie, dont l'empereur d'Autriche ne sera qu'un simple administrateur (But the Emperor of Austria administrers), et l'Angleterre, convertie en masse au papisme, aura rendu à l'Eglise romaine Westminster, toutes les cathédrales, églises et propriétés ecclésiastiques. Elle mettra sa justice au service de l'Eglise et pendra les hérétiques comme au moyen-âge.

« L'Irlande aura conquis son indépendance et conquerra tour à tour, par le flot de ses croyants, l'Australie et l'Amérique du Nord, qui, submergées, seront devenues entièrement irlandaises et catholiques (entirely Irish and Catholis).

«Les ordres religieux prendront possession du pays et de toutes les propriétés, de telle sorte que, en fait, toute l'Irlande sera un enclos d'ordre religieux.

«La Chine et le Japon convertis par les missionnaires recevront leur récompense : une grande partie du Far West sera donnée au Japon ; quant aux Etats-Unis, brisés en trois tronçons, l'un sera rattaché au Canada et formera une colonie américaine.

« Et quant aux Etats du Sud, latinisés par l’Eglise, ils sont attribués, avec tout le Mexique et ce qu'on appelle l'Amérique du Sud, à S. M. catholique le roi d'Espagne ! » 
On aurait peut-être tort de sourire de ce projet, car chaque jour qui passe, et nous en avons déjà fourni des exemples, le rapproche un peu plus de la réalité.

La propagande effrénée de l'Eglise romaine dans tous les mondes, la complicité qu'elle trouve dans tous les pays auprès de leurs dirigeants,sous prétexte de tolérance, les immenses ressources qu'elle peut mettre en jeu, tout indique que le plan de 1911 n'est pas aussi fantaisiste qu'on pourrait le croire. 


\section{XXXIII \\ L’Église catholique, apostolique et romaine est seule responsable de la guerre de 1914}

\section{Les preuves capitales}

\section{$\underline{\text { Retour à la table des matières }}$}

On peut épiloguer à perte de vue sur les responsables de la guerre : prétendre que ce sont les empires centraux, ou encore la France et la Russie ; dire que, si l'Allemagne et l'Autriche ont rendu la guerre possible, la France et la Russie l'ont rendue inévitable : la première, pour reprendre l'Alsace et la Lorraine ; la seconde pour la possession de Constantinople et des Détroits ; invoquer la force d'expansion de la Russie, le sentiment de revanche en France, l'égoïsme de l'Angleterre et les hésitations de lord Grey, attendant jusqu'à la dernière seconde de l'heure décisive pour prendre une résolution qui, avec vingt-quatre heures d'avance, pouvait sauver des millions de vies humaines; et, surtout, faire état de l'aveu de culpabilité de l'Allemagne inscrit dans l'article 231 du Traité de Versailles, alors que les auteurs du traité ignoraient tout, pour la plupart, des documents diplomatiques versés depuis au débat et qui l'éclairent d'un jour plutôt défavorable à leur opinion personnelle. 
Malheureusement pour le Vatican, les faits sont là, innombrables, indéniables, qui parlent plus haut que toutes les discussion, plus nettement que toutes les controverses, et établissent que : l'Eglise catholique, apostolique et romaine est seule responsable de la guerre de 1914, qu'elle l'a voulue et l'a rendue possible.

D’abord, comment admettre que la papauté, cette "grande puissance morale du monde ", comme la qualifient emphatiquement, surtout en France, ceux qui composent volontiers avec elle, n'aurait pas eu, de par cette puissance même, le pouvoir de conjurer cette catastrophe, comme eût dû le faire le pontife d'une religion prétendue de charité et d'amour du prochain ? La carence de cette force spirituelle qui, selon Montalembert, « n'est ni l'esclave, ni la cliente, ni l'auxiliaire de personne ", de son représentant, " père des princes et des rois, pasteur de l'univers sur terre ", est : ou bien un aveu d'impuissance, ou bien un acte de complicité. Il faut choisir. L’Église esquive le dilemme en rejetant sur « le nommé Dieu » sa responsabilité. Cette entité morbide dont l'humanité souffre depuis vingt siècles est l'alibi moral excipent les prêtres de toutes les religions passées et présentes, pour se disculper d'une complicité quelconque avec les massacreurs auxquels ce Dieu sert également d'emblème.

Cette simple constatation suffirait à elle seule pour justifier l'accusation que déjà, en présence de la tournure inquiétante des événements, les esprits avertis sur la duplicité politique de l'Eglise et la manière d'agir des jésuites portaient contre eux : " Si la guerre éclate, entendez-le bien, femmes qui allez au confessionnal, hommes qui considérez que l'Eglise est une garantie d'ordre et de paix, n'allez pas chercher les responsables ailleurs qu'au Vatican, car c'est lui qui en sera responsable, comme il a été responsable de la guerre de 1870-71 (Yves Guyot : Le Bilan de l'Eglise, 1912, Paris.)

Tous les libres penseurs avaient cette même intuition du prochain avenir sanglant qui attendait l'Europe, et, deux heures avant d'être assassiné par l'un de leurs affiliés, Jaurès, à la bibliothèque de la Chambre, ne faisait qu'exprimer une opinion identique : " Ah ! disaitil, on a fort blagué Eugène Sue, mais tout de même, si c'était encore un coup des jésuites!»Et il ajoutait, faisant allusion à la longue conversation de François-Joseph avec son confesseur, quelques jours 
auparavant : "Comment ne pas se dire, pour qui connaît toute cette filiation cléricale, que Rome et les jésuites n’ont pas pesé dans la balance de la destinée, à l'heure où l'empereur d'Autriche, par son ultimatum à la Serbie, a lancé toute la machinerie qui aboutit à une guerre européenne ? »

Il y a, en outre : les menaces prophétiques, les faits et gestes des cardinaux, archevêques, évêques, prêtres, les articles des feuilles cléricales et catholiques de tous les pays avant et pendant les hostilités, et qui, tous, sur l'ordre de Rome, ont attisé les haines, prêché dans tous les pays la guerre à outrance, et accablé de mépris et de sarcasmes toutes les manifestations en faveur de la paix.

Toutes les occasions catastrophiques, le clergé français n’a cessé, pendant les vingt années qui ont précédé la guerre, de les exploiter contre la France. Le moindre malheur public devient des ses sermons « un châtiment mérité par elle pour l'abandon de ses traditions » traduisez: de la politique cléricale — «Dieu ne voulant pas l'abandonner devait soumettre la France à l'expiation ». C'est ainsi que s'exprime le P. Olivier, à Notre-Dame, après l'incendie du bazar de la Charité (9 mai 1897). Le P. Didon, en juillet 1898, renchérit encore : " Allons, généraux vaincus, frappez d'estoc et de taille sur ces têtes civiles, pour que le fer s'affile dans les entrailles et que le sanglant bénisseur puisse renifler ses cadavres à son aise. » Tel est le début d'un appel aux chefs de l'armée contre la République, au cours duquel le dominicain sanguinaire fait l'éloge enthousiaste de la force pour " couper les têtes, sévir et frapper ». On devine sur qui... Enfin, brochant sur le tout, le P. Monsabré s »écrie : «Ce qu'il faudrait, pour régénérer la France comme tout le reste, c'est une bonne invasion de cosaques, de nègres, si vous voulez, pour tout balayer, tout emporter... Puis, comme jadis, l'Eglise viendrait auprès de ces simples et doucement, persuasivement, leur passerait la main sur l'échine et les apprivoiserait. »

Les hostilités sont à peine commencées que des "intellectuels ", parmi lesquels des académiciens, au lieu de se borner à exposer simplement la nécessité de la défense, osent glorifier la guerre comme génératrice de toutes les vertus. En chaire, les sermons de presque tous les curés exaltent la théorie odieuse de «l'expiation ». " Sépara- 
tion, expulsion, laïcisation sont des étiquettes sous lesquels sont renfermés des crimes sans nombre. Mais les crimes appellent des châtiments (L'Ami des Familles, 20 septembre 1914). La guerre est la colère de Dieu s'exerçant sur la France coupable. » Pour cette déclaration, le curé de Montalien (Isère) est arrêté, puis... relâché. (Temps, 13 octobre 1915).

Un mois plus tard, c'est l'abbé Lagardère - un de ces aumôniers que le renégat Millerand a réintégrés dans l'armée — qui, à l'occasion d'un service anniversaire d'un officier tué à l'ennemi, prononce à peu près les mêmes paroles, et auquel — chose extraordinaire - le ministre de la Guerre inflige une punition. (Temps, 12 novembre 1915). Mais aucune sanction ne fut prise contre un curé de Saint-Cyr-l'Ecole qui, le 15 août 1915, prononçait les paroles suivantes : " Pour la fête du 15 août, nous avons consacré toutes nos prières à la Vierge Marie, comme autrefois le roi Louis XIII, puisque les individus qui sont à ma tête de notre France ne sont pas capables de la sauver » (!)

C’est par milliers que nous pourrions citer de semblables exemples.

Il y eut aussi des trahisons : Un bénédictin français Dom Germain Morin, resté en Allemagne après la déclaration de guerre, obtint les faveurs du kaiser, en mettant sa plume au service de la propagande allemande (Le Vatican et la Guerre, (Paris, 1926).

Enfin, il y a les preuves par l'action directe du Vatican et des jésuites en France. Contre celles-là, aucun démenti n'est possible. C'est ainsi que pendant les années qui ont précédé la guerre et pendant toute la durée des hostilités, l'Eglise a accaparé l'armée pour la doter d'officiers sortant des jésuitières. Lors de son trop court passage au ministère (1902-1905), le Général André a pu constater et déclarer publiquement : «Qu'il n'était pas d'exemple d'un officier auquel le fait d'être républicain n’ait pas nui. »

On s'explique aujourd'hui l'insuffisance de la préparation de notre défense nationale et la conduite meurtrière de la guerre par un étatmajor qui avait reçu pour consigne d'exécuter aveuglément le plan de défaitisme jésuitique dressé par les bons pères, et qui comprenait, en première ligne, la campagne de calomnies systématiquement organi- 
sée contre les chefs républicains : Percin, Sarrail et tant d'autres. C'est cet état-major qui, par son ignorance crasse des méthodes de guerre et même des ressources du pays, livra notre fer, notre houille à l'ennemi ; qui se refusait avec un Castelnau - lequel ne devrait songer qu'à se faire oublier - à croire à l'utilisation des réserves allemandes (Morizet : Le Plan 17, Paris, 1920) ; c'est cette réunion des plus hauts gradés, dénommée Conseil supérieur de la Guerre, mais volontairement cent fois inférieure à sa tâche, qui manœuvrait à son gré le père Joffre sans qu'il s'en doutât, qui le 28 août avait donné l'ordre d'abandonner Paris sans combattre et refusait, comme Galliéni le proposait, d'attaquer entre la Marne et la Seine.

Galliéni passa outre et le plan des jésuites échoua. La France laïque ne fut pas écrasée. Et pourtant, dès 1911, les jésuites avaient manœuvré en conséquence. Sur 33 postes du conseil supérieur de guerre, de l'état-major et du gouvernement de Paris, 11 étaient occupés par des cléricaux, 5 par des douteux et 17 par des républicains. Mais en 1913, les jésuites qui ont gagné à leur cause le renégat Millerand occupent 18 postes sur 30, les républicains en comptent 5 et les douteux 7. Cinq sur trente! C'était toute l'armée jésuitisée. Aussi, avec leur coutumière hypocrisie, les jésuites affectèrent de glorifier la victoire de la Marne comme un miracle dû à leurs prières.

Les disciples de Loyola avaient peuplé de leurs élèves « la carrière ». L'incident soulevé lors du coup d'Agadir par le jésuite blanc de Selves, héritier de la duplicité traditionnelle de son oncle de Freycinet, fut autant le fait des "jeunes hommes qui l'entouraient » que le désir du perfide de Selves, gagné lui aussi à la cause des jésuites, de tout envenimer, tandis que son président du conseil, Caillaux, s'efforçait d'arranger les choses et réunissait une fois encore à éviter la solution sanglante. M. Cambon n'a-t-il pas écrit à ce propos « qu'il est difficile de gagner la bataille quand on sent derrière soi certaines gens qui souhaitent qu'on la perde »?

Les preuves vont crescendo de la préméditation du crime de l'Eglise contre la France républicaine et laïque. Les deux suivantes sont d'une telle force probante qu'elles se passent de longs commentaires. 
$1^{\circ}$ Le catéchisme du diocèse de Paris, édition de 1908, page 77 , reproduisant les dix commandements, énonce ainsi le $5^{\circ}$ :

Homicide point ne sera

De fait ni volontairement.

Mais six ans plus tard, alors que la guerre pourrait encore évitée, que dans tous les cas, rien ne dit qu'elle aura lieu, l'édition du même catéchisme datée du 2 juillet 1914 contient le même commandement, mais avec une variante :

Homicide point ne sera

Sans droit, ni volontairement.

Evidemment, l'Eglise seule pouvait être sûre que l'égorgement allait suivre, puisqu'elle l'avait préparé. Elle avait révisé le catéchisme en conséquence et contrairement à la défense canonique ratifiée par tous les Conciles: Tu ne tueras point.

$2^{\circ}$ Entre les deux éditions de ce petit livre que l'ambassadeur Claudel, notre Polieucte moderne, considère comme le seul chef-d'œuvre littéraire de l'humanité, ce qui n'est pas flatteur pour elle, mais témoigne de la part du néophyte ultra d'une superhystérie religieuse dont s'amusent fort nos amis yankees, l'épiscopat français avait fait une singulière et troublante démarche auprès du Vatican. Ces messieurs, ralliés par de Mun au programme de la revanche, venaient demander au pape Pie $\mathrm{X}$ un «bref » autorisant les jeunes séminaires ou prêtres à tuer, à la guerre, sans encourir la déchéance canonique. Sarto, que le haut clergé appelait ironiquement « le curé de Venise » et dont le cardinal Mathieu disait élégamment qu'il menait la barque de saint Pierre à la gaffe, le bon Sarto fut, paraît-il, quelque peu estomaqué d'une telle requête, que, dans son esprit simpliste et tenu dans l'ignorance des intrigues jésuitiques, rien ne justifiait. Néanmoins, sur un avis qui pouvait presque passer pour un ordre, de la Curie romaine, il expédia le «bref ». Deux années encore nous séparaient de la guerre. Prendre une telle précaution à si longue échéance, n’est-ce pas, au vrai, la preuve que l'Eglise savait d'ores et déjà la guerre inévitable, parce qu'elle la voulait et avait tout fait pour qu'elle éclatât ? 
Enfin, après les preuves,nous avons les aveux signés des coupables eux-mêmes. C'est d'abord le télégramme expédié à la veille de la guerre par le ministre bavarois près du Vatican, $\mathrm{M}$. von Ritter, a son gouvernement, le 17 juillet 1914.

Baron Ritter à gouvernement bavarois :

Le pape approuvera une action énergique de l'Autriche contre la Serbie. Le cardinal secrétaire d'Etat espère que, cette fois, l'Autriche tiendra bon. Il se demande quand elle pourrait faire la guerre si elle n'était pas résolue à repousser par les armes un mouvement étranger qui a déterminé le meurtre de l'archiduc et qui, vu la situation présente de l'Autriche, menace son existence. Dans ses déclarations se manifeste la crainte de la Curie romaine contre le panslavisme.

\section{Signé : RITTER.}

La publication de ce document d'une importance capitale sur les origines de la guerre a causé, à Rome surtout, et dans le monde entier, une émotion énorme que la Vatican s'efforça d'atténuer en le présentant comme le point de vue personnel du cardinal Merry del Val. Mais l'importance du document Ritter est telle qu'il apparaît comme invraisemblable que Merry del Val en ait été l'unique inspirateur. Enfin, en juin 1915, les journaux des empires centraux n'hésitent pas à publier que parmi les buts de guerre de ceux-ci figure la délivrance du SaintSiège. Aussitôt, le Vatican, gêné, on s'en doute, par cette indiscrétion, faisait déclarer le 25 juin par le cardinal Gasparri « qu’il n’attend le règlement convenable de la situation du Saint-Siège que du triomphe des sentiments de justice dont il souhaite la diffusion de plus en plus large au sein de la nation italienne ". Mais comme corollaire à cette attitude de fausse dignité offensée, l'Eglise allait, selon l'expression d'un organe catholique, pendant quatre années de guerre, "forger à l'Italie cette conscience nationale que devait hâter l'évolution souhaitée par le Vatican. »

Les preuves ci-dessus ne concernent en partie que les préparatifs belliqueux du Vatican avant l'explosion formidable qui va ravager l'Europe. L'acrtion des jésuites pendant la guerre en révèle une foule d'autres qui presque quotidiennement les accusent de plus en plus et 
finissent par inspirer aux sincères catholiques eux-mêmes une sorte de mépris pour leur chef et son Eglise. 


\section{Les crimes des Jésuites}

\section{Le cardinal Rampolla meurt empoisonné}

La longanimité de la France, qui s’était affirmée à diverses reprises dans sa politique extérieure depuis 1909, s’avéra plus inquiète avec la présidence Poincaré, qui succéda à la présidence Fallières (17 janvier 1913). On en eut la preuve manifeste, lorsque le ministère Briand, battu au Sénat (18 mars 1913) sur la proportionnelle, fit voter (13 juillet 1913) le retour au service de trois ans, malgré la très vive et très juste opposition des républicains, qui jugeaient sainement - et la guerre leur donna que trop raison! - qu'il n’était pas nécessaire, pour savoir défendre son foyer, de passer trois années d'abrutissement à la caserne. Non moins absurde et même dangereuse fut cette politique dite " d'apaisement » que le nouveau ministère prétendit pratiquer vis-àvis de l'Eglise en déclarant solennellement — éternelle comédie ! les lois scolaires et de séparation intangibles «à condition de les appliquer sans tracasseries et sans partialité ». Une telle compréhension des devoirs d'un gouvernement se disant républicain, qui jette luimême la suspicion sur les lois qu'il est chargé de faire respecter, ressemblait fort à une trahison. Dans tous les cas, elle provoquait chez les cléricaux un mépris plus grand desdites lois et une audace croissante dans l'assaut qu'ils leur livraient quotidiennement. Témoin l'histoire 
rapportée dans l'Homme Libre (5 juin 1913) par Clemenceau, de cet instituteur de Couffoulen (Tarn), contre lequel l'évêque du diocèse, à propos de manuels scolaires, avait ameuté toute la population : "On parle de le tuer comme un chien, et l'on tira, en effet, des coup de fusil de la rue dans sa chambre, où il y avait lieu de croire qu'il se trouvait avec sa femme en ce moment. Précédemment, les deux infortunés avaient reçu une lettre abominable signée de l'enfant qu'ils venaient de perdre, pour leur annoncer du séjour des bienheureux qu'ils étaient damnés... Mais cela n’est rien encore. Au procès, l'accusé, contre qui s'élevaient des charges abominables, est acquitté par le jury. Mais le misérable instituteur, avec ses deux balles à la tête de son lit, qui sont venues là sans doute de leur propre mouvement, croirait-on qu'il avait voulu se porter partie civile et demander la somme de un sou à titre de dommages-intérêts ? On le lui refuse, bien entendu, et le voilà condamné aux dépens. Cela lui coûtera quelques centaines de francs qu'on ait voulu l'assassiner...

« Il y a quelques mois, l'évêque de Poitiers, s'étant mis en révolte contre un arrêté du maire, tenta de faire du désordre dans la rue. Commencement de poursuite aussitôt arrêtée par ordre du gouvernement chargé de faire respecter la loi...»

Et Clemenceau de conclure : "Voilà où nous en sommes de la République française sous le règne de $\mathrm{M}$. Poincaré. L’alliance du fauteuil et de l'autel produisent de ces résultats. »

Et c'est parce que non plus dans une ou deux localités, mais des coups de fusil qu'on n'ose plus tirer, instituteurs et institutrices laïques sont encore traités comme des bêtes fauves par la tourbe cléricale et ses prêtres, que nous avons cru utile de reproduire au long le véhément réquisitoire que Clemenceau signerait encore aujourd'hui sous le proconsulat cher à l'Eglise de M. Poincaré.

On comprend qu'en présence de tels faits, la majorité républicaine de la Chambre se soit regroupée, comme aux grands jours de bataille, contre le péril clérical, et qu’à la première occasion (débat sur l'immunité de la rente), elle ait signifié son congé au ministère Barthou. Nous devons impartialement reconnaître qu'avec une correction toute constitutionnelle, M. Poincaré suivit les indications de la majori- 
té et constitua avec le sénateur Gaston Doumergue un ministère radical-socialiste (décembre 1913) auquel son chef assigna pour tâche unique : les élections législatives de 1914.

Nous touchons ici au point culminant des tragiques événements qui servent, pour ainsi dire, de prologue à la guerre de 1914. C'est la phase des crimes perpétrés par les jésuites pour faire triompher l'Eglise de leur idéal. À toutes les époques de son histoire, l'Eglise a employé le crime, soit contre les particuliers, soit contre les collectivités, pour parvenir à ses fins. Sa théologie autorise le meurtre sous toutes les formes et par tous les moyens, quand le bien de l'Eglise l'exige. Le crime politico-religieux a été légitimé par les doctrines des Pères les plus illustres de l'école d'Escobar (Ribadana, Scribanus, Mariana, Verana, Constantinus, Sâ et des centaines d'autres), pour le salut de l'orthodoxie. Ces doctrines, le Vatican ne les a jamais condamnées, parce que " c'est la voix même de Dieu qui dicte ces crimes »; l'Eglise, sous la domination des jésuites, les a faites siennes et en impose la pratique absolue par l'obéissance passive.

Le supérieur peut ordonner un crime, le jésuite doit obéir aveuglément. Il ne doit pas raisonner un ordre, parce qu'il ne doit pas croire que son Dieu permettait dans l'exercice de la sainte obéissance une erreur grave. Dans tous les noviciats, dans tous les séminaires de France, cette doctrine est enseignée à l'aide du Manuel de la Perfection chrétienne, du P. Rodriguez : "A l'appel de son supérieur, le religieux quittera tout : il n'achèvera pas une lettre commencée... »

Nous avons d'ailleurs exposé cette théorie de l'obéissance passive et du crime qu'elle peut exiger de la part des mystiques fanatisés en traitant des Monita Secreta et du Code des Jésuites. Il était pourtant nécessaire de la rappeler, ne fût-ce que pour démontrer l'absolue sincérité des faits qui vont suivre.

Maîtres du Vatican sous le pontificat de Pie X, les jésuites, avec Merry del Val, en défendaient jalousement l'entrée à toute autre politique que la leur. Leurs intrigues avaient réussi à faire du Sacré Collège une assemblée composée pour les trois quarts de cardinaux italiens et allemands et toute dévouée à la Compagnie de Jésus. Néanmoins, les anciens partisans de Léon XIII ne perdaient pas tout espoir 
de reprendre un jour le siège apostolique. L'âge et la santé très chancelante de Pie X autorisaient Rampolla. Nombreuses étaient les entrevues et fréquentes les conciliabules, tant à la villa Malta (Italie) où résidait, alors qu'il était ambassadeur à Rome, le prince de Bulow, qu'à sa résidence de Lucerne, entre les délégués des empires centraux, les cardinaux allemands et les représentants des jésuites, dont le général résidait à Zizeis, près de Coire. Rampolla, qui ne quittait jamais Rome, prétextant au début de 1913 un voyage en Suisse pour raison de santé, s'était installé à Einselden, où il préparait sa candidature dans ces réunions que l'on a appelées « le conclave d'Einselden ». deux candidatures seules paraissaient probables à la succession éventuelle de Pie X : celles des cardinaux Gasparri et della Chiesa, ce dernier ancien secrétaire et ami " fidèle » du cardinal de Rampolla. Cette fidélité n'allait pas cependant jusqu'au sacrifice de la tiare en faveur de son ancien maître et ami. Les jésuites, avec leur coutumière habileté, se montrèrent aussi bien disposés pour l'un que pour l'autre, et le pacte conclu avec Rampolla, qui semblait s'être rapproché des empires centraux et de l'Autriche en particulier, cause de son échec au pontificat, le fut aussi avec Della Chiesa.

Mais en réalité, Rampolla était tenu en défiance par les jésuites, qui redoutaient un retour de sympathie de sa part pour la France et, dans tous les cas, ne le trouvaient pas suffisamment porté à favoriser leurs desseins. Seulement, c'était l'obstacle. Sa suppression s'imposait. Pas un instant ils n'hésitèrent. Écoutons l'abbé Daniel, témoin de ces journées tragiques, nous les rapporter dans son livre Le Baptême de Sang, malgré l'excommunication majeure dont l'auteur et les lecteurs furent solennellement frappés par le cardinal Amette le 18 janvier 1919 :

« Le 10 décembre 1913, le cardinal Rampolla était encore en bonne santé et avait fait sa promenade habituelle au Corso.

«Le 15, il se sentit fatigué et ne dit pas la messe, sur les instances de son valet.

« Le soir, à 11 heures, le cardinal reçut la visite habituelle de son secrétaire, qui ne remarqua rien d'anormal. Cependant, le valet se dispose à passer la nuit auprès de son maître. Le cardinal s’y oppose, il 
n’en voit pas la nécessité. Le valet se retire, pour revenir une heure après. Il trouve son maître un peu plus oppressé et, comme il l'a déclaré lui-même dans l'enquête, cette fois, il commet l'imprudence d'aller chercher lui-même le docteur. Il se hâta...

« Dans l'intervalle, l'alarme avait été donnée dans la maison. Par qui ? On ne sait. On accourut, les familiers se pressèrent dans l'antichambre... Il y eut des allées et venues dans les couloirs, des courses précipitées de la chambre à l'office... Beaucoup de zèle, même un excès de zèle... Chacun avait son traitement qu'il offrait...

« Le retour du valet avec le docteur ne fut pourtant pas long. Mais, quand ils arrivèrent, il était trop tard. Rampolla n’était plus.

« Cette fois encore il était évincé de la papauté par un veto inexorable.

« On parla d'abord d'un testament que l'on ne retrouverait pas. Les scellés furent apposés sur les appartements, qui occupaient une partie des dépendances de la Basilique.

« Le 25 décembre, le Messagero fit savoir l'inutilité des recherches du testament.

« Le 27, le Giornale d'Italia parlait pour la première fois d'une cassette que le cardinal s'était fait remettre dans les mains, une heure avant sa mort, par son secrétaire ; pendant que l'on procédait à la toilette posthume, la cassette avait été aperçue encore une fois, mais à partir de cet instant on perd ses traces.

« Il est certain que Berlin aurait payé bien cher une pareille restitution.

« On annonça enfin une autopsie légale et une exhumation du cadavre. Merry del Val fit publier qu'il ne s'opposait pas à l'exhumation quoiqu'il en eût le droit. Il voulait montrer aussi qu'il méprisait toutes les insinuations qui occupaient l'opinion. » 
Le ton et l'allure de cette page extraite du Baptême de Sang surprendront peut-être. On devine en effet, à la lecture, que son auteur, l'abbé Daniel, témoin muet des diverses tragédies dont la Rome papale fut alors le théâtre, a dû laisser dans l'ombre bien des détails d'une précision écrasante pour les coupables. On sera moins étonné lorsque l'on saura que son manuscrit, déposé le 3 mars 1917 à la censure, que la guerre avait fait rétablir, fut interdit en bloc et qu'on lui refusa l'imprimatur intégralement. Mais il tint bon, et coupa et ratura tout ce que les censeurs exigèrent, voulant à tout prix livrer au public, sinon la vérité tout entière, au moins des parcelles suffisamment probantes des agissements criminels de l'Eglise responsable de la guerre mondiale et des crimes des jésuites.

Après Rampolla, ce devait être, au début de la guerre, Pie X, puis le cardinal Ferrata les trois hommes dont la disparition était nécessaire aux fils de Loyola pour exécuter, en toute liberté, le plan qu'ils avaient conçu de « ramener dans le droit chemin, par la bonne saignée, la France impie et corrompue ». 


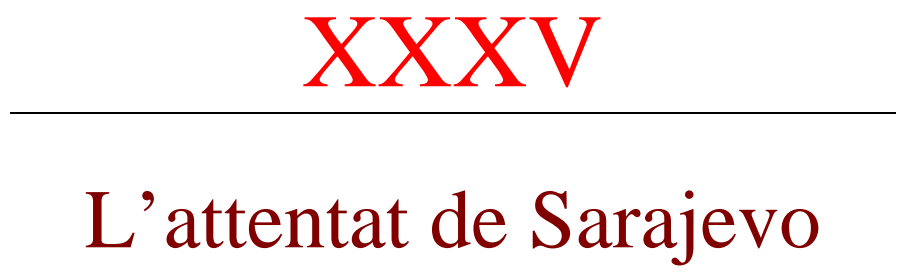

\section{Les lois laïques et le carnet B}

Cependant, les choses n’allaient pas assez vite au gré de la Curie romaine ; Merry del Val s'en inquiétait. Le temps pouvait travailler contre lui et ses complices et aboutir au retournement d'un plan si laborieusement dressé. Déjà, François-Joseph, mesurant les dangers d'une guerre avec la Serbie, à laquelle il avait enlevé contre tout droit, en 1908, la Bosnie-Herzégovine, faisait demander, dès le printemps de 1913, à l'Italie, si elle prendrait les armes dans le cas où l'attaque contre la Serbie provoquerait une guerre générale. D’autre part, l'Italie, où les gauches étaient revenues au pouvoir avec le cabinet Giolitti, n’ayant retiré aucun avantage de son accession à la Triplice, s'était rapprochée de la France par des " accords méditerranéens ", déterminant l'action réciproque et amicale des deux pays dans « la mer latine » ; elle avait pris soin d'en exclure, en ce qui la concernait, la cause de l'agression contre la France et tout engagement latéral militaire. Ce qui faisait prévoir la neutralité qu'elle garda au début de la guerre et dans laquelle la papauté — nous en donnerons la preuve s’efforça vainement de la maintenir.

Enfin, en France, la tentative de régression, au début de la présidence Poincaré, avait rendu plus vive encore la lutte entre les républicains et le parti clérical. Partout, on signalait les outrages, les violen- 
ces des soutiens de l'autel contre les lois laïques et les fonctionnaires chargés de leur application. Aussi les élections de 1914 furent un véritable triomphe pour tous les partis d'extrême gauche, et l'on savait fort bien, à Rome, que les 102 socialistes unifiés, les 23 républicainssocialistes et les 201 radicaux-socialistes, que les électeurs avaient élus en manière de protestation contre la loi de trois ans et la politique de capitulation, dite " d'apaisement », contre les menées cléricales, ne formeraient qu'un seul front unique, chaque fois qu'il s'agirait de défense laïque, malgré les divergences de doctrine.

De telle sorte qu'il ne restait plus, ; comme soutien de l'Eglise, que l'Autriche, le seul pays de l'Europe où les jésuites aient aujourd'hui encore conservé toute leur influence, et l'Allemagne, incomplètement convertie au protestantisme, mais offrant, par la Bavière ardemment catholique, un appui assez sérieux. Cette situation bénéficiait, il est vrai, de la force que tirait l'Allemagne d'une organisation militaire formidable, alimentée par une population croissante ; d'une activité commerciale et industrielle d'impérialisme qui avait grisé le peuple lui-même avec le rêve d'une Mitteleuropa absorbant l'Europe et soumettant l’Orient sous le sceptre des Hohenzollern.

Mais tout le succès de cette criminelle entreprise contre la paix du monde et l'existence de la France dépendait de sa rapidité d'exécution. Une trop longue attente risquait de déjouer tous les calculs. Aussi le Vatican multipliait les instances des plus vives auprès des deux empereurs pour les décider à faire naître l'occasion du conflit mondial, tant désiré par l'Eglise. Et comme les chancelleries des empires centraux, travaillées par les nonciatures, s'attardaient à la recherche d'un casus belli qui laissât aux criminels agresseurs le bénéfice d'une attitude loyale ; comme, d'autre part, la France s'affirmait plus résolue que jamais à poursuivre sa laïcisation " intégrale », selon l'expression d'Emile Combes, en rejetant un second ministère progressiste Ribot - lequel dura vingt-quatre heures - pour donner sa confiance à un cabinet radical-socialiste (Viviani), alors les jésuites, eux, n’hésitèrent plus devant un double meurtre.

L’attentat de Sarajevo fut leur œuvre. 
L'assassinat, le 28 juin 1914, à Sarajevo (Bosnie), par un jeune lycée, de dix-neuf ans Garilo Prinzip, élève des jésuites, de l'archi-duc François-Ferdinand et de sa femme, la duchesse de Hohenberg, son épouse morganatique, atteinte par ricochet, c'était le fait brutal, inattendu, qui frappait l'Autriche dans son prestige national et encore plus dans sa sécurité. Car, au rapport de l'ambassadeur britannique à Vienne, Maurice de Bunsen, l'attentat n'était que la conséquence de l'agitation slave dans les provinces du Sud de l'Autriche, agitation que celle-ci imputait à tort ou à raison à la Serbie. Or, des excuses, des réparations pécuniaires, la punition des coupables ne feraient qu'exaspérer davantage la haine des Slaves contre la monarchie austro-hongroise. Il faudrait donc en venir quand même à réduire la Serbie à l'impuissance, dût-il en résulter ce que souhaitaient ardemment le Vatican et les jésuites : une guerre européenne.

Tout se passa comme l'avaient prévu et escompté les criminels de la curie romaine. L'Autriche rendit la Serbie responsable du double meurtre ; celle-ci accepta l'ultimatum humiliant du 23 juillet. Mais cela ne faisait pas l'affaire des ministres de François-Joseph, stylés par les jésuites. Leur intransigeance exigea plus encore. Ce que voyant, la Russie mobilisa, Guillaume II la somma de revenir sur cette mesure et, lorsque l'Autriche allait peut-être accepter soit la proposition anglaise d'une conférence, soit la proposition française d'une commission internationale, soit encore la proposition d'arbitrage de la Russie, alors, sur un signe de Rome, François-Joseph, revenant à son intransigeance première, déclarait la guerre à la Serbie, le 28 juillet 1914 ; trois jours après, l'Allemagne envoyait un ultimatum à la Russie et à la France ; le $1^{\mathrm{er}}$ août, elle déclarait la guerre à la Russie, et, le 3 août, à la France.

Le ministère Viviani avait, dès le moment où la guerre paraissait inévitable, pris la résolution de maintenir nos troupes à dix kilomètres de la frontière. On l'a nié depuis. Mais nous avons le témoignage de Jaurès, qui, dans la semaine précédant la rupture, s'était mis en contact permanent avec la présidence du conseil, au nom du parti socialiste. Sortant un jour du ministère des affaires étrangères, Jaurès disait à un collègue, en parlant du recul de dix kilomètres : Vous savez, nous serions à leur place, je ne sais pas ce que maintenant nous pourrions faire de mieux pour assurer la paix. » 
On fit cependant plus encore du côté des républicains. La loi du 7 juillet 1904 supprimant l'enseignement congréganiste en France avait accordé un délai de dix ans aux congrégations enseignantes pour organiser leur liquidation. Ce délai, après lequel elles étaient en état de rébellion contre ladite loi et susceptibles de poursuites correctionnelles, expirait précisément le $1^{\mathrm{er}}$ août 1914 . C'est l'une des raisons pour lesquelles les jésuites avaient hâté la guerre.

Grisés par l'expression aussi hypocrite dans la forme que dans le fond d'Union sacrée, les républicains, généreusement dupes de l'éternelle perfidie de l'Eglise, ajournèrent l'exécution de la loi du 7 juillet 1904. On a prétendu, et certains indices recueillis ça et là pendant les premières heures trépidantes de la mobilisation tendraient à le faire croire, que si le gouvernement, en dépit du péril extérieur, avait maintenu la loi contre les congrégations enseignantes, c'était une nouvelle chouannerie qui se préparait. Les jésuites en étaient, certes, fort capables, et le langage en chaire des messieurs prêtres n'était rien moins que celui d'une visible hostilité contre la France et son gouvernement républicain et laïque.

Dans la même situation, la Convention avait répondu à la révolte par la plus implacable énergie, mais Viviani n'était pas Robespierre et Jaurès n’avait de commun avec Danton qu'un ardent amour de l’humanité.

Cette menace de guerre civile greffée sur la guerre étrangère entrait évidemment dans le plan des jésuites. Le parti socialiste, rendons-lui cette justice, en eut l'intuition, et puisque, de l'autre côté du Rhin, « intellectuels et social-démocrates » suivaient le kaiser dans la guerre « fraîche et joyeuse », les partis extrêmes en France ne pouvaient, sans compromettre l'avenir de leurs revendications et surtout l'existence de la République, se dérober à la lutte formidable qui allait pendant quatre années bouleverser le monde entier. Le ministre républicain Malvy, qui les devança dans ce geste de solidarité sociale en détruisant le carnet $B$, devait mériter d'autant plus la haine des jésuites qu'en agissant ainsi il leur enlevait l'un des atouts sur lequel ils avaient certainement compté le plus. Ils le lui firent bien voir par la suite. 


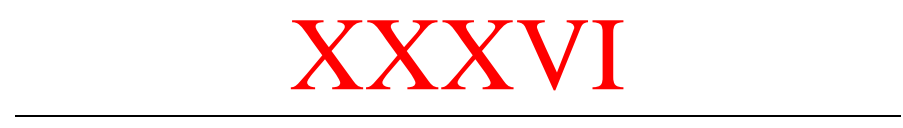

\section{La propagande royaliste}

\section{Pie X et Ferreta meurent empoisonnés}

Pour qu'on ne nous accuse pas d'insinuer sans preuve, nous signalerons, à l'appui de quelques essais de propagande monarchique au front comme à l'arrière, le fait suivant : Dans la deuxième quinzaine d'août 1914, c'est-à-dire à peine au début de la guerre, un certain nombre d'affiches illustrées, quart-colombier, furent placardées nuitamment sur les murs de Paris et de quelques grandes villes ; elles représentaient au premier plan, sur fond noir, un poilu et un prêtre, celui-ci montrant à celui-là une couronne royale irradiée s'élevant, telle un soleil d'une aurore nouvelle, au-dessus d'un horizon de sang. A Paris, très peu de personnes, certainement virent ces affiches, symboles des espérances de l'Eglise au regard de la France, parce que la Préfecture de Police les fit enlever ou lacérer dans les vingt-quatre heures. Dès le lendemain, un arrêté du Préfet interdisait l'apposition de toute espèce d'affiche sans son visa préalable. Les jésuites s'en dédommagèrent en envoyant aux tranchées des milliers de circulaires et de tracts rédigés dans le même esprit.

L'existence de cette propagande royaliste et cléricale fut confirmée par M. Briand lui-même à la délégation de la Fédération française de la Libre Pensée, qui était venue protester énergiquement auprès de lui contre ces agissements répétés et impunis. Le ministre convint que des 
ballots d'imprimés de ce genre étaient continuellement dirigés sur le front, par toutes sortes de moyens clandestins, mais que la majeure partie, reconnue et saisie en route, n’arrivait pas à destination.

Le récit de la guerre n'est pas de notre ressort. Pour rester dans le cadre de cette étude, nous nous bornerons donc à suivre uniquement, au gré des événements, l'action de la papauté et des jésuites pendant la sanglante hécatombe, dont, nous ne cesserons de le répéter, la préparation et la réalisation furent exclusivement leur œuvre.

Le sinistre avertissement donné à Pie $\mathrm{X}$ par la fin tragique de Rampolla l'avait, on s'en doute, profondément affecté. Avec cet art de la dissimulation qui semble être le privilège exclusif du prêtre, parce que l'éducation religieuse est basée uniquement sur la fourberie et le mensonge, il eut soin, très prudemment d'ailleurs, de n'en rien laisser paraître. Mais lorsque, six mois plus tard, l'irréparable s'accomplit par le meurtre de l'archiduc François-Ferdinand, le pape, non seulement télégraphia ses condoléances à l'empereur d'Autriche, mais suspendit la réception qui devait avoir lieu le lendemain, pour la fête de saint Pierre, dans la cour Saint-Damase, et pour laquelle dix mille invitations avaient été lancées, cependant que son entourage ne paraissait guère ému par l'attentat, ni, du reste, Rome elle-même, où la grande fête populaire du Pincio battait son plein, le soir même. Il est juste d'ajouter que l'on avait toujours considéré l'archiduc comme hostile aux éléments italiens de la monarchie austro-hongroise ; à partir de ce moment, Pie $\mathrm{X}$ - et nous devons ces renseignements à une personnalité aussi digne de foi que l'abbé Daniel — sembla prendre aux événements qui se succédaient et aux pourparlers entre les nations futures belligérantes un intérêt de plus en plus vif. Trop vif, même, pour la camarilla jésuitique qui s'efforçait de créer au Vatican une ambiance défavorable à une intervention qu'elle redoutait de sa part. Et c'est, précisément, autant pour accélérer les choses que pour rendre impossible le geste pacificateur de son maître, que le secrétaire d'Etat avait lancé, avec l'assentiment de la Curie romaine, le fameux télégramme du baron Ritter, excitant l’Autriche à faire la guerre.

Cette manœuvre, bien digne des jésuites, fut certainement connue, après coup, de Pie X. Et, à dater du 26 juillet 1914, malgré le danger qu'il pressentait proche pour sa vie, il en témoigna quelque humeur, 
sans aucun doute, mais ce fut seulement, les hostilités engagées, qu’il résolut d'agir. Mais trop tardivement, car sa perte était résolue. Le récit du crime, d’après l'abbé Daniel, vaut la peine d'être rapporté ici :

« Le 17 août 1914, Pie X était dans sa chambre, devant sa table de travail ; le cardinal Ferrata était à sa droite, dans un fauteuil.

"Soudain, Merry del Val entra sans se faire annoncer comme c'était sa coutume aux heures de la faveur.

« Aussitôt, Ferrata se leva, comme pour s'effacer. D’un geste impérieux, Pie X l'arrêta et l'invita à reprendre sa place.

« Merry del Val pâlit et s’inclina respectueusement, tout en murmurant : «Alors, c’est moi qui dois me retirer? »

« Il déposa sur la table quelques papiers et sortit. Pie X, impassible, n'avait pas ajouté un seul mot.

« Aussitôt, il se retourna vers le cardinal Ferrata et reprit sans plus la conversation.

« Merry del Val était allé immédiatement conférer de sa disgrâce avec Mgr Von Gerlach. Vela a été établi par les témoignages les plus sûrs. »

On devine la suite : le geste de Pie $\mathrm{X}$ se ressaisissant, à quinze jours à peine des hostilités, et revenant avec Ferrata à une politique défavorable aux empires centraux, c'était la ruine du plan des jésuites et, qui sait ? peut-être une paix à courte échéance, sans avoir été précédée de l'écrasement de la France.

Or, il ne faut pas qu'il en soit ainsi. Un meurtre de plus ou de moins n'est pas une affaire pour les fils de Loyola, dont la morale tient tout entière dans cette formule : "La fin justifie les moyens. » D’ailleurs, depuis quelque temps, le bruit habilement répandu par eux, les craintes qu'inspirait la mauvaise santé du pape, aggravée par l'âge, feraient accepter une fin souvent annoncée. 
Reprenons le récit de l’abbé Daniel :

« Dans la nuit qui suivit la révocation in petto du secrétaire d'Etat, Pie $\mathrm{X}$ ne dormit pas. Il fut très agité et, par suite, suffoqua - tout comme Rampolla. - Le 19 août, la rumeur se répandit soudain que tout espoir était perdu. A 8 heures du soir, on annonça que l'agonie était commencée ; à 1h. 20, Pie X expirait...

«Quant à Merry del Val, il ne parut que dans les derniers instants de l'agonie, juste au moment où sa personne ne pouvait plus compter pour le moribond.

«Dans la chambre mortuaire, on a souvent entendu murmurer : «Cette mort ne semble pas naturelle. »

« Les membres présents de la famille n’osèrent risquer aucune opinion. « Les docteurs, affirma-t-on, se prononcèrent nettement, mais on ne dit pas dans quel sens... »

Sarto, nous l'avons dit, avait eu l'appréhension d'un empoisonnement dès son installation au Vatican. "Il connaissait, ajoute l'abbé Daniel en matière de conclusion, l'histoire ecclésiastique des Borgia et les vieux procédés classiques. Il ne connaissait rien des progrès de la science moderne en cette matière. »

Dès l'ouverture du Conclave, après la mort de Pie $\mathrm{X}$, le cardinal Czernoch, primat de Hongrie, offrit à Della Chiesa, sur l'inspiration des jésuites, les voix des empires centraux. Et, dès le premier jour du conclave, le P. Tacchi Venturi, secrétaire général de la Compagnie de Jésus - le même qui a pris une part si active au traité de Latran annonça que le cardinal élu serait Della Chiesa. Ainsi, les accords d'Einselden, en 1913, établis par feu Rampolla, dans son propre intérêt - ce qui avait été son arrêt de mort — atteignaient leur but : la nomination d'un pape élu par les empires centraux, grâce aux jésuites, et lequel allait pouvoir, durant la guerre, servir de docile instrument à la politique allemande.

On verra que Della Chiesa, qui prit le nom de Benoît XV, fut fidèle aux engagements pris envers l'Allemagne, dont il payait la tiare. 
Cependant, il restait encore un point noir : Della Chiesa, qui a trahi son maître Rampolla et trahi les amis de la France, n’avait obtenu les voix de la majorité du conclave qu'en promettant le renvoi de Merry del Val, jugé trop compromettant par le Sacré Collège et les jésuites eux-mêmes pour les servir encore.

Benoît XV tint parole : Ferrata fut nommé ministre d'Etat. Mais les jésuites veillaient. Ils ne laissèrent pas le temps d'agir au nouveau secrétaire : un mois leur suffit pour se débarrasser de Ferrata, comme de Rampolla et de Pie X. Entré au Vatican le 20 septembre, il en sortait le 20 octobre 1914.

\section{Écoutons l’abbé Daniel :}

« Parmi les valets du Vatican, l’un d'eux était plus spécialement attaché à la personne de Ferrata... Il avait un nom à consonance italienne, quelque chose comme Baldini, si toutefois c'était bien son nom. Car les Suisses du Vatican sont presque tous cousins à la mode de Bretagne avec de prétendus Alsaciens des bords du Rhin ou des brasseries de Munich.

« Il arrivait parfois à Ferrata de prendre, sans quitter son bureau, quelque consommation : du chocolat, du thé.

« Ce n’était pas prudent. Mais la faim est, dit-on, mauvaise conseillère.

« Ce jour-là, il rédigea de sa main la lettre de condoléances à la famille du célèbre orateur catholique de Mun, distribua le travail aux secrétaires, eut un long entretien avec le pape et passa le reste de son temps à donner des signatures.

« Entre temps, il s’était fait servir une légère consommation. Il était à son bureau, quand il fut pris, soudainement, de vomissements d'une extrême violence, et tomba comme foudroyé. 
« Un médecin, appelé en toute hâte, reconnut aussitôt la gravité du mal. Devant une si grande responsabilité, il demanda une consultation immédiate.

« Ferrata, de son côté, avait tout compris et ne se faisait déjà plus aucune illusion. Sans perdre une minute, il voulut, malgré la gravité de son état, être transporté à son hôtel.

« Il disait bien haut qu'il ne voulait pas mourir au Vatican. Son corps, du moins, ne serait pas à la merci des espions et des traîtres.

« La consultation médicale eut lieu aussitôt à son hôtel. Six médecins étaient accourus. D’un avis unanime, ils déclarèrent qu'il n’y avait plus d'espoir. Ils se refusèrent à rédiger un bulletin médical. Celui qui a été rédigé ne porte pas de signature. On ne lui connaissait ni maladie ni infirmité.

« Le scandale de cette mort fut tel qu'une enquête s'imposa. Elle fut des plus sommaires, et pour la forme seulement. Le résultat fut qu'un bocal avait été brisé à l'office. On expliqua ainsi tout naturellement la présence du verre pilé dans le sucrier dont le cardinal s'était servi. Le sucre cristallisé n’est pas sans inconvénients.

« Peu de jours après, cependant, on commentait fort la disparition du domestique dont il a été question plus haut. On racontait que, loin d'être un compatriote de Guillaume Tell, il était devenu artilleur dans l'armée allemande et n'était autre chose que l'ordonnance du cardinal Von Gerlhac avant sa vocation ecclésiastique.

« Tout cela se disait presque à l'oreille, avec des réserves et une sorte de terreur que l'on s'explique facilement. »

C’est pourtant de ce Von Gerlhac que des évêques français, entre autres l'un des plus acharnés contre les lois laïques, ont eu le triste courage de recevoir le chapeau de cardinal...

Par coïncidence plus que troublante, le $P$. Wernz, général des jésuites, était mort vingt-quatre heures après Pie X, et le fameux Ledo- 
chowski, qui en fait conduisait déjà la Compagnie de Jésus, lui succéda.

Gaspari, de nouveau concurrent à la succession de Pie X, prit la place de Ferrata, qui lui avait été promise d’ailleurs.

Désormais, les jésuites sont les maîtres absolus de la situation. Nous allons les voir à l'œuvre pendant la guerre. 


\section{XXXVII}

\section{Benoît XV, le faux neutre}

On a dit avec raison que le rôle de l'Eglise au cours des hostilités, a laissé dans la mémoire de la France et de ses alliés contre l'impérialisme germanique, un souvenir d'iniquité qui ne s'effacera jamais.

Élu par une majorité de cardinaux à la dévotion de l'Autriche et de l'Allemagne, affectionnant les jésuites au point qu'étant évêque de Bologne, il avait menacé les professeurs du séminaire de les remplacer par eux, Benoît XV était entièrement dévoué à leur société. Dès lors, cette neutralité quand même, en tout, et au-dessus de tout qu'il affectait d'observer avec le plus excessif scrupule vis-à-vis des belligérants, n'était qu'une impudente façade derrière laquelle s'abritait toute la propagande des empires centraux.

La doctrine pontificale de la guerre est d'ailleurs cyniquement exposée dans une série de pièces officielles. Les Actes du siège apostolique, où la guerre est représentée comme " querelle de princes », sans intérêt pour les peuples, querelle qui ne saurait être ni justement, ni durablement terminée par une paix imposée par les armes. 
Quant à la tactique de neutralité malveillante du Vatican, on la trouve sous sa forme la plus nette dans l'Osservatore Romano, organe du Vatican (25 janvier 1916), par ces deux passages concernant Guillaume II :

« Se faire lion ou agneau pour le plus grand bien de l'Eglise et de la société à l'image du moine Hildebrand, le futur Grégoire VII... Et par conséquent ne pas contrarier le kaiser qui tient en main la paix et la guerre. »

Dès son premier message aux catholiques du monde entier (8 septembre 1914), Benoît XV présente la guerre comme le fléau de la colère de Dieu dont l'Allemagne n'est que l'instrument. C'est la thèse pangermanique que l'Eglise reprendra et soutiendra pendant toute la guerre. En janvier 1915, il ordonne à ces mêmes catholiques une prière unique et les invite « à faire des œuvres de mortification expiatoire pour les péchés qui provoquent les justes fléaux de Dieu. » Or, tel était le sens de cette prière ultra-neutraliste qu'elle scandalisa tous les catholiques français et que le cardinal Amette se vit obligé de la commenter à Notre-Dame, le 7 février 1915, et d'en dénaturer le sens pour la faire accepter des fidèles. Ce qui lui valut une verte réprimande du Mattino de Naples, journal commandité par le pape, pour son "sentiment païen de la vengeance ", tandis qu'un autre organe romain, édité par un certain Benedetto Governa - pseudonyme transparent « Benoît gouverne », autrement dit du pape lui-même — félicitait les évêques allemands d'avoir fait réciter la prière à leurs ouailles, sans commentaires déplacés.

Les exemplaires de cette prière, que le Temps du 7 février 1915 assimilait avec raison aux publications délétères, furent saisis en France par ordre du ministre de l'Intérieur. Benoît XV récidiva dans le consistoire du 6 décembre et tint de tels propos que toute la presse de l'Entente protesta.

Quant aux crimes des envahisseurs, Benoît XV ne répond que par un accusé de réception le remerciant des détails qu'il lui donne et de leur exactitude le 20 septembre 1914 au cardinal Luçon les lui signalant. À ceux de son clergé qui s'adressent à lui pour lui demander d'intervenir et la destruction des biens, Benoît XV, d'une plume im- 
passible, répond par des formules vagues «sur les malheurs du temps ; le pénible spectacle de tant de douleurs ; la situation vraiment déplorable; les funèbres événements; la guerre calamiteuse et cruelle... " S'il osait, il emploierait volontiers la fameuse formule : «Impossible... mille regrets!» opposée aux solliciteurs opportuns. Mais à la fête de Noël (24 décembre 1914) il propose une trêve pour célébrer de tranchée à tranchée la messe par les aumôniers catholiques des deux armées ennemies. Le Temps railla longtemps ce geste du "représentant sur terre de la divinité qu'invoquent par les mêmes prières ceux qui s'égorgent ». Par contre, Benoît XV reste muet en apprenant le torpillage du Lusitania.

Mais, à un rédacteur catholique de la Liberté, M. Louis Latapie, qui se rend auprès de lui pour savoir à quoi s'en tenir réellement sur l'attitude de Benoît XV et lui énumère tous les forfaits dont les empires centraux se sont déjà rendus coupables, le pape, malgré une subtilité bien jésuitique, trahit néanmoins dans toutes ses réponses son unique préoccupation de rendre l'Entente responsable de tout. Les crimes allemands ? Mais ceux-ci accusent aussi les armées de l'Entente. La neutralité belge violée ? C'était sous le pontificat de Léon $X$ (textuel), son successeur n'a que faire d'une pareille vétille. Des otages ont été fusillés ? Les évêques autrichiens en ont dit autant au pape sur les armées italiennes et russes. Des religieuses ont été violées? Sept congrégations belges sont indemnes, protégées qu'elles étaient par la Sainte Vierge ou quelque saint. L'incendie de Louvain ? Le bombardement de Reims ? Les soldats de l'Entente ont tiré les premiers sur les Allemands, et il y avait un observatoire sur la cathédrale de Reims. Le torpillage du Lusitania ? C'est affreux, mais le blocus des empires centraux n’est guère humanitaire. Admirez cette réponse qui assimile le torpillage d'innocents passagers d'un paquebot à une tactique de guerre entre belligérants. Enfin, l'Italie est restée quelque temps neutre ? Ici, c'est l'aveu formel de Benoît XV. «Oui, nous avons retenu tant que nous l'avons pu l'Italie, mais c'était aux intérêts du SaintSiège que nous pensions en agissant ainsi. »

À mesure que la guerre se poursuit avec la certitude grandissante que les empires centraux n'obtiendront rien par la force des armes et que même leur défaite semble assurée, Benoît XV et ses complices, les jésuites, multiplient les intrigues pour qu'une paix blanche termine 
le conflit. Le pape, d'après le P. Hénusse, jésuite belge, ayant déclaré que la Belgique devait être rétablie dans tous ses droits et possessions, cette information est aussitôt démentie par l'Osservatore Romano (janvier 1915) et, pour justifier la violation belge, les jésuites exhibent les fameux papiers (?) Barnadiston, qui prévoyaient des mesures défensives anglo-belges, documents fabriqués de toutes pièces dans l'officine du Vatican.

Bien mieux, le pape refuse au cardinal Mercier une enquête sur les atrocités allemandes en Belgique, et, pour comble de cynisme, le journal du Vatican déjà cité proclame (14 juin 1918) que «le nom de Benoît XV sera célébré et exalté comme celui d'un bienfaiteur et d'un protecteur de la Belgique ». Quelle odieuse hypocrisie! Alors que dans les journaux qu'il subventionne, Benoît XV rend la Belgique responsable de son invasion, s'en prend à la Révolution française (!), cause de la guerre mondiale, alors qu'en 1918, à Lourdes, le cardinal Bourne s’écrie: "Personne n’a jamais oublié le Saint-Siège sans avoir eu à s'en repentir. Les gouvernementaux de France et l'Italie ont oublié la notion de la Providence qui gouverne tout et aussi l'existence de l'Eglise surnaturelle du Christ, d'où la guerre actuelle. »

Le gouvernement italien avait fini cependant par s'émouvoir de cette "neutralité hostile ». En avril 1917, le chevalier Ambrogetti, ancien condisciple de Benoît XV, directeur du journal Il Batone, était traduit avec le prélat von Gerlach en conseil de guerre à Rome, pour intelligence avec l'ennemi. Les débats établirent que le pape commanditait cet organe pour 37000 lires par an. Telle fut la version du Vatican pour sauver la mise aux accusés. Mais, en réalité, les fonds furent prouvés venant de l'Allemagne. Les deux protégés de Benoît $\mathrm{XV}$ eurent chacun trois ans de prison. Ce furent les presses de la «typographie Vaticane » qui imprimèrent la plaidoirie de von Gerlach, que Benoît XV garda, nonobstant sa condamnation, sur l'annuaire pontifical. De même, lorsqu'en 1917, le Corriere del Friuli, clérical bolcheviste, que dirigeait le comte Della Torre, fut suspendu par le gouvernement italien, le comte fut nommé président du conseil d'administration de l'Osservatore Romano, journal officiel, comme on sait, du Vatican. 
Faut-il citer encore l'anniversaire du kaiser célébré chaque année magnifiquement dans l'église de l'Animat, à Rome, avec toute la pompe pontificale ? et contre lequel le ministre Orlando protesta publiquement. La trève demandée aux Alliés, le jour de la Fête-Dieu, en 1918, et inobservée par les Allemands qui bombardèrent la Madeleine ? Ce que Benoît XV expliqua par ce fait : qu'il n'avait pas demandé aux Allemands la réciprocité de la trêve (sic). Faut-il rappeler encore les efforts de l'Eglise pour isoler l'Entente et conseillant à l'Italie de "faire payer son concours », de Nice et de la Savoie » (Civitta Cattolica, 6 avril 1918) ? Les intrigues auprès de l'Amérique pour qu'elle s'abstienne, révélées par Karl von Wiegand, agent des jésuites au service du kaiser (11 avril 1915), et qui n’ont jamais été démenties parce que celui-ci possédait le texte des déclarations papales apostillées par Benoît XV ? A ces intrigues pour conjurer la rupture entre l'Allemagne et les Etats-Unis furent mêlés, un ancien député catholique et le jésuite français, François Deloncle, (Messagero du 6 mai 1916), Mgr Bonzano, délégué apostolique à Washington, Aversa, nonce au Brésil, et Gibbons, archevêque de Baltimore.

Enfin, tout le monde sait aujourd'hui que les mutineries dans l'armée française et le désastre de Caporetto, en 1917, furent l'œuvre exclusive du Vatican et des jésuites. Benoît XV n’avait-il pas lancé aussitôt après son Invitation à la Paix, réclamant une paix favorable à l'Allemagne ? Puis ce furent les démarches et l'appel auprès du roi Albert I ${ }^{\text {er }}$ pour qu'il acceptât une paix séparée (Osservatore Romano, 1918) ; pour armer la Russie contre la France (1915-1916), puis encore pour la séparer de l'Angleterre, tandis que les pères jésuites travaillaient si bien les grandes villes de l'Inde que le gouvernement anglais, pourtant libéral, dut les interner dans deux camps de concentration à Bellari et Ahmednagar.

L'âme de toutes ces campagnes en faveur des empires centraux, ce fut « le pape noir », dont pourtant jamais le nom ne fut prononcé pendant la guerre, le général des jésuites, Vladimir Ledochowski, qui avait fait élire Benoît XV. 


\section{XXXVIII \\ L’Église seule a tiré profit de la guerre de 1914 \\ Un Saint-Empire catholique La diplomatie du Bloc National complice des Jésuites}

Lorsqu'elle eut acquis la certitude de l'imminente défaite de ses complices, l'Eglise, toujours inspirée des jésuites, s’arrangea de façon qu'au moins l'un des siens fût l'ouvrier de la dernière heure : celui de la victoire. Ainsi, le christianisme qui, en réalité, « a pourri la civilisation dès sa naissance ", pourrait se vanter impunément, auprès des peuples, de l'avoir sauvée une fois encore. L'Entente, aux premiers mois de 1918, avait alors à sa pleine disposition tout ce dont elle avait manqué au début, augmenté de l'invention de nouveaux engins comme les tanks; des 1200000 Américains remplaçant un nombre presque égal de ses défenseurs immolés à trois années de guerre ; en face d'elle, un ennemi que l'usure commençait à ronger, que le découragement de n'avoir atteint aucun de ses objectifs affaiblissait peu à peu ; et, plus loin, par delà le Rhin, les sourds grondements d'un peuple enfin désabusé et tout prêt à la révolte. Une situation aussi favorable n'exigeait, certes, ni un être providentiel, ni même un surhomme (en supposant qu'il en existe jamais) pour savoir en profiter et l'exploiter jusqu'au triomphe définitif. Et c'est faire bien peu de cas 
de l'intelligence française que de supposer qu'en dehors de Foch, un Pétain, un Galliéni, un Lanrezac ou un Sarrail ne se seraient pas acquittés tout aussi bien de la même tâche, avec ou sans morceau de « la vraie croix » dans ses chausses. L'histoire connaîtra peut-être, dans tous ses détails, ce bluff habilement conduit aboutissant à l'imposition par le Gesu, du chef qui recueillit le laurier planté par d'autres. À moins que M. Clemenceau dont le refus sybillin de «polémiquer devant une tombe ouverte » fait présumer des choses intéressantes connues seulement de quelques initiés, ne se soit décidé à nous en faire part, avant d'aller rejoindre aux Champs-Elysées l'ombre du dernier stratège.

La victoire des peuples de liberté sur l'impérialisme germanique ajournait une fois encore le rétablissement du pouvoir temporel de l'Eglise qui ne s'en montra pas autrement affectée. N'était-ce pas, en réalité, et malgré tout, « le grand, le principal profiteur de la guerre » comme ses partisans se sont complus à le reconnaître même avant la fin des hostilités. Elle avait mis à profit les deuils et les souffrances de cette terrible tourmente pour exploiter les hésitations, les faiblesses, les défaillances et intensifier son action et sa propagande au chevet des blessés, auprès des familles éplorées. Elle avait parlé d'expiation divine aux populations ravagées et désemparées ; et dans le désarroi profond des esprits et la désespérance des consciences, elle avait réussi à se faire écouter.

« Les catholiques seront de nouveau l'âme du monde », affirmait un prélat, Monsignor Bianchi Cagliesi, dans l'Europe Nouvelle (17 août 1918).

"Nous les aurons. Oui, nous les aurons tous, les Boches de l'intérieur... Nous nous lèverons, catholiques français, et nous appellerons Boches de l'intérieur tous ceux qui, sous n'importe quelle forme, parleront et agiront contre la liberté (des catholiques). Ces Boches-là aussi, nous les aurons d'une manière ou d'une autre. " (La Croix, 5 septembre 1918).

Les actes suivirent de près ces menaces. Malgré plus de dix années écoulées depuis la fin de la guerre, les agissements de l'Eglise et des jésuites en France sont encore trop connus pour que nous nous y attar- 
dions. Il suffira de les résumer sommairement. Ce fut d'abord, on l'a vu, avant même la signature de l'armistice, les manifestations du haut clergé contre les lois laïques par la déclaration des cardinaux auxquels Edouard Herriot répondit de sa meilleure encre ; puis la reprise officielle des relations avec le Vatican au mépris des lois laïques non abrogées; la poussée formidable des congrégations demeurées en France à la faveur de la guerre et qui, celle-ci prenant fin, auraient dû être expulsées aussitôt, et d'une façon définitive cette fois ; la guerre à l'école laïque, guerre odieuse, infâme envers les maîtres et les maîtresses de l'enseignement public, que le gouvernement du Bloc national, bien loin de les défendre, trahissait en fermant le plus possible d'écoles publiques pour permettre aux écoles libres de se substituer à celles-ci ; la campagne pour la proportionnelle scolaire dont le résultat aboutirait à encourager l'enseignement dirigé exclusivement dans les écoles libres contre la démocratie et sa liberté ; et ces derniers temps, l'offensive plus vigoureuse que jamais contre la République ellemême par l'organisation sur tous les points du territoire de pèlerinages, meetings, processions, manifestations de toutes sortes, auxquels le gouvernement prétendu républicain et laïque de $\mathrm{M}$. Poincaré semble tout fier de se faire représenter, quand il ne pousse pas le mépris des lois laïques jusqu'à s'y associer en la personne de son chef ou de l'un de ses membres. La loi de Séparation ne reconnaît aucun culte en France, dit son article premier, mais le président de la République a mis le plus grand empressement à venir s’asseoir auprès du légat Lépicier, en tournée à Orléans. Pour sauver les apparences et ne pas trop humilier le premier magistrat de la France, l'envoyé du pape a daigné consentir à ce que le fauteuil du président à la cathédrale soit plus haut que le sien de deux ou trois centimètres !

Nous n'aurions garde d'oublier la manœuvre dernière concernant les autorisations à accorder à certaines congrégations et que la Chambre de 1928, renchérissant sur la pusillanimité de celle qui l'a précédée, a votée sans honte.

Il y eut pourtant un moment d'espoir pour les républicains avec cette Chambre de 1924 qui semblait exprimer si bien l'accord parfait au point de vue laïque de tous les partis de gauche contre le péril clérical. Mais les jésuites, avec l'aide des « banquiers christianisés », eurent tôt fait de juguler la France par la menace de la banqueroute pu- 
blique, si le Cartel demeurait au pouvoir. Et comme la France est encore de tous les pays prétendus libres celui où le fétichisme est le plus en honneur, où la théorie du sauveur, de l'homme indispensable, rencontre, aux moindres alarmes, le plus grand nombre de partisans, alors on en revint à une politique intérieure fortement additionnée de conservatrice et... ce fut pour les jésuites et l'Eglise un nouveau retour de fortune. Leur reconnaissance envers un gouvernement qui allait au-devant de toutes les capitulations se traduisit par le mouvement du Heitmabund en Alsace et en Lorraine, mais surtout dans la première de ces deux provinces. Dans cette région revenue à la France après cinquante années d'absence, les jésuites et leurs succédanés tiennent la direction des séminaires, des couvents, des écoles catholiques, et possèdent la presse cléricale de langue allemande.

Avec sa perfidie habituelle, le Vatican a toujours protesté de la pureté de ses intentions dans les affaires de l'Alsace et de la Lorraine, mais il est hors de doute que la Curie romaine, dont le premier projet d'une Europe Centrale jésuitisée a été bousculé par le traité de Versailles, envisage aujourd'hui un tout autre plan.

C'est celui d'un grand royaume catholique romain, avec l'Autriche, la Bavière des Witelsbach, qui a toujours partie liée avec Rome, Bade, la Prusse Rhénane, l'Alsace-Lorraine et le Palatinat (enlevé à la France en 1815). A ce vaste empire confédérant les Etats catholiques de l'Allemagne, se joindraient, sous la pression économique, les Etats ouvriers et luthériens du reste de l'Allemagne Centrale, Septentrionale et Orientale. Ce nouveau Saint Empire s'unirait par alliance, d'une part, avec la Pologne catholique, d'autre part, avec la Hongrie catholique et, sans doute aussi, avec la Roumanie catholique.

Ainsi, tout le continent européen de l'océan Atlantique au Dniester, et de la mer du Nord à la Méditerranée, formerait un bloc solide aux mains de l'Eglise catholique. Dans la pensée, ou mieux l'arrièrepensée de Rome, ce vaste Saint Empire constituerait une muraille infranchissable contre la Révolution russe, il détruirait l'esprit démocratique expulsé d'Europe et de l'Amérique.

Le formidable réseau d'organisation, d'influence, de police, d'intrigues, d'envahissement, de manœuvres et de diplomatie, dont la 
Curie romaine, servie à la fois et menée par les jésuites, e envahi le monde, travaille depuis le lendemain de la guerre à l'exécution de ce plan gigantesque dont la réalisation serait la fin de toutes les libertés et l'esclavage quasi universel sous l'abominable tyrannie du dogme.

C’est ainsi que, conformément à la politique traditionaliste de ses prédécesseurs, après chaque bouleversement politique, Benoît XV se préoccupa aussitôt d'assurer la liaison de la papauté avec les nouveaux Etats qu'avaient fait éclore les différents traités terminant la guerre en établissant avec chacun d'eux un concordat et s'assurant de leur part une représentation diplomatique réciproque. En outre, et jusqu'au coup d'Etat de Mussolini, le parti populaire italien, dont nous reparlerons plus amplement, fut chargé de servir de trait d'union entre l'Allemagne et les Etats de l'Europe Centrale nés de la dissociation de l'empire austro-hongoris. En Espagne, les jésuites travaillèrent également à la formation d'un parti populaire du roi d'Espagne qu'effrayait quelque peu l'envahissement des pères. En Belgique, grâce aux Hollandais, les dirigeants catholiques ont repris le contact avec ceux de Cologne.

Enfin, peu après, la politique mussolinienne, secondant la papauté, devait conclure avec l'Espagne un accord visant à restreindre notre influence et notre place au Maroc.

De telle sorte qu'à l'Est comme au Sud et au Sud-Ouest, la France, qui s'obstine à demeurer anticléricale, du moins en principe - car la violation quotidienne des lois laïques ferait croire plutôt le contraire - se voit entourée par les manœuvres des jésuites des puissances rivales, jalouses, hostiles même, et qui, au Maroc, en Tunisie, en Syrie, en Abyssinie, seraient certainement toutes prêtes à se coaliser contre elle.

Cette conception d'un grand empire catholique a eu sa répercussion en France aux dernières élections. Nous devons, en effet, aux manœuvres des jésuites la présence à la Chambre d'environ quarante députés nettement catholiques, ce qui signifie aujourd'hui « affiliés aux jésuites ", et tout dévoués à la réalisation du plan d’hégémonie mondiale poursuivi par l'Eglise. Encore quelques années - quelques mois peut-être - et ce noyau catholique sera devenu, comme en Allema- 
gne, « le centre » d'une agitation cléricale permanente, cherchant à dominer toute la France. Actuellement, les œuvres innombrables que le « Gesu » a créées, et dont il augmente chaque jour le nombre, ont repris leur activité d'avant-guerre : modernistes, sillonnistes, socialistes chrétiens formés autrefois à l'instigation au P. Benigni, jésuites démocrates catholiques, sont autant de masques dissimulant des organisations tout entières aux mains des fils de Loyola; le simple bon sens indique, en effet, que le principe d'une obéissance absolue à une divinité exclut toute liberté de conscience ; on sert difficilement deux maîtres à la fois. Comment un démocrate peut-il obéir aux lois laïques, alors que le chef de sa religion, qui représente son dieu sur la terre, doit être le seul obéi, le seul respecté par ce soi-disant démocrate?

L'activité de l'Eglise n'a pas épargné l'Angleterre, où s'affirme en maintes occasions - chose assez troublante - la collusion de la haute finance israélite avec les catholiques militants, peut-être grâce à la finance allemande. Elle a pénétré la Russie, où, malgré le soi-disant pénétré la Russie, où malgré de soi-disant persécutions contre les religieux, le Vatican expédia, lors de la dernière famine, douze millions de lire et une douzaine de jésuites pour convertir les Soviets. Enfin, en Amérique même, les Chevaliers de Colomb, cette organisation ultramontaine dont les membres dont le serment « d'étriper tous ceux qui ne pensent pas comme eux ", et dont l'affiliation aux jésuites ne fait pas l'ombre d'un doute, ont organisé, depuis la guerre, un bureau international des œuvres, subventionnent largement toutes les organisations catholiques cosmopolites (irlandaises, italiennes, espagnoles, etc.), et s'efforcent de remplacer en Extrême-Orient les missionnaires français par des religieux allemands.

Le plus triste dans tout cela, c'est que la diplomatie française, surtout au temps du Bloc national, de 1918 à 1924, a joué un véritable rôle de dupe, en favorisant inconsciemment, sans vouloir le croire, ou par ignorance des manœuvres des jésuites l'extension de leur politique.

Pour réaliser, en effet, le but de la Société de Jésus, il fallait qu'une grande puissance européenne le fît sien. Or, la politique de désintégration du Reich, sous prétexte de garantir la France contre tout agression 
à l'Est, a servi admirablement le plan des jésuites. En réalité, l'occupation de la Ruhr fut faite non pour obtenir le paiement des réparations, mais pour parvenir à la désintégration du Reich.

C'est également dans ce but que le Bloc national, malgré l'épuisement de la France, subventionnait les séparatistes rhénans, palatins, et les royalistes bavarois, qu'il croyait détacher de l'Allemagne. Les réparations et leur paiement étaient le paravent derrière lequel la politique jésuite put se développer à l'aise.

Toujours en vertu de cette même politique de désintégration du Reich, le Bloc national français, à l'instigation des jésuites, dont il ne devinait pas le jeu, subventionnait, par des centaines de millions de francs, la Pologne, la Roumanie et l’Autriche.

Pendant ce temps-là, le contribuable français, écrasé d'impôts, vivait dans l'anxiété d'un cataclysme financier toujours imminent et qui n’est pas, d'ailleurs, encore conjuré.

Les conséquences de cette politique se traduisirent par les coups d'Etat de Von Kahn en Bavière, de Ludendorff et de Hitler en Prusse, des séparatistes en Rhénanie et dans le Palatinat.

Mais la formation d'un Saint Empire n'est qu'une fraction du but poursuivi par l'Eglise ; son rêve de domination universelle ne sera accompagné que lorsqu'elle aura réalisé l'unité de la chrétienté. L'Église catholique veut unifier le monde dans une même foi, sous une même règle, dans un même gouvernement qui est le sien.

Or, il lui fallait avant tout recouvrer, sinon sa souveraineté temporelle, au moins les apparences de cette souveraineté adaptée aux contingences actuelles. C'est alors qu'elle a poursuivi, avec une ténacité que la guerre elle-même n'a pas arrêtée, la reprise de Rome sur ses légitimes possesseurs, afin de faire de l'Italie la première province de ce Saint Empire projeté par les jésuites. 


\section{XXXIX \\ Le parti populaire et don Sturzo \\ La lutte contre la franc-maçonnerie et le socialisme}

On pourrait supposer, à première vue, que le traité du Latran a été un coup de théâtre : alors que depuis la prise de Rome (1870) l'Eglise n'a cessé de renforcer son organisation, dans le but de reconquérir, avec la patience et la ténacité qui sont ses qualités dominantes, le terrain perdu en Italie et d'y établir l'autorité temporelle du pape, fût-ce dans les conditions les plus modestes en apparence. C'est ainsi que le 6 décembre 1870, se constituait, avec l'assentiment du pape : la Société romaine pour les intérêts catholiques, dont l'organe, la Voix de la Vérité, était également celui de l'œuvre des congrès et des comités catholiques en Italie, divisée en cinq sections : $1^{\circ}$ œuvres religieuses et associations ; $2^{\circ}$ œuvres de charité ; $3^{\circ}$ instruction et éducation ; $4^{\circ}$ presse ; $5^{\circ}$ art chrétien.

Ces diverses modalités de l'activité catholique laissant à la papauté le bénéfice d'une attitude intransigeante s'employèrent à cette lutte sournoise de tous les instants, la même d'ailleurs que les jésuites conduisirent de tout temps dans tous les pays et qui consiste à se servir, contre le régime que l'on entend renverser, des moindres erreurs du pouvoir, des faits les plus insignifiants de sa politique, en les grossissant et les dénaturant, comme après Adona (1896), pour l'en affaiblir d'autant et ruiner peu à peu son influence dans l'esprit du peuple ; 
à exploiter les mécontentements jusqu'à l'émeute inclusivement, comme il advint lors de la semaine rouge de Milan (mai 1898).

C'est surtout contre la franc-maçonnerie italienne, qu'elle rendait responsable de la défaite de la papauté et de la prise de Rome, que s'acharna la milice noire du Vatican, autrement dit les jésuites. Le parti socialiste affectant comme en France de dédaigner la question religieuse pour la question sociale, malgré, nous le répéterons inlassablement, leur étroite connexité, n'était pas considérée par l'Eglise comme un péril sérieux. Elle avait d'ailleurs, dans ses rangs, des affiliés qui se chargeaient de le domestiquer pour son propre compte. Et puis, sous Pie X, qui, tout en gardant la même attitude de protestataire que ses prédécesseurs, avait autorisé le retour des catholiques à l'activité politique, devait se constituer l'Union Populaire, dont les membres «se mettaient promptement et sans hésitation entre les mains du pape, comme des instruments dociles et empressés pour la grande œuvre de restauration sociale. »

Mais la franc-maçonnerie, qui, depuis 1876, avait fourni presque tous les présidents du Conseil (Depretis, Crispi, Zarnadelli, di Rudini, maçons : Cairoli, Giolitti, Bonomi, San Guiliano, au moins favorables à la franc-maçonnerie), qui, en Sicile, berceau du carbonarisme de la noblesse libérale, constituait pour le Vatican l'ennemi assez fortement organisé pour lui avoir résisté pendant près de quarante ans, et qu'il leur fallait abattre à tout prix, avant même de donner le signal de la guerre mondiale. C'est à cette tâche que se consacra surtout l'Eglise romaine, aidée puissamment en cela par des transfuges comme Ruggero Bonghi, Ettore Ciccotti, Alessandro Luzio, Mario Missiroli — et enfin Benito Mussolini, l'homme de tous les reniements.

Cette équipe de traîtres, précieusement recueillis au sein de la Compagnie de Jésus, mena si bien son action jusqu'à la guerre, que l'évolution au sein de la nation italienne, dont Benoît XV, au début de la guerre, déclarait « attendre le règlement convenable de la situation du Saint-Siège, était alors un fait accompli. L'Italie était retombée, malgré son gouvernement, sous l'influence papale ; la terre de Cavour et de Garibaldi était à point pour la dictature. 
Toutefois, le mérite de la situation nouvelle n'incombait pas exclusivement aux Judas des divers groupements anarchistes, socialistes ou simplement démocrates-chrétiens, qui avaient monnayé très fructueusement leurs convictions d'antan. L'Union populaire, tout en se maintenant en dehors et au-dessus de toute question d'ordre purement matériel et politique, avait donné son adhésion à la constitution d'un parti populaire italien, dont l'appel était rédigé par une commission provisoire nommée avec l'agrément de Benoît XV.

En réalité, c'étaient, suivant le dicton populaire, deux têtes dans le même bonnet, l'une servant soi-disant un idéal uniquement religieux, l'autre à des fins à la fois politiques et religieuses, ce qui permettait à la papauté, tout en se déclarant intransigeante, de paraître s'adapter à toutes les idées modernes, sous une autre forme. C'est ce que la Luce, journal protestant de Florence, appela : « le parti sacro-profane politico-religieux démo-clérical ». Ironie à part, le nouvel organisme obtint un succès considérable, mais qui s'explique par ce fait que le parti populaire, mêlant habilement aux articles de réformes sociales de son programme la question de l'indépendance du Saint-Siège, incitait l'opinion à envisager la question romaine au point de vue de la liberté. On sait avec quel art l'Eglise sait jouer de ce mot magique, qui pour elle signifie : privilège et autorité, et pour les autres : oppression des consciences. «Liberté de l'enseignement, liberté de l’Eglise », ces expressions forment le leit motiv du parti populaire.

Ces diverses tentatives de renflouement de la barque de saintPierre, quoique conduites avec beaucoup d'adresse et d'énergie par le moine dom Sturzo, ne constituaient que des succès partiels dont les jésuites ne pouvaient se contenter. L'orientation de leur politique visait à compléter l'unité matérielle de l'Italie, par une sorte d'unité morale impliquant, par voie de réciprocité, au nom de la papauté la reconnaissance du fait accompli le 20 septembre 1870, et de la part de la monarchie italienne l'abandon de ses prérogatives laïques, sacrifiées à une vaine réconciliation de l'Italie avec l’Eglise. 


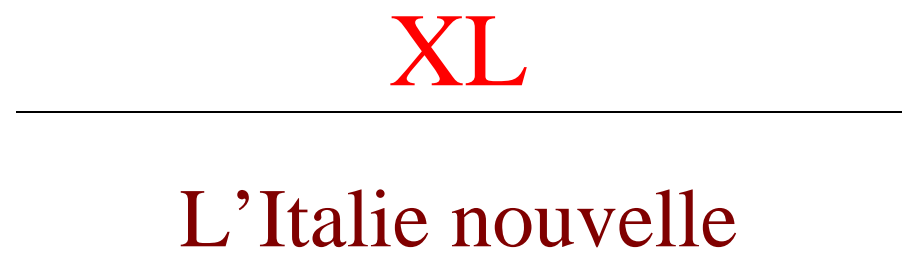

\section{Les étapes de la trahison La première victoire du Vatican et des Jésuites}

Pour parfaire cette œuvre, sur laquelle ils comptent pour redonner au catholicisme un nouvel éclat et assurer son prochain et universel triomphe, les jésuites ont trouvé et pris à leur solde, et ce, bien avant la guerre, celui que, dans leur ridicule enthousiasme, les cléricaux qualifient de surhomme et d'homme providentiel, et qui n'est, en réalité, qu'un aventurier de basse envergure, l'un de ces tristes héros de toutes les turpitudes, vierge de tous scrupules, toujours prêt à commettre les pires forfaits, depuis l'odieuse trahison des partis qui se confiaient à lui, jusqu'au crime sauvage, féroce, comme l'assassinat de Matteotti.

Tel est, en effet, Mussolini, L’AGENT DES JÉSUITES, le fameux " duce », en réalité inspiré, dirigé et... surveillé par le P. Ventura, de la Compagnie de Jésus, son socius, qui a pris sur lui la plus grande influence.

À vrai dire, même dès ses débuts dans la politique militante, où il semblait qu'il dût suivre les traces de son père, emprisonné à diverses reprises pour son active propagande, Mussolini fut pour ainsi dire à vendre. Non pas pour trente deniers, mais pour satisfaire au sadisme 
formidable de la toute-puissance qui possède entièrement cette nature orgueilleuse au suprême degré, avec " ce goût du grand, de l'éclatant, de ce qui surprend, de ce qui épate les peuples », cet esprit brutal et dominateur, décidé aux alliances les plus criminelles, aux lâchetés les plus viles, et dont chaque minute d'existence est un acte d'infamie.

D’aucuns s'étonnent à tort qu'un peuple fier et généreux, plus superstitieux que religieux, comme le peuple italien, se soit abandonné avec autant de facilité à un tel maître. La raison en est double. C'est d'abord, au sortir d'une guerre effroyable, cette situation, commune d'ailleurs à tous les belligérants, d'une nation dont quatre années de misères et de souffrances ont brisé le caractère, aveugli le courage ; dont - ainsi que le disait récemment, dans l'une de ses balles conférences, notre éloquent ami Henri Béziès — « les individus ont perdu dans les tranchées le goût de l'initiative, et en ont rapporté, au contraire, une sorte d'abandon et d'oubli d'eux-mêmes. L'habitude de la sujétion au commandement pendant ces quatre années de luttes leur ont fait perdre également l'usage de leur volonté. »

Profonds psychologues, et ainsi servis par les circonstances, après s'être servis eux-mêmes en dissociant, avant et pendant la guerre, la forces sociales qui auraient pu leur faire obstacle, les jésuites n'avaient plus qu'un seul effort à faire pour être les maîtres absolus de la situation : cet effort, ce fut l'élection au pontificat d'un autre des leurs, le P. Ratti, élu le 6 février 1922, succédant à Benoît XV. Huit mois après, c'était la marche sur Rome (octobre 1922), c'est-à-dire l'établissement de la dictature.

Toutes les étapes franchies par Mussolini sont autant de preuves de cette trahison irrécusable, sur laquelle nous nous en voudrions de ne pas insister. Anarchiste, il parcourt les divers pays d'Europe, s'affirmant surtout comme libre penseur, par des conférences où la «tyrannie du dogme, l'inutilité de la croyance, la négation de l'existence d'un dieu », aux attributs absurdes qui répugnent à la Raison humaine, sont démontrées avec une puissance d'argumentation saisissante, il faut bien le reconnaître. L'une de ces conférences, celle du 26 mars 1904 à la Maison du Peuple de Lausanne, a été rééditée récemment, après avoir été publiée par lui-même. Elle est tout simplement admirable de logique et de bon sens, et l'on comprend que le 
pasteur Tagliatcla, qui représentait la contradiction, soit resté plusieurs fois bouche close.

À cette époque, Mussolini est non seulement en paroles, mais en action, l'acharné destructeur de tout ce qui, sur son passage, représente un symbole religieux quelconque. Des camarades libres penseurs d'une modeste bourgade de la Seine-Inférieure, chez lesquels Mussolini, en tournée de propagande, s'était arrêté, nous en ont fourni la preuve.

De l'anarchie, où son âpre désir d'être et de paraître ne saurait trouver à se satisfaire, le futur " duce " passe au parti socialiste italien. Et c'est ici une toute autre attitude qui justifie bientôt la suspicion du parti à son égard. Membre de l'extrême-gauche, ses violences de langage visent surtout à faire naître des dissentiments au sein de l'organisation. En 1912, il mène, dans son journal L'Avanti, dont les subsides sont puisés à toutes les sources, mais surtout chez les jésuites, une vive campagne contre les éléments pondérés et responsables du socialisme italien, s'attaque, comme les transfuges cités plus haut, à la franc-maçonnerie, et obtient l'expulsion du parti des «derniers modérateurs ».

Au début de la guerre, il est, comme le pape Benoît XV, neutraliste à outrance. Le dernier article publié par lui dans l'Avanti (18 octobre 1914) est encore pour la neutralité, mais «active et opérante », et pouvait être interprété comme un appel à la révolution.

Familier avec les fonds secrets de plusieurs puissances, agent bénévole mais récompensé tout de même des services de sûreté générale de certains pays auxquels il servait volontiers d' "indicateur » dans ses tournées de propagande internationale ; en rapport permanent avec des marchands de conscience tels que Philippo Naldi, il obtient de la France des subsides qui lui furent remis à Genève " et sur lesquels, d'après $M$. Ubaldo Triaca, auquel nous empruntons ces détails, $M$. Cachin pourrait fournir maintes précisions ». Et aussitôt, il se convertit à la cause de l'intervention italienne dans la guerre et fonde un organe personnel, le Popolo d'Italia, qui devient l'organe de la guerre à outrance. Cette volte-face, il est bon de le noter, s'accorde avec la nouvelle attitude de Benoît XV, déclarant dans le même moment, dans 
l'interview Latapie, que, neutraliste au début, il est maintenant interventionniste, parce que les intérêts supérieurs du Saint-Siège l'exigent. Donc, nulle contradiction entre les faits et gestes de ceux qui l'emploient et le rôle qu'ils lui ont dévolu, et dont il s'acquitte, du reste, avec une rare violence contre ses anciens amis, et sur un ton grossier en général; les rancunes personnelles de renégat s'assouvissent à chaque numéro. Il ne craint pas de déclarer que le Popolo d'Italia est sustenté par une spéculation industrielle faite avec des capitaux bourgeois. Et c'est le même homme qui, à trois mois de distance, ose écrire : " Accepter le critérium de la guerre, c'est passer de l'autre côté de la barricade » et que «la propagande antiguerrière est la propagande de la lâcheté ».

Mais la partie la plus odieuse de son œuvre commence véritablement au lendemain de la guerre. Elle est suffisamment caractérisée par l'assistance à tous les fauteurs de désordre, la formation de troubles, d'émeutes continuelles, d'où, après l'épuisement des forces prolétariennes, doit sortir le fascisme triomphant.

En outre de la propagande bolcheviste réelle en 1919 et 1920, mais en décroissance sensible vers la fin de cette dernière année, l'Italie compta alors au moins trois autres foyers de trouble et de dissolution. D’abord, le parti nationaliste, conspirant contre le souverain légitime en faveur du duc d'Aoste, très populaire dans les milieux militaires et qui avait pu espérer recueilli la couronne, lorsqu’une tardive progéniture de la famille royale lui enleva toute illusion de ce chef. Il y avait aussi les germes de sédition qu'entretenait dans l'armée la question de Fiume et, enfin, le fascisme naissant, qui eut l'habileté de se servir de l'idée de patrie pour barrer la route aux uns comme aux autres et aussi de leur faire croire à tous que l'Italie ne pouvait vivre et prospérer sans " cette unique idée universelle qui, selon lui, irradiait du Vatican », autrement dit sans la réconciliation " avec la papauté ». (Discours à la Chambre italienne, 1919). Ainsi, le militant Fredo Franzoni avait-il cent fois raison lorsque, il y a quelques années, dans une conférence à Boulogne-sur-Mer, il définissait le fascisme : «Le plus mauvais nationalisme qu'on ait jamais rêvé. » C’est, en effet, par les chemins les plus tortueux, dans la boue et dans le sang, que Mussolini réalise, d'étape en étape, en trois années, l'asservissement de l'Italie. Le fascisme tend d'abord la main aux ouvriers confédérés, bien avant 
l'occupation des usines, et leur adresse, le fait accompli, ses plus vives approbations. Mussolini lui-même se rend aux usines de Dalmine, dont s'était emparé le camarade Rossoni (actuellement secrétaire général des corporations fascistes), et félicite les ouvriers de ce beau geste. Pendant l'été de 1919, le Popolo d'Italia provoque dans plusieurs villes des émeutes contre la vie chère et, renchérissant sur le programme bolcheviste, le programme fasciste réclame la « confiscation partielle des fortunes ». Puis, vers le milieu de 1921, lorsque, après l'échec du grand mouvement révolutionnaire contre le capitalisme, le prolétariat n'ayant su ni maintenir, ni organiser sa victoire de quelques semaines, les forces capitalistes s'avisent à leur tour de passer à l'offensive contre les ouvriers pour leur reprendre les quelques concessions arrachées par eux au cours de la lutte, Mussolini offre aux syndicats patronaux son organisation de combat pour en faire le noyau " d’une armée de défenseurs recrutée rapidement grâce aux sommes mises à sa disposition par la propriété industrielle et agraire ». Et, ainsi, aux « chemises rouges », succèdent les « chemises blanches ».

Il résulte des témoignages et des documents les plus probants qu’à cette époque, maître d'une milice considérable et ayant gagné l'armée aux trois quarts par sa propagande dans les casernes, Mussolini eut la tentation de se servir de ces forces pour renverser la monarchie. Mais les nationalistes du duc d'Aoste, peut-être de moitié dans ce projet, eurent-ils la claire vision que le « duce » victorieux les trahirait peutêtre à leur tour? Jugèrent-ils, d'accord avec les jésuites, la partie trop grosse pour la jouer avec chance de remplacer Victor-Emmanuel III, roi falot, mais patriote et peu clérical, par leur prétendant tout dévoué au pape ? Craignirent-ils la réconciliation et le soulèvement général de la démocratie italienne contre le couple ambitieux dont elle connaissait le fanatisme catholique ? Toujours est-il que Mussolini dut faire amende honorable au Congrès d'Udine. Ce qui ne l'empêchait pas, quelques mois plus tard, de renouer avec divers groupements révolutionnaires pour les convier à s’allier au fascisme, sous prétexte de proclamer la République. Entre temps, il signait, dans le Popolo d'Italia, ces lignes ayant pour but de paraître solliciter les sympathies du Vatican et qui le désignent déjà suffisamment comme son compère : 
"A bas l'Etat sous toutes ses formes et personnifications: l'Etat d'hier et de demain ; l'Etat bourgeois et l'Etat socialiste. Pour nous, il ne reste que la religion consolatrice de l'anarchie. "

On sait le reste : le 22 janvier 1922, mourait Benoît XV, et, le 6 février suivant, le cardinal Ratti, de l'ordre des jésuites, archevêque de Milan, était élu pape sous le nom de Pie XI. Dès son élection proclamée, le nouveau pape, rompant avec la tradition de ses prédécesseurs apparaissait à la loggia extérieure du portique de la basilique de SaintPierre pour donner sa bénédiction à la foule agenouillée sur la place et aux troupes italiennes présentant les armes. Du sein de la foule, un cri s’éleva : «La question romaine est résolue ! » c’était, on l'a dit, aller un peu vite en besogne. Les jésuites n'ont pas l'habitude d'agir avec précipitation. Mais, ce qu'il y a de certain, c'est que leur homme-lige, le chef providentiel dont ils s'étaient assuré le concours, tout en le surveillant de près, comme aujourd'hui d'ailleurs, poursuivait, en dépouillant de plus en plus ses oripeaux démographiques et en entretenant dans tous les milieux cette fièvre d'inquiétude, de semi-terreur du bolchevisme, pourtant devenu peu redoutable, la tâche qui lui était imposer et qu'un orgueil insatiable lui avait fait accepter : créer une Italie nouvelle à laquelle lui, Mussolini, restituait sa vraie âme, romaine et catholique. 


\section{Sous la matraque}

\section{Le parti populaire s'efface Le fascisme c'est la guerre}

Au lendemain même de sa prise de possession du pouvoir, et pour mieux marquer sans doute la signification de son entreprise ad majorem dei gloriam, c'est-à-dire au profit exclusif des jésuites, l'ancien anarchiste, le leader socialiste, le rédacteur impie de l'Avanti, traître au mouvement ouvrier, traître à la Libre Pensée, traître aux vrais intérêts du peuple italien et de l'humanité, l'homme qui avait déclaré publiquement, en 1904, à la Maison du Peuple de Lausanne, que la religion était une forme de "l'aliénation mentale » et que l'homme religieux était un "anormal », cet même homme qui proclamait alors " l'immoralité » de la morale religieuse, s'agenouillait pieusement à l'autel de Sainte-Marie des Anges, donnant ainsi à sa victoire le caractère d'une fête religieuse. "Pour la première fois depuis cinquantedeux ans, la politique italienne, selon l'expression d'Henri Béraud, faisait le signe de la Croix. » Cette génuflexion fut à peine notée par la presse du Vatican : la consigne était alors de paraître tenir en défiance le nouveau pouvoir.

Mais le 23 décembre 1922, dans sa première encyclique, Pie XI faisait une discrète allusion " au jour très heureux de la restauration du règne du Christ pour la pacification de l'Italie ». Cependant, le Vati- 
can gardait toujours le contact avec le Parti Populaire, que l'abbé sicilien dom Sturzo n'entendait pas soumettre à Mussolini. Pour lui, le fascisme n'était qu'une expérience transitoire, et il prétendait le combattre, alors que les habiles, les opportunistes prenaient acte du fait et estimaient qu'il fallait s'y rallier. Dom Sturzo avait encore une raison péremptoire de demeurer l'ennemi du fascisme: «les populari géraient pour ainsi dire les "Caisses rurales", qui sont comme l'armature de l'action sociale et politique du Vatican, et que celui-ci a constituées au prix de trente ans d'efforts. Au nombre de plus de deux mille, ces caisses représentent un roulement annuel de un milliard de lire et un demi-milliard d'argent déposé. C'est la réserve de l'action catholique de demain. C'est l'appui du Vatican contre les difficultés que peut lui réserver le fascisme. Or, ce trésor de guerre... civile était dans les caisses de Banco di Roma, passé aux mains du gouvernement fasciste. L'organisation catholique, qui ne voulait pas être livrée pieds et poings liés au fascisme, dut se préoccuper du retrait de ces fonds pour les placer dans une autre banque indépendante.

Le duce n’était pas homme à se laisser « rouler ». Il agit par « monnaie d'échange » en offrant la dissolution de la franc-maçonnerie contre celle du parti populaire. La crainte de représailles fascistes contre le clergé solidarisé alors avec dom Sturzo émut le Vatican, ainsi que l'espoir d'une solution possible de la question romaine. Il désavoua le parti populaire et imposa à son chef une retraite indéfinie au mont Cassin, tandis que le palais Ginstiniani, qui donnait asile à la franc-maçonnerie, était fermé, et le commandeur Bachetti, secrétaire général, déporté avec de nombreux maçons à Ponza, l’île de la Douleur.

Ainsi, peu à peu, d'année en année, Mussolini, n’agissant qu'en plein accord avec la Curie romaine, crée, par une série d'actes hostiles à tout ce qui peut rappeler encore à l'Italie le régime libéral dont elle avait joui depuis 1870, une ambiance nouvelle grâce à laquelle il achemine la royauté, incapable désormais de résister, aux accords du Latran.

L'histoire de six années de méditations, de tractations, d'avances tantôt froidement accueillies, tantôt dédaigneusement repoussées comme la suppression de l'exequatur royale pour l'entrée en fonction 
des évêques, la restitution aux jésuites et aux oratoires de leurs bâtiments, dans lesquels, toutefois, une pièce doit être toujours tenue à la disposition du gouvernement ; l'enseignement religieux, le catéchisme obligatoire à l'école, la croix replacée au Colisée, la dissolution de la franc-maçonnerie et des livres civiques ; "c'est, en fait, très peu de chose ", disait, en 1926, le cardinal Gasparri à un rédacteur de l'Avenir. C'est que, en effet, le successeur de Merry del Val savait trop bien à quoi s'en tenir sur ces lenteurs calculées, ces alternatives voulues de heurts et de rapprochements, dont la suppression des boysscouts catholiques ou la retraite de dom Sturzo offrent des exemples. De même, le sondage des milieux catholiques internationaux sur l'ordre de Pie XI, par le " pape noir », le général des jésuites Ledochowski, appartient à cette " préparation savante » du « coup de théâtre » du Latran, que nous avions cent fois raison de qualifier de comédie au début de cette étude.

L'attitude de commande du Vatican lui faisait une obligation de ne pas paraître répondre trop vite aux avances du duce, et même de maintenir ses protestations et ses réserves envers la présence à Rome du gouvernement italien. C'est ce qui explique qu'en ce qui touche alors la politique extérieure de Mussolini, elle lui laisse carte blanche. Pie XI est aussi neutre que son prédécesseur, et d'une neutralité tout aussi hostile à la France que celle de Benoît XV. C'est ainsi qu'il ignore le bombardement et l'occupation de Corfou, cette brutalité d'un matamore qui sait n'avoir personne devant lui pour repousser ses violences ; il ignore également le massacre d'une mission grecque presque sous les canons d'une escadre alliée. Mais l'occupation de la Ruhr l'indigne presque autant qu'elle mécontenta en France les hommes de bon sens.

Une toute récente preuve - elle date d'hier — de cette duplicité de la papauté nous est fournie par Pie XI lui-même, dans son allocution aux élèves du collège catholique de Mondragone. Il est hors de doute que le fascisme, constitue pour l'Europe, pour le monde entier, un danger permanent de guerre. C'est la torche incendiaire que l'Eglise peut jeter d'un moment à l'autre sur tel ou tel point du globe, c'est la menace incessante d'un nouveau conflit mondial. Personnellement, le duce pourrait hésiter à jouer cette terrible partie. Il peut atteindre, en effet, qu'aussitôt, l'Italie du dedans et celle du dehors se rejoignent 
fraternellement au pied des Alpes et, d'un formidable effort, ne brisent la dictature et le dictateur. Car toutes les entreprises du genre opera Ferrari, pour conserver à l'étranger la liaison entre le fascisme et ceux qu'il a contraints de s'expatrier pour fuir la prison ou la mort violente, n’y changeraient rien. Et cependant, si telle est la volonté des jésuites, le fascisme se jettera sur le premier prétexte venu, dès qu'ils lui auront donné l'ordre. Pie XI, profès de l'Ordre, n'ignore pas non plus ces choses, et son allusion dernière aux visées de conquête du fascisme, qu'il a l'air de blâmer, n'est une fois encore qu'une attitude.

Bien que nous n'ayons pas à juger, dans le cadre de cette étude, la politique économique et soi-disant réformatrice du duce, cependant, nous devons signaler la grossière erreur des observateurs superficiels pour lesquels l'Italie peut paraître en pleine renaissance économique. L’émigration, " cette hémorragie du corps national italien », a enlevé à la péninsule, malgré les mesures les plus sévères, la meilleure partie des ouvriers antifascistes, qui se gardent bien d'envoyer leurs économies dans leur pays d'origine. Le tourisme a déserté un pays où le moindre mot, le plus innocent geste peut vous valoir des années d'emprisonnement, sans préjudice des mauvais traitements. Sans doute, il y a les fêtes religieuses, les pèlerinages, les jubilés, surtout depuis la "réconciliation ». Mais tout cela, formant une foule innombrable et répétée chaque année, ne compensera jamais les effets bienfaisants d'une bonne balance commerciale, et celle-ci s'obtient rarement en traitant à coups de matraque l'agriculteur ou l'industriel, ou en le contraignant à intensifier une production sans débouchés. A cet égard, il n'est pas inutile de rappeler qu'en 1889, les francs-maçons du gouvernement italien, d'accord avec leurs collègues des différents ministères français, furent les artisans de la reprise des relations commerciales entre la France et l'Italie. Ce fut pour l'Italie un débouché précieux à ses produits.

Quant au prolétariat qu'il a tour à tour flatté, excité et... massacré à l'occasion, faire des corporations fascistes le véritable organe de la vie publique, établir son absolutisme sur le prétendu bonheur de l'ouvrier, c'est un singulier essai d'émancipation ouvrière pour aboutir à une dictature syndicaliste. Il n'est pas démontré que les ouvriers accepteront d'être les dupes d'une organisation que Mussolini pourra toujours supprimer et à laquelle il n’accorde même pas le droit de se plaindre. 
Enfin, s’il est nécessaire de dresser un programme de bonification intégrale du sol national, encore faut-il avoir les moyens de le réaliser. Or, on ne change pas, même par compression du jour au lendemain, la mentalité d'un peuple qui jusqu'ici a plutôt toujours vécu des restes de ses splendeurs passées que du développement de son agriculture et de son industrie. Il y avait encore, à la veille de la guerre, près de 3 millions d'hectares de terres incultes en Italie, plus d'un million d'émigrés en Argentine, 600000 au Brésil et 200000 à BuenosAyres.

On objectera qu'en attendant l'ère de prospérité promise à notre sœur latine par le duce, l'ordre règne à Rome et dans toute la péninsule : l'ordre, c'est-à-dire cette servitude durable dont parle Montesquieu à propos du règne de l'empereur Auguste, et qu'il serait plus juste encore de dénommer le terrorisme.

Il suffit qu'aujourd'hui, sous le ciel bleu d'Italie, un homme ait une conscience, qu'il soit trop honnête, pour que, malgré les plus grandes preuves de patriotisme, il risque la mort, celle des siens et peut-être de tous ses amis, s'il ose défendre un de ses semblables contre la tyrannie fasciste. Une escouade d'action des Chemises noires, composée de vingt à quarante hommes, mercenaires haineux, armés, casqués, bottés, a tôt fait de rentrer dans la maison d'un libre penseur, de tuer, de massacrer, de piller tout, sans qu'aucune entrave puisse l'arrêter. Pour un enfant qui fredonnait la chanson du Drapeau rouge, chant de victoire du prolétariat italien, devant les fascistes, ce fut l'assassinat de toute une agglomération. Bref, aucun être ne peut vivre, agir ou respirer sur le sol italien sans être toujours sous le coup de l'emprisonnement ou du bannissement. Les prions regorgent de victimes et les déportations aux îles infernales dépassent en horreur, par les mauvais traitements et les assassinats répétés des condamnés politiques, tout ce que l'ancienne Rome a connu d'effroyable en matière de tortures.

Malgré les déportations, les tortures, les assassinats qui font encore des milliers de victimes dans la péninsule, les démocrates italiens se refusent à déclencher une guerre civile dont la responsabilité morale leur semble trop lourde à porter. 
Combien de temps l'Italie s'accommodera-t-elle d'un pareil régime, qui est - Mussolini l'a déclaré lui-même - l'opposition systématique à la révolution de 1789, dont, pourtant, les enseignements ont bien été pour quelque chose dans la naissance nationale de l'Italie ? C'est le secret des nationalistes italiens auxquels la guerre sourit peu, c'est celui des extrémistes du fascisme qui la voudraient et n'épargnent à la France aucune insolence dans ce but. Mais c'est surtout le secret de la Curie romaine et du « pape noir », le fameux Ledochowski. 


\section{XLII}

\section{CONCLUSION}

\section{La Question Romaine n'est pas résolue Le triomphe des Jésuites Vers une Révolution fédérative et jésuitisée?}

Quoi qu'il advienne dans un prochain avenir, la question romaine n'est pas résolue.

Il existe cependant un moyen bien simple de la résoudre sans traité : c'est pour la démocratie romaine, lorsqu'elle sera redevenue maîtresse de ses destinées, de prier le pape et sa cour archaïque à l'excès d'aller résider autre part.

Malheureusement, dans l'état actuel des esprits, c'est une solution qu'aucune des parties en cause ne voudra adopter, mais chacune d'elles pour des raisons bien différentes.

L’Église a beau prétendre que son universalité est la conséquence de son caractère divin ; c'est le « duce » qui a raison, lorsqu'il lui rappelle qu'elle est redevable de cette universalité à son installation au milieu des dernières splendeurs de l'Empire romain. Pie XI est trop érudit pour penser le contraire, mais son métier de pape l'oblige à le dire. Il apprécie trop, comme ses prédécesseurs qui préféraient se 
claustrer, le prestige moral qui se dégage de ces deux mots rendus inséparables : Rome et le Vatican, pour songer à quitter l'une à l'autre.

Du côté italien, la masse, en dehors de toute opinion politique, voit la chose sous un angle peu édifiant : celui de la valeur vénale du pape par rapport au grand concours d'étrangers qui viennent chaque année en Italie pour le voir, avec les antiquités et les objets d'art. On compte vingt pèlerins pour un touriste. Plus que tout le reste en Italie, le pape à lui seul fait " recette "; c'est une raison de poids... en or, qui se justifie amplement chez un peuple dont les ressources sont modiques. Il est bien entendu qu'aucune conscience libre penseuse ne s'arrête devant un aussi misérable argument et que, ceux qui vivent de l'Eglise ou par l'Eglise s'effraient à la pensée d'une Italie veuve du pape.

La question romaine n'est pas résolue. Les accords du Latran ne sont, ajoutés à ceux qu'a retenus l'histoire, qu'un concordat de plus, c’est-à-dire un de ces traités occasionnels qui laissent « l'Eglise armée dans un Etat désarmé ». Conclu entre des gouvernements, sans que les peuples aient voix au discussions, ils sont généralement destinés à disparaître avec le régime qui les a rédigés, tel, en France le concordat entre Pie VII et Napoléon ; tel il en sera du concordat entre Pie XI et Mussolini, avec la débâcle certaine du fascisme.

La question romaine reste entière, et c'est, soit dit en passant, la raison pour laquelle nous ne nous attardons pas à disserter sur les trois documents qui constituent ce que els feuilles catholiques appellent pompeusement le traité du Latran.

Toutes les clauses et leurs gloses ne prévaudront jamais contre cette constatation faite au début même de cette étude. La réconciliation de Latran est une pure comédie à deux personnages : le pape et son compère Mussolini, pantins dont les jésuites ont tenu les fils. Nous en avons donné les preuves au cours de cette étude, au risque de l'allonger. Ces preuves reparaissent éclatantes dans le texte même des accords du Latran. Tous les prédécesseurs de Pie XI avaient posé comme condition d'un rapprochement entre l'Italie et l'Eglise : $1^{\circ}$ la garantie collective des puissances ; $2^{\circ}$ un territoire suffisant, à défaut de la restitution du patrimoine de saint Pierre. 
Or, aucune de ces conditions n’est réalisée par le traité ; question d'amour-propre, a-t-on dit de ces deux conditions. La papauté est assez grande par elle-même pour se passer de la garantie des nations européennes et d'un territoire. Soit. Mais alors, mieux valait laisser les choses en l'état. Car sa reconnaissance du royaume d'Italie sous la dynastie de la maison de Savoir, avec Rome pour capitale, ne lui a rapporté absolument rien, à moins de considérer autrement que comme une vulgaire puérilité la reconnaissance par l'Etat italien de l'absolue autorité et de la juridiction souveraine de la papauté sur la " cité vaticane ». Il est vrai qu'avec Pie IX, cette « juridiction souveraine » sur quelques grands édifices permettait le renouvellement des pires forfaits. " Ni un palais, ni une maison », avait dit autrefois Crispi, en déclarant net au roi Humbert « qu'un traité avec le Vatican déclencherait contre lui la guerre ouverte des patriotes ».

Si l'Eglise n'a rien gagné, l'Etat, ou plutôt la royauté, est au même point ; disons mieux, elle risque de perdre. Car les partis d'opposition, parmi lesquels on peut d'ores et déjà compter un certain nombre de nationalistes, c'est-à-dire de ceux qui ont toujours refusé, quoique royalistes, mais patriotes avant tout pouvoir temporel, toute souveraineté juridique à l'Eglise, et dont la formule était et est encore : «L'Église libre dans l'Etat libre », ces partis qui déjà murmurent et se réorganisent, ont déclaré qu'ils ne reconnaîtraient jamais ni la souveraineté juridique du pape, ni le concordat. Grâce à eux, la question romaine se poser de nouveau, avec ou sans le fascisme.

Pie XI et Mussolini n’ont cependant pas collaboré en vain.

Il est une victoire — bien éphémère, espérons-le — qu’ils ont remportée, au nom et au profit des jésuites, leurs maîtres.

Cette victoire, c'est d'avoir réussi à livrer l'Italie à l'empire du cléricalisme ; de posséder aujourd'hui, par la conquête de l'Italie, devenue terre papale, un domaine autrement important que les anciens Etats de l'Eglise, même au temps de leur plus grande étendue. Car l'introduction du droit canonique, côte à côte avec le droit civil, l'obligation de l'enseignement religieux d'après les programmes établis en collaboration avec le pape et l'Etat italien, ont consacré du même coup l'abdication humiliante de la royauté et la prise de posses- 
sion de la péninsule par les fils de Loyola. C'est, on en conviendra, un très beau résultat, et Mussolini, l'infâme, peut être fier de son œuvre ! C'est aussi - et pour les jésuites la chose est d'une extrême importance - le triomphe sur toutes les autres religions (protestante, juive, musulmane, etc.), auxquelles le concordat du Latran refuse l'égalité de traitement quant aux effets du mariage religieux et en ce qui concerne l'enseignement.

La répercussion morale de cet outrage à la liberté de conscience, de cet attentat à la dignité humaine ; l'exploitation auprès des autres nations de ce triomphe - sans lendemain, qu'ils le sachent bien — sur l'esprit laïque, civique et démocratique qui anime, à cette heure, la plupart des peuples, c'est ce que les jésuites ont voulu, c'est l'unique but recherché par le traité dont ils ont revu soigneusement tous les articles, et au bas duquel l'indigne successeur de Victor-Emmanuel II et de Humbert $\mathrm{I}^{\mathrm{er}}$ a honteusement — apposé sa signature.

Mais qu'on ne s'y trompe pas : le concordat du Latran n'est que la première partie de la tâche imposée au renégat Mussolini par les jésuites. La seconde s'apparente au rêve de domination universelle dont l'Eglise romaine, depuis Grégoire VIII, n’a cessé de poursuivre la réalisation à travers les siècles. Il s'agit, en effet, de mettre à profit la désaffection de plus en plus marquée des démocrates-patriotes italiens pour la maison de Savoie après le coup du Latran, pour substituer, à la faveur de troubles habilement fomentés, la République à la Monarchie. L'idée n'est pas nouvelle, d'ailleurs. Le pape Grégoire VII souhaitant de l'appliquer à toute l'Europe confédérée sous le signe de la Croix, et, plus près de nous, mais en la limitant à l'Italie, Pie IX, à ses débuts, puis Léon XIII, l'avaient reprise. Pendant toute la durée de son pontificat, il souhaita, pour la péninsule, une République, autant que possible fédérale. Il estimait, en effet, comme inacceptable de la part de l'Eglise romaine et de son Chef, la coexistence de la monarchie de Savoie, " spoliatrice insolemment installée dans la Rome des Papes, dans le Quirinal des Papes, et promenant par la ville une royauté rivale et triomphante de celle du pontife romain. » (De Germiny : La Politique de Léon XIII, Paris 1902.)

On s'explique, maintenant, les intentions prêtées à Mussolini et que nous avons relatées, de renverser la monarchie, ses hésitations par la 
crainte des nationalistes-patriotes, et aussi des socialistes qui n’auraient certes pas demandé mieux que d'établir la République au plus fort des émeutes qui précèdent l'intervention du duce, "s'ils n'avaient pas eu peur, ce faisant, de trop bien faire les affaires du Saint-Siège ». (Léon XIII, op. cit.)

C'est à n'en pas douter, vers ce dernier but que s'orientera la politique du Vatican et des jésuites. Faire de l'Italie une République fédérale jésuitisée sous la dictature d'un Mussolini, c'est créer un foyer permanent d'agitation et de propagande cléricales à notre frontière des Alpes, et c'est surtout préluder à la formation de ce vaste et puissant Saint Empire catholique qui, au lendemain de la grande guerre, est devenu la préoccupation principale de l'Eglise romaine et des jésuites pour réaliser leur œuvre de domination universelle.

À cette sainte alliance qui menace la liberté des peuples et leur existence même, les démocraties mondiales et, au premier rang, la démocratie italienne, ont l'urgent devoir d'opposer la résistance la plus énergique. Si grave que soit le péril, il n'est pas invincible. La France de 89, qui affirma le caractère universel des Droits de l'Homme et du Citoyen, a commis la faute de ne plus s'en inquiéter après 1905 et de considérer comme accomplie par la séparation l'œuvre émancipatrice et pacificatrice de la conscience humaine, dont elle avait pris la charge au regard de la civilisation.

Aujourd'hui, ce n'est plus seulement l'Italie qui doit proclamer, comme au jour mémorable du 20 septembre 1870 où elle reprenait Rome, le droit humain, le droit social que tous les peuples revendiquent de se soustraire à la domination despotique de toutes les théocraties et de toutes les oppressions ; ce sont toutes les nations qui doivent se dresser avec Elle et à ses côtés contre Loyola et Mussolini, associés pour l'asservissement des mondes.

Qu'au cri de ralliement de notre sœur latine : «Italia fara da se ! » réponde celui des libres penseurs du monde entier : "Umanita fara da se!» 